\title{
Screening Coarse Airborne Dust for Lead-Rich Phase Occurrence during Characterisation of Particle Mineralogy, Chemistry and Provenance: Application to Deposits in the Vicinity of an Integrated Steelworks
}

\author{
James Small ${ }^{1}$, Corrie van Hoek ${ }^{1}$, Frank van der Does ${ }^{1}$, Anne-Bart Seinen ${ }^{1} \mathbb{D}$, Stefan Melzer ${ }^{1}$, Peter Tromp ${ }^{2}$ \\ and Sieger van der Laan ${ }^{1, *}$ \\ 1 Tata Steel, P.O. Box 10.000, 1970 CA IJmuiden, The Netherlands; james.small@tatasteeleurope.com (J.S.); \\ corrie.van-hoek@tatasteeleurope.com (C.v.H.); frank.van-der-does@tatasteeleurope.com (F.v.d.D.); \\ anne-bart.seinen@tatasteeleurope.com (A.-B.S.); stefan.melzer@tatasteeleurope.com (S.M.) \\ 2 The Netherlands Organisation for Applied Scientific Research, TNO, P.O. Box 80015, \\ 3584 CB Utrecht, The Netherlands; peter.tromp@tno.nl \\ * Correspondence: sieger.van-der-laan@tatasteeleurope.com
}

Citation: Small, J.; van Hoek, C.; van der Does, F.; Seinen, A.-B.; Melzer, S.; Tromp, P.; van der Laan, S. Screening Coarse Airborne Dust for Lead-Rich Phase Occurrence during Characterisation of Particle Mineralogy, Chemistry and Provenance: Application to Deposits in the Vicinity of an Integrated Steelworks. Minerals 2021, 11, 929 https://doi.org/10.3390/min11090929

Academic Editor: Emily Sarver

Received: 22 July 2021

Accepted: 23 August 2021

Published: 27 August 2021

Publisher's Note: MDPI stays neutral with regard to jurisdictional claims in published maps and institutional affiliations.

Copyright: (c) 2021 by the authors. Licensee MDPI, Basel, Switzerland. This article is an open access article distributed under the terms and conditions of the Creative Commons Attribution (CC BY) license (https:/ / creativecommons.org/licenses/by/ $4.0 /)$.

\begin{abstract}
A method has been developed to screen large numbers ( $10^{3}-10^{4}$ per sample) of coarse airborne dust particles for the occurrence of $\mathrm{Pb}$-rich phases, together with quantification of the particles' mineralogy, chemistry, and inferred provenance. Using SEM-EDS spectral imaging (SI) at $15 \mathrm{kV}$, and processing with the custom software PARC, screening of individual SI pixels is performed for $\mathrm{Pb}$ at the concentration level of $\sim 10 \%$ at a length-scale of $\sim 1 \mu \mathrm{m}$. The issue of overlapping $\mathrm{Pb}-\mathrm{M} \alpha$ and $\mathrm{S}-\mathrm{K} \alpha$ signal is resolved by exploiting peak shape criteria. The general efficacy of the method is demonstrated on a set of NIST particulate dust standard reference materials (SRMs 1649b, 2580, 2584 and 2587) with variable total $\mathrm{Pb}$ concentrations, and applied to a set of 31 dust samples taken in the municipalities surrounding the integrated steelworks of Tata Steel in IJmuiden, the Netherlands. The total abundances of $\mathrm{Pb}$-rich pixels in the samples range from none to 0.094 area \% of the (total) particle surfaces. Overall, out of ca. 92k screened particles, $\mathrm{Pb}$ was found in six discrete Pb-phase dominated particles and, more commonly, as superficial sub-particles (sub-micron to $10 \mu \mathrm{m}$ ) adhering to coarser particles of diverse and $\mathrm{Pb}$-unrelated provenance. No relationship is apparent between the samples' Pb-rich pixel abundance and their overall composition in terms of particle provenance.
\end{abstract}

Keywords: airborne dust; particulate; steelmaking; lead; provenance; mineralogy; microscopy; SEM; characterisation; methodology

\section{Introduction}

The impact of airborne dust on human health and the environment is of great concern in the industrialised world. Studying airborne dust is necessary to provide insight regarding the diversity of contributing sources and patterns of dispersion. In addition to the load of respirable fine particulate matter (PM 2.5) coarser material is also of relevance, specifically the chemical composition and bioavailability of the potentially toxic constituents in the dust material. The coarse airborne dust fraction (defined here as 10-100 $\mu \mathrm{m}$ ) is most readily available for study because it settles from the air, forming deposits for which systematic sampling protocols can be set up. Bulk chemical analysis is routinely applied to dust samples where the focus is on the concentration of potentially toxic elements (PTE) (e.g., [1,2]). Determining the speciation of PTE in dust is more challenging, and multiple techniques are used. At the bulk sample level, sequential extraction [3-5], X-ray diffraction [4,6-8] and X-ray absorption fine structure (XAFS) [6-8] are used. On the micro-scale, the most commonly used techniques include scanning electron microscopy with energy dispersive spectroscopy (SEM-EDS) or electron probe microanalysis (EPMA) (e.g., [4,6,8-12], while 
transmission electron microscopy (TEM) $[8,10]$ and micro-Raman spectroscopy have also been applied [11]. A key question is how the PTEs are related to the various contributing sources for the dust. Answering this would open the door to specific mitigation measures regarding the identified ongoing emission sources.

Identifying the multiple specific sources in dust samples, and evaluating the distribution of PTEs across them, requires analysis at the individual particle level with enough particles to draw statistically meaningful conclusions. In a previous study [13] we demonstrated a method to quantitatively characterise the mineralogy, chemistry and provenance of coarse airborne dust particles, with specific attention to dust sources related with integrated steelmaking in the vicinity of the Tata Steel works in IJmuiden, the Netherlands. The method is based on scanning electron microscopy with energy dispersive spectroscopy (SEM-EDS) and spectral imaging (SI), with largely automated data processing and evaluation using a custom in-house software PARC (PhAse Recognition and Characterisation [14]). The subject of the previous article [13] was demonstrating a method to identify particle populations associated with specific steelworks processes, raw materials and by-products, while some preliminary conclusions were drawn on the distribution of the PTEs vanadium (V) and manganese (Mn) in terms of main host grain populations and host phases. At that time, the method was incapable of providing any information regarding the distribution of lead $(\mathrm{Pb})$. A fundamental limit of the analytical approach used is that an element must be sufficiently concentrated to be detected with the SEM-EDS-SI measurement conditions used. Effectively this translates to minor element concentrations (> 0.1-1\%) for some elements, and major element concentrations ( 1-10\%) for others (due to issues with peak overlap), at a spatial resolution of ca. $1 \mu \mathrm{m}$. The analytical limitations pose a challenge for studying the distribution of PTEs occurring at trace levels $(<0.1 \mathrm{wt} \%)$ in the (bulk) materials, which is commonly the case for lead $(\mathrm{Pb})$. If a trace element is uniformly distributed throughout the material at such low concentrations, it is effectively undetectable for a SEM-EDS-based approach. If, however, an element is concentrated at the levels described above, in discrete phases or material volumes at the spatial resolution of the analyses, then its occurrence can be detected in the SI datasets.

Detailed studies of dust material by Jiang et al. (2014) [8] and Lee et al. (2016) [10], using transmission electron microscopy (TEM), identified discrete $\mathrm{Pb}$-phase occurrence in the form of nano-particles within a Pb-poor matrix. Specifically, in the latter study, dry dust deposition samples from Daejeon, South Korea, with $\mathrm{Pb}$ mass fraction of up to several thousand parts per million (ppm), were shown to contain spherical black-carbon aggregates with nano-sized $\mathrm{Pb}$-chromate inclusions. In the study of Jiang et al. [8], two standard reference materials (SRMs) from NIST (National Institute for Standards and Technology, Gaithersburg, MD, USA), comprising urban dust (SRM 1649a) and indoor dust (SRM 2584), were analysed. In addition to nano-sized Pb-sulphate sub-particles in the urban dust SRM, micron-sized $\mathrm{Pb}$-carbonate sub-particles (with variable zinc $(\mathrm{Zn})$ and titanium (Ti) concentrations) were encountered in the indoor dust SRM. In both studies, the focus was on detailed characterisation of the nano-sized particles and on precise phase identification and speciation of $\mathrm{Pb}$. The overall elemental concentrations of $\mathrm{Pb}$ in the NIST SRMs studied by Jiang et al. were 12,400 ppm in SRM 1649a and 9761 ppm in SRM 2854. However, that study gives no direct quantitative indication of the distribution of $\mathrm{Pb}$ phases across the particles, i.e., whether the $\mathrm{Pb}$ phases are widely distributed over a high proportion of the total particles or highly concentrated in few particles. The study of Lee et al. concerned material with an occurrence rate of 10 in 800 particles with detectably elevated $\mathrm{Pb}$ concentration in SEM-EDS screening. Moreover, the latter study noted a mismatch between the results of bulk chemical sequential extraction analysis on dry dust deposits from the same area, implying $\mathrm{Pb}$ occurrence in carbonate-bound and reducible forms [4], and the observation of $\mathrm{PbCrO}_{4}$ being the only discrete $\mathrm{Pb}$ phase encountered with microanalysis. A key challenge, then, is how to approach samples with potentially very scarce occurrence rate of particles with elevated $\mathrm{Pb}$ concentration. In this latter case, 
much larger numbers of particles may need to be screened for $\mathrm{Pb}$ occurrence than in either of the aforementioned studies.

In 2019 [1], elevated dust $\mathrm{Pb}$ loadings of up to $137 \mu \mathrm{g} / \mathrm{m}^{2} \mathrm{~Pb}$ per sampled surface area were reported for wipe samples of airborne dust deposits in the heavily industrialized IJmond Region of the Netherlands. Clearly there is an urgent need to know how this $\mathrm{Pb}$ is associated with specific sources. To address this need, we have expanded our existing [13] dust characterisation approach to incorporate the detection of $\mathrm{Pb}$ in the samples, where it presents as localised major element concentrations at the spatial resolution of $\sim 1 \mu \mathrm{m}$ at the exposed surfaces of the particles. The development of the analytical approach is explained here; its general efficacy is demonstrated by application to four NIST SRMs (including two of those studied by Jiang et al. [8]); and the method is applied to a set of 31 samples taken from locations in the vicinity of the Tata Steel integrated steelworks in IJmuiden, the Netherlands, on 24 February 2021.

\section{Materials and Methodology}

The sample preparation, raw data acquisition and much of the data processing used in the present study are described in detail in [13]. Only basic information is given here regarding these aspects of the methodology, while focus is given to those aspects which differ from the previous study.

To summarise the approach: dust deposit samples are mounted, without sieving or any other preparation, on a pin stub for analysis. The bulk mineralogy of the mounted samples' crystalline portion is analysed with quantitative X-ray diffraction (QXRD). Quantitative characterisation of the individual particles' surface-exposed mineralogy and microchemistry is performed using SEM-EDS-SI. The SEM-EDS-SI data are then processed using in-house software PARC [14]. There, the primary SI datasets are converted to segmented mineral-phase maps and, after segmenting individual grains via image analysis procedures on the SEM-BSE imagery, the grains are classified under grain populations based on their mineral-phase proportions. These grain populations, in turn, are grouped together under interpretive source/material categories for the purpose of source apportionment of the constituent grains (particles) in the material. Since our previous study [13], the detection of $\mathrm{Pb}$-rich pixels in the SI data has been added to the base functionality of the PARC method. This is discussed in more detail in following sections. The resultant data, exported by PARC for further detailed analysis, comprises the following:

(1) absolute and relative areas of pixel groupings, where these groupings refer to
a. individual grains
b. grain populations
c. total grains per sample
d. the corresponding constituent PARC phases for each of (a)-(c)

(2) EDS sum-spectra of these same pixel groupings for quantitative chemical analysis

(3) size and shape information regarding the grains

As with any two-dimensional image analysis approach, the directly measured abundances of phases and grain populations in the PARC analyses are in terms of area. When dealing with sectioned material, the area proportions can generally be translated simply to volumetric proportions, and with assumed phase densities, these can be converted into mass proportions. In the current study, the dust particles are analysed in their original three-dimensional form and the pixel counts and relative (normalised proportions), therefore, represent (projected) silhouette areas and relative proportions thereof. These are not strictly equivalent to true surface areas, which reflect the topography of the rough particle surfaces, but they are a reasonable approximation for the abundances of phases in terms of the fraction of the particle surface occupied by the phase. The encountered surface textures commonly comprise fine-grained multiphase intergrowths, and certain phases are inferred to be preferentially concentrated at the surface of the particles as weathering products or adhering sub-particles. This makes it difficult to translate the measured area 
proportions into mass proportions and we report only area proportions in this article. The abundances of PARC groups reported in the rest of this article refer to silhouette areas. Absolute areas are expressed as raw pixel counts and relative abundances are expressed as area percentages or as parts per million (ppm) area.

\subsection{Sampling}

Thirty-one dust deposit samples were collected in urban areas in the vicinity $(0.5-4.5 \mathrm{~km})$ of the Tata Steel integrated steelworks, in the municipalities of Wijk aan Zee, Beverwijk, Velsen and IJmuiden (Figure 1). On the day of sampling, 24 February 2021, the weather was dry, as was the five days prior to the sampling. The wind direction during those days was predominately southerly $\left(180^{\circ}\right)$ with an average speed of 6-8 m/s. Samples were collected in public outdoor areas from flat horizontal surfaces at a height between $30-150 \mathrm{~cm}$, by sweeping deposited dust together with a brush into a sealable glass jar. The samples discussed here were the first-collected of an ongoing time-series sampling campaign at these localities and, as such, the sampled surfaces were not cleaned prior to sampling. Hence, the accumulation time of the dust at each location is not precisely known. The total dust mass concentrations per area ranged from 25 to $3327 \mathrm{mg} / \mathrm{m}^{2}$ for the samples. The sampled dust was prepared for analysis by PARC and QXRD after drying at $40^{\circ} \mathrm{C}$ for $2 \mathrm{~h}$. The sample location numbering includes gaps for 4,16,19,20, and 34, where no viable sample was obtained on the date of sampling. All collected samples from this date have been analysed and reported here.

\subsection{Sample Preparation}

Samples are prepared for analysis by mounting the particles on a $12 \mathrm{~mm}$ diameter pin stub covered with a conductive, adhesive carbon sticker. The material is sprinkled over the sticker using a micro spatula and lightly tapping it loaded with material approximately $15 \mathrm{~cm}$ above the stub to achieve as even a distribution as possible over the entire surface of the sticker.

\subsection{Raw Data Acquisition}

\subsubsection{QXRD}

Following the approach in [13], QXRD analysis for crystalline compounds was performed on the samples as mounted for microscopic analysis. An area of ca. $25 \mathrm{~mm}^{2}$ was analysed using a Bruker D8 Discover instrument (Bruker AXS GmbH, Karlsruhe, Germany) with a 2D position-sensitive area detector (Våntec 500, Bruker, Karlsruhe, Germany) and $\mathrm{Co} \mathrm{K} \alpha$ radiation $(30 \mathrm{kV} / 40 \mathrm{~mA}$ ) with sample rotation during the measurements. Three individual frames were recorded to cover a range from 10 to $100^{\circ} 2 \theta$ with total measurement time per sample of $30 \mathrm{~min}$. Following measurement, the frames were merged. Quantification of phase proportions in weight percent (wt \%) is performed using the Rietveld approach using the software Topas version 5 (also from Bruker). Phase proportions are converted to volume percent ( $\mathrm{vol} \%$ ) using phase densities calculated during refinement of a representative sample (see Supplementary File S1). True phase densities vary with their chemistry, but average chemistry per phase is not expected to vary widely from sample to sample in the phases where this plays a role (such as wustite solid solution). Volume percentages can be more readily compared than weight percentages with the PARC results which are reported in terms of area percentages. 


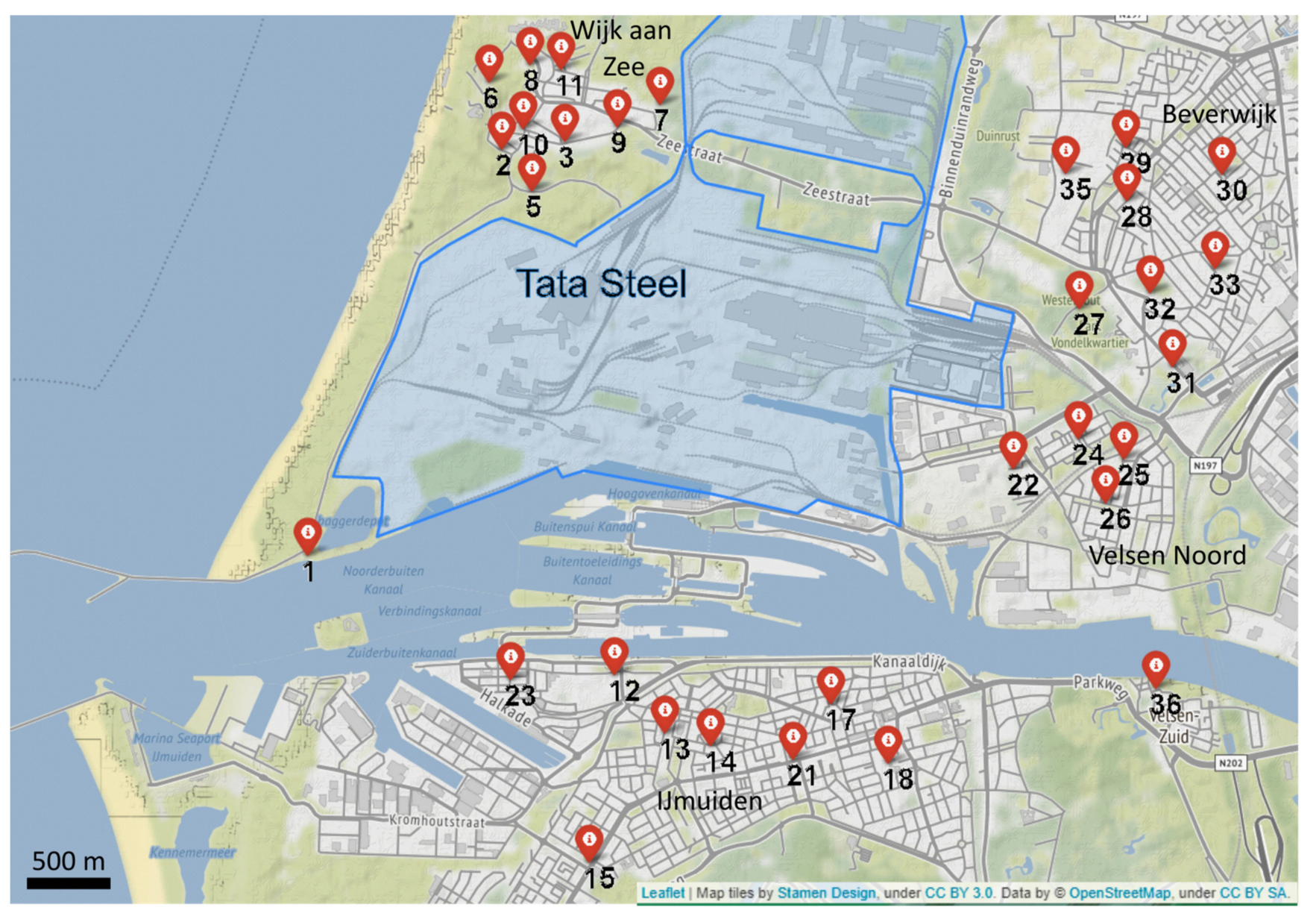

Figure 1. Map showing sampling locations in the IJmond Region of dust deposit samples analysed.

\subsubsection{LOM Raw Data Acquisition}

An extended depth of field (EDF) darkfield mosaic image is acquired using a Zeiss Axio Imager Z1 (Carl Zeiss Microscopy GmbH, Oberkochen, Germany) of the full stubmounted sample area to get an overview for guidance with selecting the three EDS-SI areas. Subsequently, the sample is carbon coated (approximately $15 \mathrm{~nm}$ layer thickness) and transferred to the SEM for SI acquisition.

\subsubsection{SEM-EDS-SI Raw Data Acquisition}

The measurement approach in this study was broadly the same as that in [13], except for the instrument used and the larger number of fields analysed. The current study was conducted with a Zeiss Gemini 450 instrument(Carl Zeiss Microscopy GmbH, Oberkochen, Germany), equipped with an Oxford microanalysis system (Oxford Instruments NanoAnalysis, High Wycombe, UK) with two SDD/EDS detectors (with crystal area per detector of $170 \mathrm{~mm}^{2}$ ). The accelerating voltage used was $15 \mathrm{kV}$, with a beam current of $12 \mathrm{nA}$. The magnification for spectral imaging was 150×, with image field resolution of $512 \times 384$ pixels and a resultant pixel size (step size) of $1.6 \mu \mathrm{m}$. The pixel dwell time was $1200 \mu \mathrm{s}$, translating to a total field acquisition time of approximately $5 \mathrm{~min}$ (including dead-time correction). Per sample, SI were acquired for three widely separated areas, each consisting of $3 \times 3$ fields, representing triplicate analyses (and referred to by this name throughout the rest of the article). For each $3 \times 3$ matrix, an overlap of $5 \%$ was used to aid stitching of the BSE and SI fields in subsequent processing of the data.

Quantitative chemical evaluation of EDS spectra exported from PARC was performed using the EDS software Pathfinder version 2.5 (Thermo Fisher Scientific, Madison, WI, USA) in standardless mode, using the inbuilt filter fit method for peak-fitting and PROZA 
(Phi-Rho-Z) correction method, and element concentrations are reported here as oxide wt $\%$ (using assumed oxide stoichiometries for the elements).

\subsection{Data Processing with PARC}

An overview of the SEM-EDS-SI raw data processing with PARC, including $\mathrm{Pb}$ detection, is shown in Figure 2 (adapted to the current study from Figure 3).

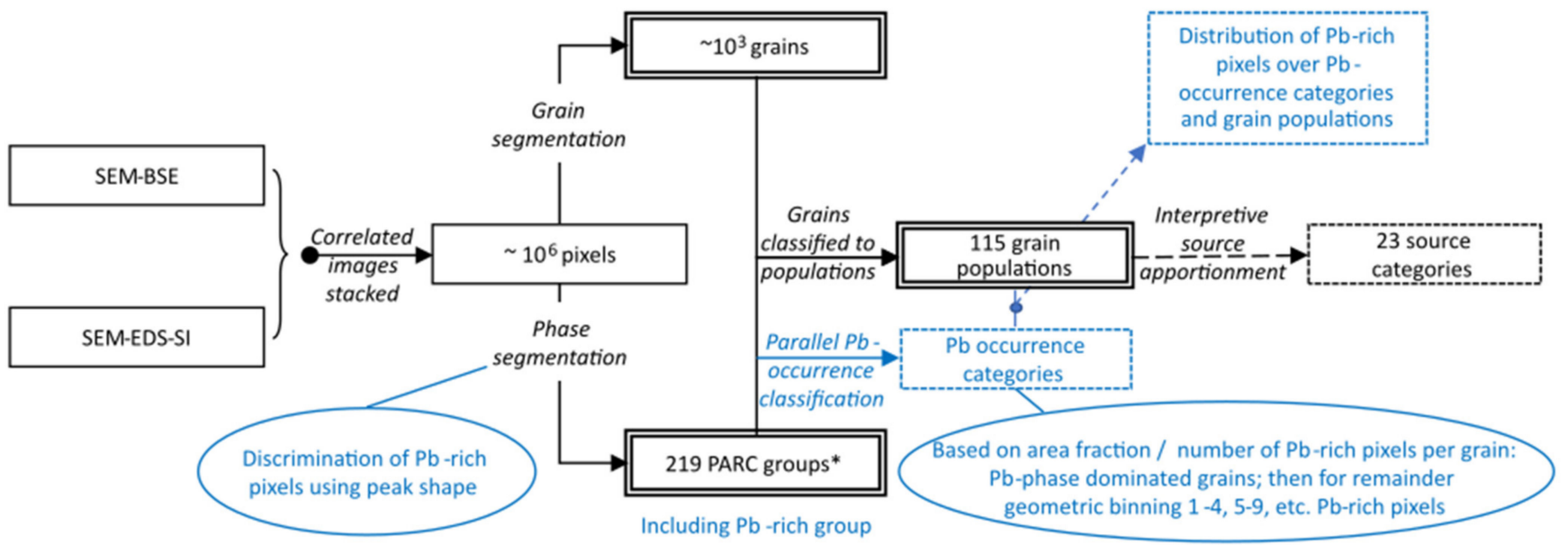

Data generated

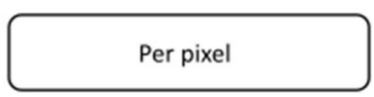

Raw -

SEM-BSE: greyscale;

SEM-EDS-SI: EDS spectrum;

Processed-

Label: PARC group;

Label: grain ID;

Label: grain population

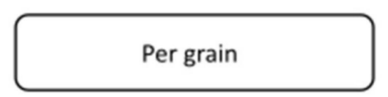

Total area \& morphological parameters;

Number of sub-grains;

Sum-spectrum (all pixels);

PARC group areas, area \%;

PARC group sum -spectra;

Grain ID;

Grain population assignment

${ }^{*}$ Cross-verification of major PARC groups with QXRD analysis

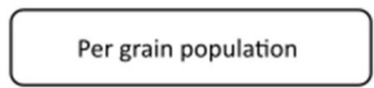

Total area ;

Grain size/morphology

statistics;

Sum-spectrum (all pixels);

PARC group areas, area \%;

PARC group sum -spectra;

Interpretive assignment to

source/material category
Per image (field)

PARC group areas, area \%; PARC group sum -spectra; Area \% of grain populations; Area $\%$ of source/material categories

Figure 2. Flowchart of raw (spectral-)image data acquired, processing and data generated by PARC software (PhAse Recognition and Characterisation, [14]), adapted to the current study from [13]. Processing steps indicated with arrows and italic text. Key to outlines in flow-chart: single solid line = image/image stack; double solid line = segmented image (map); single dashed line = derived information. Data produced per PARC group are listed under the relevant grain/grain population/field mask used to collate pixels. The number of PARC groups, grain populations and interpretive source categories in the processing is indicated. Number of pixels and grains varies per dataset and the numbers shown are approximate indications only. Additions in the current study, regarding Pb detection are marked in blue. SEM = scanning electron microscopy; EDS = energy dispersive spectroscopy; BSE = backscattered electron (imagery); SI = spectral imaging; QXRD = quantitative X-ray diffraction; ID = identity.

\subsubsection{PARC, General Phase Model}

Using the PARC software, the SEM-EDS-SI data are converted into phase distribution maps following general procedures described in [14] and, more specifically for dust characterisation, in [13]. In short, for this study, the individual SI pixels are assigned to one of 219 groups (or PARC groups) based on the combination of peaks present in their spectra with energy and signal intensity above defined threshold values (minimum energy cut-off of $0.9 \mathrm{keV}$ and 25 counts, respectively). In our previous study [13], the PARC groups were based exclusively on the combination of element peaks in the SI pixel spectra. This results 
in rather broadly defined PARC groups, with potentially multiple true phases captured within them, and with a certain degree of overlap (confusion) between groups where channel intensities fluctuate around the threshold intensities. Hence, for naming purposes, the PARC groups are generally notated simply with a list of their characteristic (diagnostic) element peaks in order of increasing energy: e.g., $\{\mathrm{Mg}, \mathrm{Si}, \mathrm{Ca}\}$ (unless otherwise indicated, referring to the $\mathrm{K} \alpha$ line of the listed elements). With two exceptions, this remains the case in the current study. First, the $\{\mathrm{Si}, \mathrm{Ca}\}$ group is split into two sub-groups, based on the log-ratio of $\mathrm{P} / \mathrm{Si}$, to distinguish between grains containing P-rich di-calcium silicate (C2S) vs. lower-P C2S or other Ca-silicates to improve discrimination between grains from the steelmaking basic oxygen furnace (BOF) converter process versus those from other steelmaking processes and, most importantly, from cement and building material containing Ca-silicate phases. Second, and most importantly for the current study, the detection of pixels with $\mathrm{Pb}$ signal deviates from the simple peak thresholding described above, and it is based on multiple filter conditions concerning the precise location and shape of the $\mathrm{Pb}-\mathrm{M} \alpha$ peak vs the overlapping $\mathrm{S}-\mathrm{K} \alpha$ peak. This is discussed extensively in following sections and is a central theme of this article. The PARC phase model, with its 219 groups, is applied uniformly to all samples, i.e., the group definitions and thresholds used remain constant with identical conditions used for a given measurement campaign. When plotting abundances, certain clearly related PARC groups are combined in later sections.

Apart from the two additions described above, the phase model used in this study is identical to that described in [13], and the correspondence between the PARC groups and true mineral phases (independently confirmed with QXRD analyses in many cases) is discussed in more detail there (see Table 1). Tables with the full listing of PARC groups are provided in Supplementary File S2 (model A as used for classifying grains; model B as used for quantitative chemical analysis). The distribution of the PARC groups, obtained by applying the phase model to the raw SI data, is visualised with a colour-coded map, alongside the SEM backscattered electron (BSE) images, and referred to hereinafter as a phase map.

A final important note concerns the PARC group 'empty spectra'. These are SI pixels for which no spectral peaks are present above the defined minimum energy and intensity thresholds specified above. This group captures the following: (1) all free carbon and organic compounds within the particles; (2) the stub (background) on which the particles are mounted; (3) pixels with very low overall signal intensity due to topography effects associated with e.g., holes, pores. The interpretation of the raw PARC results takes into account the context of occurrence to specify which of these three the empty spectra pixels represent.

\section{Grain Segmentation}

ImageJ (version 1.53h, U.S. National Institutes of Health, Bethesda, MD, USA), with a purpose-built grain segmentation plugin, was used to detect individual grains. In short, using an unprocessed SEM-BSE image as a starting point, foreground and background signals were separated in an iterative distance-transform-watershed process where, in each iteration, grains were detected and filtered on morphological features to refine the mask, creating a final grain segmentation mask used for further processing within PARC. The segmentation of grains in the samples' imagery remains highly challenging and is a primary source of misclassification of grain provenance, due to artefacts such as spurious merging of unrelated grains, splitting of single grains into multiple grains, and erroneous inclusion of background within the outline of the segmented grains. Some of these artefacts are visible in certain aspects of the results and are taken account of in the detailed interpretation discussed in later sections. To minimise the effect of any grain segmentation artefacts on the classification of those grains in which $\mathrm{Pb}$ was detected, a secondary manual check was performed on all such grains, and where necessary the grain outline was adjusted. 


\section{Grain Population Model}

Following grain segmentation and application of the PARC phase model to the SI dataset, the grains are classified under grain populations based on their mineralogy, as reflected in the area proportions of their constituent PARC groups. The general approach to grain population classification is explained in detail in our previous study [13]. In short, a manually constructed, branching set of filters is applied to sort the grains into populations. This is referred to as the grain population model. The model and its filters are defined to effectively capture and discriminate between key (industrial) materials and is continuously updated and refined based on new reference dust materials and their clearly distinctive grain populations as part of routine monitoring at Tata Steel in IJmuiden. The grain population model used for the current study contains considerably more populations than that in our previous study, but these largely comprise diverse urban dust populations and detailed sub-divisions of steelmaking slag- and flux-related populations. The key, i.e., most generally abundant, steelworks-related grain populations in the current samples retain essentially the same definitions as in the previous study. Full documentation of the grain population model, descriptions and interpretations of the individual grain populations, are given in Supplementary File S3. Table 1 shows an interpretive grouping of the grain populations under broad source material categories, henceforth referred to as source categories in this article. These broader source categories are referred to frequently throughout the rest of the article, along with the numbers of individual populations falling under them, which are described and explained directly in the text in these cases.

Table 1. Defined grain populations ordered and grouped by interpretive category. $\mathrm{C} 2 \mathrm{~S}=$ dicalcium silicate; $\mathrm{C} 3 \mathrm{~S}=\mathrm{tricalcium}$ silicate; $\mathrm{C} 2(\mathrm{~A}, \mathrm{~F})$ = brownmillerite; $\mathrm{qz}$ = quartz; fsp = feldspar.

\begin{tabular}{|c|c|c|c|}
\hline Population \# & Source Category \# & $\begin{array}{l}\text { Source } \\
\text { Category }\end{array}$ & Explanation \\
\hline $1-15$ & 1 & Site-ore & $\begin{array}{l}\text { Iron-ore and materials related to ore preparation } \\
\text { (sintering and pelletising). General mineralogical } \\
\text { characteristics: rich in FeOx } \pm \text { Ca-ferrites } \pm \mathrm{C} 2 \mathrm{~S}\end{array}$ \\
\hline 16 & 2 & Site-ore/hot metal & $\begin{array}{l}\text { Particles overwhelmingly dominated by FeOx or } \\
\text { Fe-metal (undistinguished): captures both iron-ore } \\
\text { particles and droplets of hot metal (pig iron) }\end{array}$ \\
\hline $17-53$ & 3 & Site-slag & $\begin{array}{l}\text { Diverse category of steelmaking process slags, } \\
\text { including basic oxygen furnace (BOF) converter, } \\
\text { steel ladle treatment and de-sulphurisation slags. } \\
\text { General mineralogical characteristics: BOF converter } \\
\text { slag is highly calcic material rich in C2S/C3S, } \\
\text { C2(A,F) (brownmillerite), magnesio-wustite and } \\
\text { oxidation product magnetite, } \\
\text { lime/portlandite/calcite and residue after } \\
\text { dolomite/doloma. Commonly partially encrusted } \\
\text { with sulphate-rich atmospheric weathering products. } \\
\text { Steel ladle slag is dominated by Ca-aluminates; } \\
\text { de-sulphurisation slag dust by Ca-rich silicates, } \\
\text { residue after dolomite and magnesia, and primary } \\
\text { sulphates from the process (not weathering } \\
\text { products). }\end{array}$ \\
\hline $54-55$ & 4 & $\begin{array}{l}\text { Site-slag; } \\
\text { + urban }\end{array}$ & $\begin{array}{l}\text { Particles consistent with blast furnace slag } \\
\text { mineralogy, noting that granulated blast furnace slag } \\
\text { can also have an immediate urban source as cement } \\
\text { construction material. General mineralogical } \\
\text { characteristics: dominated by Ca-Mg-Al-silicate } \\
\text { phases (melilite or glass) }\end{array}$ \\
\hline $56-65$ & 5 & Site-flux & $\begin{array}{l}\text { Iron- and steelmaking fluxes: (residue after) burnt } \\
\text { lime and limestone, dolomite and olivine (forsteritic) }\end{array}$ \\
\hline
\end{tabular}


Table 1. Cont.

\begin{tabular}{|c|c|c|c|}
\hline Population \# & Source Category \# & $\begin{array}{l}\text { Source } \\
\text { Category }\end{array}$ & Explanation \\
\hline 66 & 6 & $\begin{array}{l}\text { Site-flux/slag; } \\
\quad+\text { natural }\end{array}$ & $\begin{array}{l}\text { Burnt lime (flux)/limestone (diverse, including flux) } \\
\text { / sea-shells (natural): distinguished from the above } \\
\text { category by lack of other characteristic steelmaking } \\
\text { phases (C2S, Ca-ferrites and FeOx) }\end{array}$ \\
\hline $67-68$ & 7 & Site-flux/slag & $\begin{array}{l}\text { Probable limestone flux residue from iron-ore } \\
\text { sintering or pelletising with traces of reaction with } \\
\text { FeOx }\end{array}$ \\
\hline 69 & 8 & $\begin{array}{l}\text { Site-flux/ } \\
\text { refractory }\end{array}$ & $\begin{array}{l}\text { Ambiguous category: } \mathrm{MgO} \pm \text { sulphate phases, } \\
\text { variously flux from iron- and steelmaking processes } \\
\text { and refractory material }\end{array}$ \\
\hline $70-72$ & 9 & $\begin{array}{l}\text { Site- } \\
\text { refractory }\end{array}$ & $\begin{array}{l}\text { Likeliest refractory material from steelmaking } \\
\text { vessels. General mineralogical characteristics, } \\
\text { variously: } \mathrm{MgO}+\text { spinel; } \mathrm{MgO}+\text { forsteritic olivine; } \\
\text { alumina dominated }\end{array}$ \\
\hline $73-75$ & 10 & Site-scrap & $\begin{array}{l}\text { Zinc-rich material, likely galvanised steel scrap from } \\
\text { site (potentially also urban) }\end{array}$ \\
\hline $76-78$ & 11 & Urban + site-scrap & Fe-metal bearing particles / metallic slivers \\
\hline 79 & 12 & $\begin{array}{l}\text { Site-coal } \\
\text { \& cokes; } \\
\text { + natural } \\
\text { + urban }\end{array}$ & $\begin{array}{c}\text { Includes coal/coke material with silicate ash phases, } \\
\text { but also organic-rich soil containing the same natural } \\
\text { silicate phases. Mineralogical definition: carbon-rich } \\
\text { with qz-clay-fsp-mica or FeS or phosphates }\end{array}$ \\
\hline 80 & 13 & $\begin{array}{l}\text { Site- } \\
\text { carbon-rich other }\end{array}$ & $\begin{array}{l}\text { Carbon-rich material with steelmaking phases } \\
\text { formed during iron-/steelmaking processes, but also } \\
\text { captures spuriously segmented grains (mixing of } \\
\text { steelworks-related grains with carbon-rich grains or } \\
\text { with background) }\end{array}$ \\
\hline $81-82$ & 14 & $\begin{array}{l}\text { Site- } \\
\text { carbon-rich other; } \\
\quad+\text { natural } \\
\text { + urban }\end{array}$ & $\begin{array}{l}\text { 82: Material with highest carbon / organic content } \\
\text { (>90\% empty spectra) and lowest content of } \\
\text { non-carbon phases such as ash or steelmaking } \\
\text { phases. } \\
\text { 81: Remaining undifferentiated carbon-rich material } \\
\text { (after classification of } 79,80 \text {, and } 82 \text { ): may include } \\
\text { graphite flakes, organic carbon-based materials and } \\
\text { diverse sources }\end{array}$ \\
\hline $83-87$ & 15 & $\begin{array}{l}\text { Urban; rarely } \\
\text { site-slag }\end{array}$ & $\begin{array}{l}\text { Particles rich in Ca-silicate (lower P/Si signal ratio) } \\
\text { and Ca-(hydr)oxide/carbonate but free of silica: } \\
\text { commonly cement/building material, also detected } \\
\text { in converter slag reference materials. Ambiguous } \\
\text { source category. }\end{array}$ \\
\hline $88-99$ & 16 & Urban & $\begin{array}{l}\text { Diverse urban dust sources. For the current sample } \\
\text { set, most significant occurring populations: } \\
\text { 88-89: building material (cement/concrete) rich in } \\
\text { combinations of silica-Ca-carbonate-Ca-silicates } \\
\text { (incl. C2S), lacking key diagnostic steelmaking } \\
\text { phases and poorer in P than steelmaking slags with } \\
\text { otherwise overlapping mineralogy } \\
94: \text { particles bearing }>1 \% \text { Ba-sulphate. Less a } \\
\text { coherent grain population than a flag for high level } \\
\text { of surface contamination of other particle types with } \\
\text { Ba-sulphate. }\end{array}$ \\
\hline 100 & 17 & $\begin{array}{l}\text { Natural salt- } \\
\text { immediate }\end{array}$ & $\begin{array}{l}\mathrm{NaCl} \text {-dominated grains ( } 95 \% \text { of surface): most } \\
\text { commonly other grains with complete covering of } \\
\text { sea-salt from maritime influence (sea spray) }\end{array}$ \\
\hline
\end{tabular}


Table 1. Cont.

\begin{tabular}{|c|c|c|c|}
\hline Population \# & Source Category \# & $\begin{array}{l}\text { Source } \\
\text { Category }\end{array}$ & Explanation \\
\hline $101-103$ & 18 & $\begin{array}{l}\text { Natural } \\
\text { mineral background }\end{array}$ & $\begin{array}{l}\text { Grains with }>60 \% \text { content of natural silicates: quartz, } \\
\text { clay, feldspar, mica }\end{array}$ \\
\hline 104 & 19 & $\begin{array}{c}\text { Natural } \\
\text { mineral background } \\
\text { mixed with site or urban }\end{array}$ & $\begin{array}{l}\text { Grains with } 30-60 \% \text { of the above natural silicates, } \\
\text { with or without the presence of typical steelmaking } \\
\text { phases (FeOx, C2S). Population captures: composite } \\
\text { particles comprising sub-particles with mixed origin } \\
\text { (natural/industrial/urban); and spurious artefacts } \\
\text { of grain segmentation (steelworks-related particles } \\
\text { merged within the same PARC-grain outline as } \\
\text { separate natural silicate particles) }\end{array}$ \\
\hline 105-107 & 20 & $\begin{array}{l}\text { Natural source- } \\
\text { immediate } \\
\text { + via site }\end{array}$ & $\begin{array}{l}\text { Miscellaneous other silicate-rich particles and } \\
\text { particles rich in apatite. Natural rock-forming } \\
\text { minerals, encountered both in immediately naturally } \\
\text { sourced materials and as gangue-phases in iron ores } \\
\text { (scarce) }\end{array}$ \\
\hline $108-110$ & 21 & Unknown & $\begin{array}{l}\text { Three mineralogically distinctive grain populations } \\
\text { of uncertain provenance }\end{array}$ \\
\hline 111 & 22 & $\begin{array}{l}\text { Pb-rich } \\
\text { various }\end{array}$ & $\begin{array}{l}\text { Grains with }>40 \% \text { Pb-rich pixels. Captures both a) } \\
\text { discrete particles dominated by Pb-phases } \\
\text { (throughout their bulk) and b) particles with a large } \\
\text { concentration of } \mathrm{Pb} \text {-rich pixels reflecting only } \\
\text { superficial occurrence of Pb-phases } \\
\text { (sub-grains/layering). The sub-population (a) has } \\
\text { been counted separately for the current sample set } \\
\text { by extra filtering in downstream processing of the } \\
\text { PARC results, separately from the grain population } \\
\text { model (see Section 3.3.1) }\end{array}$ \\
\hline $112-115$ & 23 & $\begin{array}{l}\text { Unassigned (w/wo } \\
\text { partial } \\
\text { chloride cover) }\end{array}$ & $\begin{array}{l}\text { Unassigned grains, with / without partial } \\
\text { (Na-)chloride covering. } \\
\text { 114: otherwise unassigned grains, where these } \\
\text { contain } \geq 1 \mathrm{~Pb} \text {-rich pixel (implicitly }<40 \% \text {, which is } \\
\text { the threshold for classification under population } 111 \text { ) }\end{array}$ \\
\hline
\end{tabular}

2.4.2. Detection of Pb-Rich Pixels in EDS-SI Data Acquired with $15 \mathrm{kV}$ Accelerating Voltage

Rationale and Definition of Pb-Rich PARC Group

Generally, when $\mathrm{Pb}$ is an element of interest in EDS or EPMA-WDS analysis, an accelerating voltage of at least $20 \mathrm{kV}$ is used to excite the Pb-L lines, which are most clearly diagnostic of $\mathrm{Pb}$ and have least potential overlap with other element peaks. In particular, the $\mathrm{Pb}-\mathrm{M}$ lines overlap strongly with $\mathrm{S}-\mathrm{K} \alpha$ in EDS spectra, hence when attempting to unequivocally identify $\mathrm{Pb}$ signal in the presence of $S$, this is a serious issue [15]. Previous studies on the occurrence of $\mathrm{Pb}$ in dust particles have avoided this potential confusion, either by using accelerating voltages of 20-25 kV for EDS analysis [8,11,12] and/or by using EPMA-WDS element mapping during their pre-screening of the particles $[8,10]$ to identify those with high concentrations of $\mathrm{Pb}$. This allows unambiguous identification of high $\mathrm{Pb}$ concentration irrespective of the presence of $\mathrm{S}$ in the same analysed volume. For the wider objectives of the dust characterisation method in this study, an accelerating voltage of $15 \mathrm{kV}$ is preferred over $20 \mathrm{kV}$ due to the smaller excitation volume, and better effective spatial resolution, of the analyses. The characteristic phase intergrowths and surface layers of the studied dust material, used to define the grain populations (and hence infer dust provenance), are more clearly resolved with an accelerating voltage of $15 \mathrm{kV}$. A 
practical solution has therefore been developed for discriminating SI pixels with significant $\mathrm{Pb}$ M-line signal from those with high S-K $\alpha$ but lacking in $\mathrm{Pb}$.

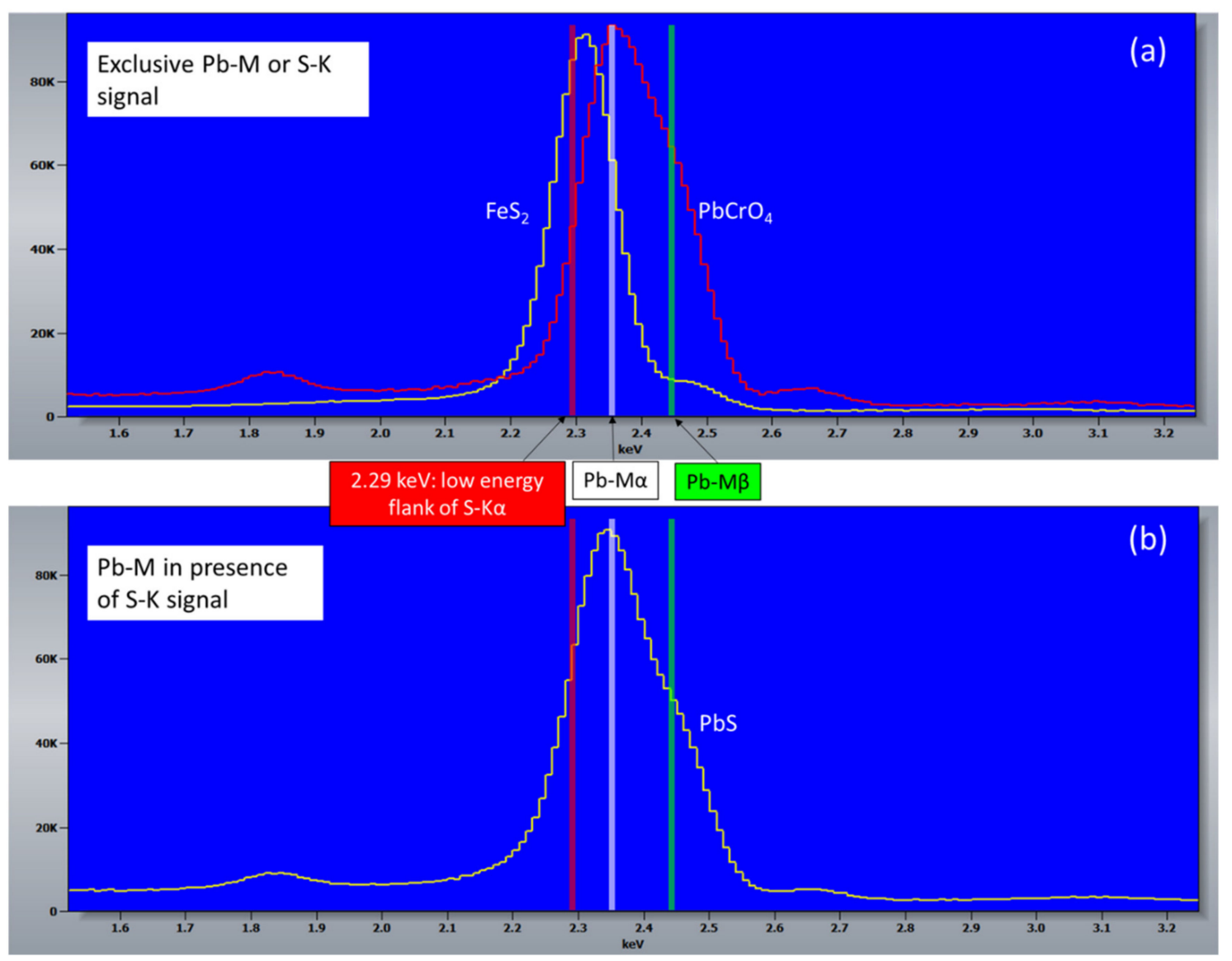

Figure 3. Illustration of differences in peak position and shape for (a) signal from $\mathrm{S} \mathrm{K}$-lines (on $\mathrm{Fe} \mathrm{S}_{2}$ ) versus $\mathrm{Pb} \mathrm{M}$-lines (on $\mathrm{PbCrO}_{4}$ ), versus (b) mixed signal of both ( $\mathrm{PbS}$ ). The three labelled vertical lines denote the three channels used for discrimination of $\mathrm{Pb}$-rich pixels from S-rich, Pb-free pixels in Figures 4 and 5.

Figure 3 shows EDS spectra with high peak to background ratio, measured by spot analysis at $15 \mathrm{kV}$ accelerating voltage, for three reference analytical standard materials (SPI supplies, $\mathrm{PA}, \mathrm{USA})$ comprising pyrite $\left(\mathrm{FeS}_{2}\right)$, crocoite $\left(\mathrm{PbCrO}_{4}\right)$ and galena $(\mathrm{PbS})$. In these spectra, the difference in precise location and shape of $\mathrm{Pb}-\mathrm{M} \alpha$ vs $\mathrm{S}-\mathrm{K} \alpha$ signal from $\mathrm{FeS}_{2}$ and $\mathrm{PbCrO}_{4}$ respectively is clearly visible (Figure $3 \mathrm{a}$ ). The $\mathrm{S}-\mathrm{K} \alpha$ peak is located at $2.31 \mathrm{keV}$ and is narrower and more symmetric in shape than the $\mathrm{Pb}-\mathrm{M} \alpha$ peak, which is located at $2.34 \mathrm{keV}$ (white line) and overlaps with $\mathrm{Pb}-\mathrm{M} \beta$ (green line) to create a distinctive asymmetric shape with a shoulder on the high energy side. In the PbS spectrum (Figure 3b), which contains both $\mathrm{Pb}$ and $\mathrm{S}$ signal, the resultant peak is clearly broader than that from either $\mathrm{FeS}_{2}$ or $\mathrm{PbCrO}_{4}$, while the distinctive asymmetry towards high energy is still present. For these spectra, current (standardless) quantification routines in the EDS software Pathfinder 2.5 provide sufficiently good peak deconvolution to clearly discriminate the three separate phases from one another. However, at the level of an individual SI pixel spectrum, with far lower peak to background ratio, the requirement for this study is to use the slight difference in location and shape of the $\mathrm{Pb}-\mathrm{M}$ vs $\mathrm{S}-\mathrm{K} \alpha$ peak profile to discriminate between pixel spectra containing significant $\mathrm{Pb}$ signal versus those lacking it, irrespective of the presence of $S$ signal in the same spectra.

The complete set of SI pixels in a measured area are first filtered to those containing signal above a minimum threshold intensity (30 counts) at the channel position of $\mathrm{Pb}$ $\mathrm{M} \alpha$ (c235, using $10 \mathrm{eV}$ channel width) and passing two additional filters to avoid: (1) $\mathrm{Mg}+\mathrm{Mg}$ sum peak artefact and (2) interference from the combination of low S-K $\alpha$ in 
combination with very high $\mathrm{Cl}-\mathrm{K} \alpha$ signal (both artefacts result in pixels plotting within the polygon defined in the following step despite being $\mathrm{Pb}$-free). These filtered pixels are then classified by whether they plot within (Pb-rich) or outside ( $\mathrm{Pb}$-free) a polygon defined in the coordinate system of raw channel intensity (counts) at channel c235 vs the log-ratio of channel intensities c244/c229 (Figure 4; c244 and c229 indicated by, respectively, green and red lines in Figure 3). The latter represents, effectively, a shape parameter of the peak detected at $2.34 \mathrm{keV}$, which would otherwise be indistinguishable between $\mathrm{Pb}-\mathrm{M} \alpha$ or $\mathrm{S}-\mathrm{K} \alpha$ (centred at $2.31 \mathrm{keV}$ ). The pixels which are included in this final discrimination step would otherwise be assigned to one of the numerous groups defined by presence of a S-K $\alpha$ peak above the minimum threshold value, or to the unassigned category (in cases where the S$\mathrm{K} \alpha$ peak is accompanied by a combination of other peaks not included in the PARC phase model used).

To define the polygon coordinates, analyses were performed, with identical measurement conditions to those used for the dust deposit samples, on a set of reference phases comprising $\mathrm{Pb}$-rich $\left(\mathrm{PbCrO}_{4}\right.$ and $\left.\mathrm{PbS}\right)$ and $\mathrm{S}$-rich, nominally $\mathrm{Pb}$-free phases $\left(\mathrm{BaSO}_{4}, \mathrm{CaSO}_{4}\right.$, $\mathrm{FeS}_{2}, \mathrm{HgS}, \mathrm{MoS}_{2}$ ) in polished section. Figure 4 shows a series of (two dimensional) density plots representing the statistical distribution of SI pixel spectra for these reference analyses within the described coordinate system (where the density of points is indicated by a colour scale). The areas of highest density correspond with pixels located within well-polished regions of the reference phase, while the lower density "tail" extending from the main cluster towards the y-axis represents a much smaller number of pixels with lower total signal due to their location in small cracks, scratches, hollows or at the margin between polished reference material and embedding material (epoxy). Other low-density traces within the plots represent minor inclusion phases contained within the reference materials. Clearly, it is possible to define a polygon that separates the main clusters of pixels in the two $\mathrm{Pb}$-rich reference phases from the rest of the $\mathrm{S}$-rich, $\mathrm{Pb}$-free phases. The analysed area within the $\mathrm{PbCrO}_{4}$ reference material contains at least one genuine S-rich inclusion (confirmed by manual inspection), which is visible in the density plot as the low-density trace extending outside of the defined $\mathrm{Pb}$-rich polygon towards the $\mathrm{x}$-axis. The main cluster of pixels in the $\mathrm{PbS}$ reference have clearly higher total signal (c235) and slightly lower log-ratio of c244/c229 than the $\mathrm{PbCrO}_{4}$ reference, reflecting the combined signals of $\mathrm{Pb}$ and $\mathrm{S}$. Still, there is clear distinction between $\mathrm{PbS}$ and the other $\mathrm{S}$-rich, $\mathrm{Pb}$-free references, and the polygon has a slightly negatively sloping lower edge to ensure that $\mathrm{PbS}$ and $\mathrm{PbCrO}_{4}$ are both detected as $\mathrm{Pb}$-rich. A small number of pixels in the $\mathrm{CaSO}_{4}$ and $\mathrm{BaSO}_{4}$ references are scattered in a near vertical trend crossing the entire $\mathrm{Pb}$-rich polygon. These pixel spectra are neither $\mathrm{Pb}$-rich, nor S-rich and manual inspection revealed that they correspond with scarce inclusions of $\mathrm{Bi}_{2} \mathrm{Se}_{3}$ introduced as contamination during grinding and polishing of the standard block which contains the latter material as well as the analysed reference phases. The Bi-M $\alpha$ line is located at $2.423 \mathrm{keV}$, explaining the observed array of points in the density plots. No extra filtering has yet been applied to exclude these, but such phases are expected to be extremely rare in the dust deposit samples, compared with the widespread large abundance of S-rich phases, and also compared to the expected low but detectable occurrence of $\mathrm{Pb}$-rich phases. 

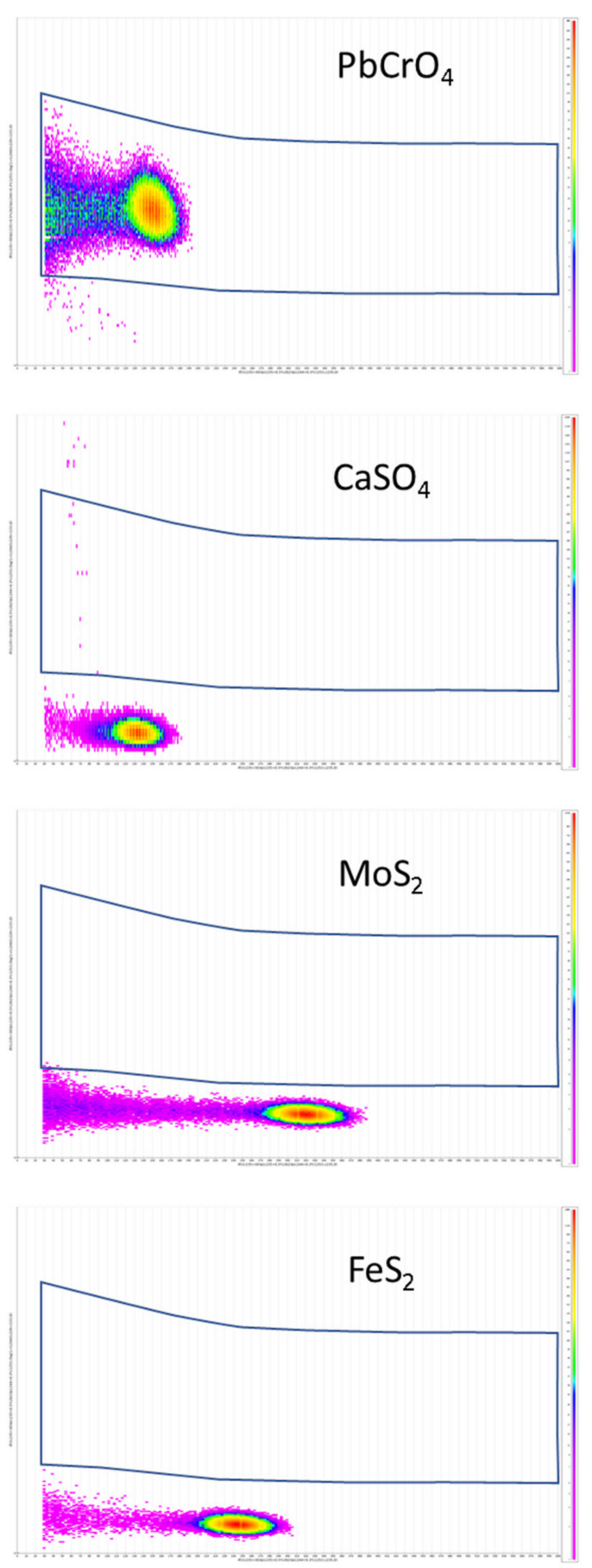
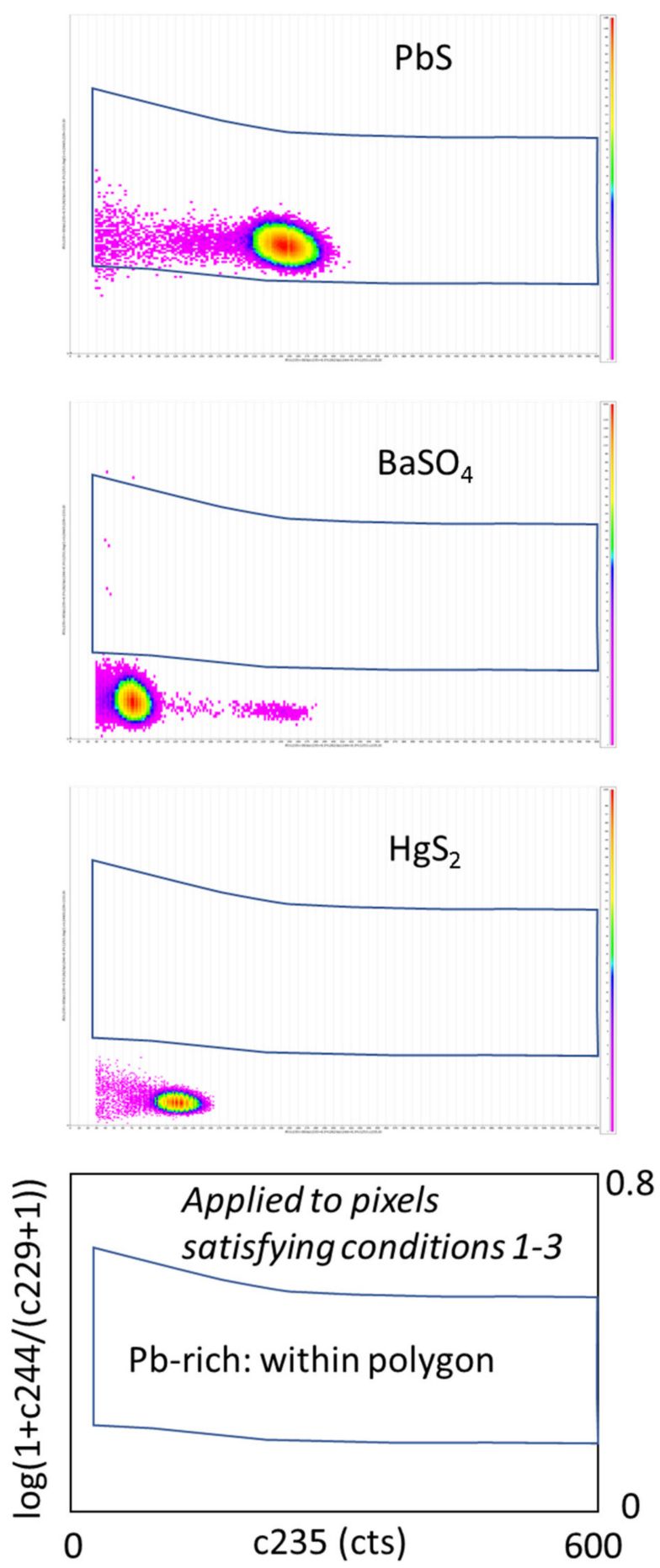

Figure 4. A 2D-density plot definition of Pb-rich PARC group based on analyses of standard reference phases in polished section, as shown. Axis definitions and ranges shown in lower-right plot. c229, c235 and c244 denote raw channel intensities (counts) corresponding with energies 2.29, 2.35 and $2.44 \mathrm{keV}$, respectively, in the spectra of individual SI pixels. The density of points (pixels) for a given $x-y$ bin is indicated by the marker colour (magenta = lowest; red = highest density). For a given dataset, all pixels satisfying conditions 1-3 are included in the density plot. Those plotting within the demarcated polygon are classified as belonging to the $\mathrm{Pb}$-rich group. Those plotting outside the polygon are returned to the main population of pixels and classified according to their peak combination or any other density plot definitions. Condition 1: c235 > 30; condition 2: c235 > $0.5 \times$ c262; condition 3: c244 > $0.3 \times$ c125, where c125, c262 correspond with channel intensities (counts) at $1.25(\mathrm{Mg}-\mathrm{K} \alpha)$ and $2.62 \mathrm{keV}(\mathrm{Cl}-\mathrm{K} \alpha)$. 
Other than the above disregarded effects visible in the calibration density plots, Pb-rich and $\mathrm{Pb}$-free pixels can be near-perfectly distinguished when analysing well-polished, large single-phase domains. However, the dust particles are analysed as rough three-dimensional objects with accompanying topography effects. Moreover, the Pb-rich phases present in the material may be present as sub-micron particles or thin layers on a substrate of unrelated phases. As can be seen in the density plots in Figure 4, as the total channel intensity at c235 decreases for all the samples (especially the $\mathrm{Pb}$-rich phases) the spread in the peak-shape parameter (log-ratio c244/c229) increases and the risk of overlap and false classification increases with this. An example SI dataset, acquired with identical measurement conditions for a dust sample, is shown in Figure 5 to illustrate the typical clustering in the density plot of a sample in which both $\mathrm{Pb}$-rich pixels and S-rich, $\mathrm{Pb}$-free pixels have been detected. At higher signal intensity (channel c235) there is better distinction between the clusters, but there are also far fewer pixels with such high signal. Towards the minimum threshold intensity (hard cut-off in the plot) there are more pixels but the distinction between the two clusters is obviously somewhat weaker. Hence, to avoid excessive false positive detections of $\mathrm{Pb}$-rich pixels, the minimum threshold for signal at the expected $\mathrm{Pb}-\mathrm{M} \alpha$ position was set at 30 counts, rather than the 25 counts used to recognise peaks for other PARC groups in the phase model. Nevertheless, the clustering of the pixels passing the initial filters and plotted in the density plot in this example is very strong, and the polygon trace passes through a region of very low density.

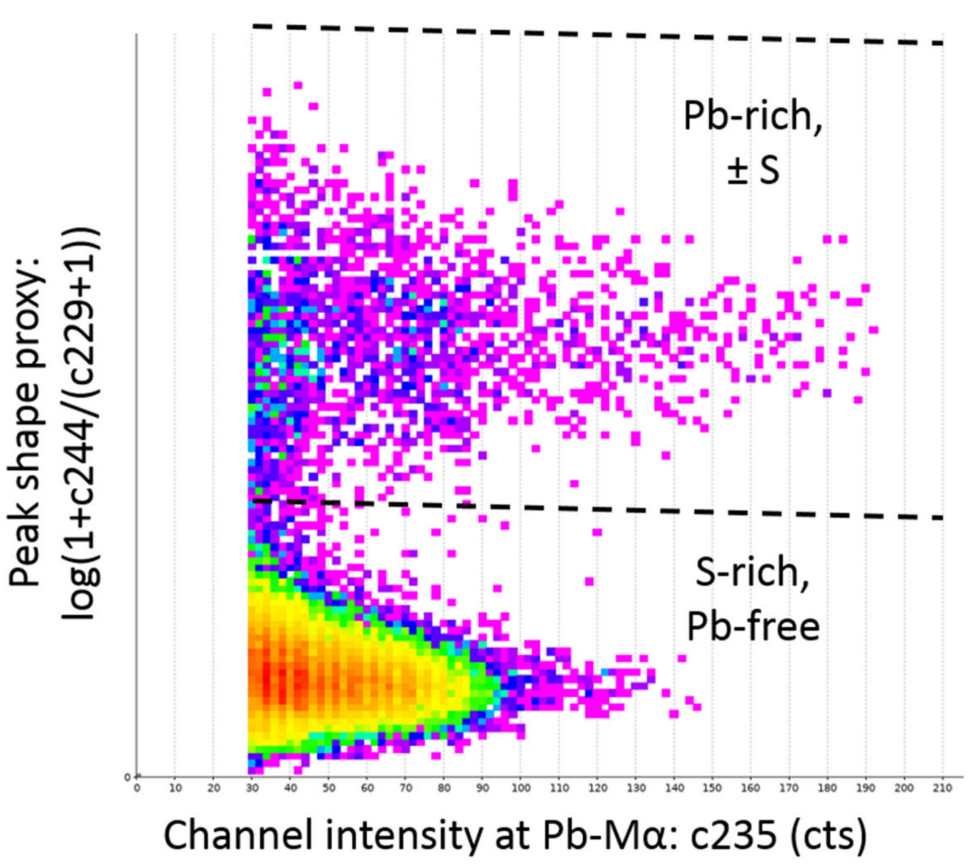

Figure 5. Illustration of density plot screening for $\mathrm{Pb}$-rich pixels (as shown in Figure 4) applied to an analysis of dust deposit sample containing both detected $\mathrm{Pb}$-rich group pixels and a much higher abundance of pixels inferred to be $\mathrm{S}$-rich and $\mathrm{Pb}$-free. The density plot definition plots a proxy for peak shape versus intensity at the expected energy for $\mathrm{Pb}-\mathrm{Ma}$, after pre-filtering for other spectral artefacts (conditions 1-3 listed in Figure 4).

Factors Influencing Sensitivity and Specificity

Since the PARC approach comprises the screening and classification of individual SI pixels, the factors influencing its sensitivity and specificity warrant discussion. Regarding the wider sensitivity of the method, the largest number of false negative pixel assignments (i.e., pixels that contain genuine $\mathrm{Pb}$ signal but are not classified as such) are expected to be those whose signal intensity at the $\mathrm{Pb}-\mathrm{M} \alpha$ position is (just) below the applied threshold value of 30 counts. In practice, however, this is simply an extension of the more general limitation of the EDS-SI measurement approach: broadly speaking, to reliably detect $\mathrm{Pb}$ in 
the spectrum of an individual pixel, it must be concentrated in the excitation volume at the level of a major element ( 10\%). By defining the $\mathrm{Pb}$-rich pixel group in PARC as being those pixels with a major element concentration of $\mathrm{Pb}$, this at least gives a clear physical meaning for what such pixels represent, which is discussed later in this section.

Disregarding the pixels with possibly genuine $\mathrm{Pb}$ signal below the threshold intensity, the sensitivity and specificity of the method to discriminate $\mathrm{Pb}$-rich pixels from S-rich pixels and those with other artefacts are primarily influenced by: (1) the effectiveness of the filters for excluding "mimic" pixels with artefacts of $\mathrm{Mg}+\mathrm{Mg}$ sum peak and the combination of $\mathrm{S}$ with high $\mathrm{Cl}$ signal, (2) the goodness of clustering of actual $\mathrm{Pb}$-rich and $\mathrm{Pb}$-free pixels in the coordinate system of the density plot and (3) the choice of polygon to define the Pb-rich group. Regarding (1) and (3), these are manually defined filters, and in both cases, there is an implied trade-off between sensitivity and specificity depending on the filter settings. In short, the section of the polygon trace separating $\mathrm{Pb}$-rich from, effectively, S-rich pixels is clearly defined based on the standard reference phases and there is very little direct justification for shifting the trace significantly from that shown in Figure 4. In the case of the pre-filtering of pixels for $\mathrm{Mg}+\mathrm{Mg}$ and $\mathrm{Cl}-\mathrm{K} \alpha$ flank artefacts, before the density plot discrimination step, there is a more prominent subjective component to the thresholds chosen, and preference was given to sensitivity above specificity. Finally, regarding the clustering of genuinely $\mathrm{Pb}$-rich and $\mathrm{Pb}$-free pixels within the density plot, this is influenced by instrument settings and sample topography. Evidently, with well-polished surfaces, distinct clusters are observed. With rough surfaces and diluted $\mathrm{Pb}$ signal, due to mixed chemical signal from adjacent and underlying (substrate) phases, the clustering becomes weaker and there is more chance of misclassification as signal intensity approaches the minimum threshold of 30 counts. At higher signal intensity, however, distinct clustering is seen (Figure 5).

Currently there is no direct quantitative estimate of the sensitivity and specificity of the described PARC approach to detect $\mathrm{Pb}$-rich pixels. The method's performance has been indirectly evaluated in two ways: (1) by application (in the following section) to four standard reference materials (SRMs) comprising urban and indoor dust, powdered paint and soil, containing certified elemental concentrations of $\mathrm{Pb}$ ranging from $3000-40,000 \mathrm{mg} / \mathrm{kg}$ from NIST; and (2) by scrutinising the reproducibility of, and any signs of analytical artefacts in, the results from the studied IJmond dust samples themselves.

\section{Physical Meaning of Pb-Rich Pixels and Analytical Results}

The detected $\mathrm{Pb}$-rich pixels are not yet subdivided into different groups (reflecting specific compounds) and are left together as a generic category for any pixels containing $\mathrm{Pb}$ at the major element concentration level. These pixels, therefore, represent major localised concentrations of $\mathrm{Pb}$ visible at the length-scale of $1 \mu \mathrm{m}$ or greater, which may at one extreme correspond with signal from nano-scale sub-particles interspersed with or atop other phases, or at the other extreme clearly identifiable individual (sub-)grains of $\mathrm{Pb}$-phases.

The chemical signal of all the SI pixels reflects that of the corresponding excitation volume, whose precise shape and dimensions are a function of the accelerating voltage and analysed material's properties. Where the excitation volume is contained entirely within a single phase(-intergrowth), quantitative analyses of the sum-spectra of grouped SI pixels (i.e., PARC groups) generally give good agreement with expected phase stoichiometry. In practice, this is rarely the case with the analyses performed on the dust materials, due to the fine intergrowth of phases and more importantly the common presence of superficial layers on particles. In the case of superficial material, the thickness of the layer relative to the depth of the excitation volume determines how much mixing of the chemical signal of that layer and the underlying substrate phase(s) there is. For example, S-rich and $\mathrm{Cl}$-rich PARC groups- $\{ \pm, \mathrm{S}, \pm\}$ and $\{ \pm, \mathrm{Cl}, \pm\}$ in the PARC group notation-most commonly correspond with apparent superficial layers and sub-particles of sulphate and chloride phases atop the phases comprising the substrate particle. The chemical signal of these SI pixels strongly reflects the substrate as well the superficial sulphate or chloride phases. 
When considering the physical meaning of detected $\mathrm{Pb}$-rich pixels in the analyses, the same general point applies. As discussed in later sections, for the overwhelming majority of the grains containing any detected $\mathrm{Pb}$-rich pixels, the $\mathrm{Pb}$-rich pixels represent superficial material, with a presumed thickness comparable to, or smaller than, the depth of the excitation volume. The chemical signal for the sum-spectra of $\mathrm{Pb}$-rich pixels, grouped by host-grain/population/sample, in these cases is therefore a mixture of the Pb-rich phase and the underlying substrate, just as encountered in the S-rich and Cl-rich PARC groups. For this reason, inferring the precise compound form of $\mathrm{Pb}$ represented by the $\mathrm{Pb}$-rich pixels, based on the exported grouped pixel spectra, is generally not possible. Some limited inferences can be made to exclude certain possible compound forms, for example if the pixel spectra lack $\mathrm{Cl}$ signal, then they cannot represent $\mathrm{Pb}$-chloride/chlorate. A final implication of the above points is that, where $\mathrm{Pb}$ is present in an extremely thin surface layer, it may not result in a sufficiently high signal to be detected as Pb-rich pixels, just as a low-density dispersal of discrete nano-particles may go undetected for the same reason.

In summary, the presented method gives the silhouette area fraction of particle surface where $\mathrm{Pb}$ is concentrated at a major element level $(\sim 10 \%)$ at the $\sim 1 \mu \mathrm{m}$ length-scale resolvable with an accelerating voltage of $15 \mathrm{kV}$. Individual pixels may represent a discrete $\mathrm{Pb}$-compound phase; a concentration of nano-scale particles or inclusions within another phase; or a continuous surface layer. Below a certain density of dispersal of discrete $\mathrm{Pb}$-compound phases, or where $\mathrm{Pb}$ is present in solid solution below the major element concentration level, this will not be detected by the method. Though beyond the scope of the present article, when combined with bulk techniques to analyse the elemental concentration of $\mathrm{Pb}$ and its speciation, inferences may also be made regarding how much of the total $\mathrm{Pb}$ contained in a sample is present in sufficiently concentrated form to be detected by the PARC approach and how much is present in more disperse(-discrete) and dilute form.

\subsection{Application to NIST Pb-Rich Urban and Indoor Dust Standard Reference Materials}

The PARC dust characterisation method, as described in the preceding sections, was applied to four standard references materials (SRM) from NIST (Table 2), comprising urban dust, powdered paint and soil material, with a range of certified concentrations (mass fractions) of $\mathrm{Pb}$ from nominal $3000-40,000 \mathrm{mg} / \mathrm{kg}$. The sample preparation, analytical conditions and processing used were identical to those for the IJmond dust deposit samples. The phase model applied was identical to that used for the IJmond dust deposit samples with no optimisation for the material encountered in the SRMs, since the primary goal was purely to evaluate the detection of $\mathrm{Pb}$-rich phases in particulate materials with known bulk chemical $\mathrm{Pb}$ mass fractions. For the same reason, the grain population model has not been applied to assign the grains to populations. The wider mineralogy and provenance of the grains hosting Pb-rich pixels are therefore not discussed in this section. The full PARC group abundances per analysis are provided in Supplementary File S4A.

The PARC detected Pb-rich pixel abundances are shown in Table 3 for the individual triplicate analyses, with per-sample the mean and standard deviation values. Figure 6 shows an overall strong, positive linear correlation between the area \% of Pb-rich pixels and the certified bulk chemical mass fraction of $\mathrm{Pb}$. The relative 1- $\sigma$ standard deviation values on triplicate analyses per SRMs range from 1.3 to $8.4 \%$ for the three SRMs with highest nominal $\mathrm{Pb}$ mass fraction, indicating rather homogeneous distribution of detectable $\mathrm{Pb}$-rich phases at the scale of total analysed area. In SRM 2587 (nominal $3000 \mathrm{mg} / \mathrm{kg} \mathrm{Pb}$ ) the outsized contribution of a single large grain with high $\mathrm{Pb}$-rich phase content in one of the triplicate analyses (\#1) has a significant influence on the overall result and contributes to a much higher relative $\sigma$ of $53 \%$ on the mean of the triplicate analyses (Supplementary File S4B,C). This highlights what is essentially a nugget effect at the spatial scale of the analyses, where the presence or absence of scarce "nugget" grains within the analysed areas dominates the results of replicate analyses [16]. Nugget grains in this context need not be discrete particles dominated by $\mathrm{Pb}$-phases throughout their bulk, as normally implied by the term in geochemistry and mineral exploration, but may also be particles with an 
extensive covering of superficial $\mathrm{Pb}$-rich phases, since the analysis method here concerns the surface exposed phase abundances.

The observed trend in Figure 6 should emphatically not be regarded as a calibration curve for inferring bulk chemical $\mathrm{Pb}$ mass fraction from the PARC analyses. It is entirely contingent on the set of samples analysed and is simply an observed trend reflecting the distribution of $\mathrm{Pb}$ in those samples (only). Grouping the four SRMs and fitting a linear trend through them neglects potentially important detailed differences in the distribution of $\mathrm{Pb}$ over detectable $\mathrm{Pb}$-rich phases vs. non-detectable form for the current method. There is indeed no a priori reason to assume that four such disparate materials should show a consistent expression of bulk-sample elemental $\mathrm{Pb}$ mass fraction in their detected $\mathrm{Pb}$ rich phase abundances with the current method. Specifically, the PARC method detects the abundance of $\mathrm{Pb}$-rich phases present at the surface of particles, which may deviate strongly from the abundance in the bulk (including interiors). Moreover, a part of the $\mathrm{Pb}$ in the material may also be present in dilute form, or sufficiently dispersed as nanoinclusions/sub-particles, such that it is not concentrated at the minimum detectable level at the length-scale of $1 \mu \mathrm{m}$, which is required for detection with PARC (see previous section). Nevertheless, it is possible to conclude that, at least for this set of materials, the variation in independently analysed bulk $\mathrm{Pb}$ mass fraction in the range $3000-40,000 \mathrm{mg} / \mathrm{kg}$ is strongly correlated with the surface abundance of Pb-rich phases detected with the PARC method. Additionally, this exercise demonstrates that a (micro-scale) nugget effect can strongly influence the analyses at the level of the total area and number of grains analysed currently, which needs to be considered when interpreting results.

Table 2. Details of NIST standard reference materials with certified Pb mass fractions (with citations for most recently issued certificates of analysis).

\begin{tabular}{ccc}
\hline SRM Number & Description & Certified Mass Fraction of Pb (mg/kg) \\
\hline $1649 b[17]$ & Urban dust & $12,864 \pm 62$ \\
\hline $2580[18]$ & $\begin{array}{c}\text { Powdered Paint (Nominal Mass } \\
\text { Fraction of 4\% Pb) }\end{array}$ & $43,400 \pm 100$ \\
\hline $2584[19]$ & $\begin{array}{c}\text { Trace elements in indoor dust } \\
\text { (nominal mass fraction of } 1 \% \mathrm{~Pb})\end{array}$ & $9761 \pm 67$ \\
\hline 3 & $\begin{array}{c}\text { Trace elements in soil containing } \\
\text { Pb from paint (nominal mass } \\
\text { fraction of 3000 mg/kg Pb) }\end{array}$ & $3242 \pm 57$ \\
\hline
\end{tabular}

Table 3. Summarised PARC results for NIST SRMs, showing Pb-rich phase abundance as silhouette area fraction (as \%) of total analysed grain surface per measurement. Relative $\sigma=\sigma /$ mean, reported as $\%$.

\begin{tabular}{|c|c|c|c|c|c|c|c|c|}
\hline $\begin{array}{c}\text { SRM } \\
\text { Number }\end{array}$ & 1 & 2 & 3 & Mean & $\sigma$ & $\begin{array}{l}\text { Relative } \\
\sigma(\%)\end{array}$ & \multicolumn{2}{|c|}{ Certified Pb Mass Fraction } \\
\hline \multicolumn{7}{|c|}{ Area \% } & $\mathrm{mg} / \mathrm{kg}$ & wt $\%$ \\
\hline 2580 & 7.04 & 7.06 & 7.20 & 7.10 & 0.09 & 1.29 & 43,400 & 4.34 \\
\hline $1649 b$ & 2.18 & 2.26 & 2.20 & 2.21 & 0.04 & 1.91 & 12,864 & 1.29 \\
\hline 2584 & 1.20 & 1.41 & 1.38 & 1.33 & 0.11 & 8.43 & 9761 & 0.98 \\
\hline 2587 & 0.35 & 0.16 & 0.15 & 0.22 & 0.12 & 52.61 & 3242 & 0.32 \\
\hline
\end{tabular}




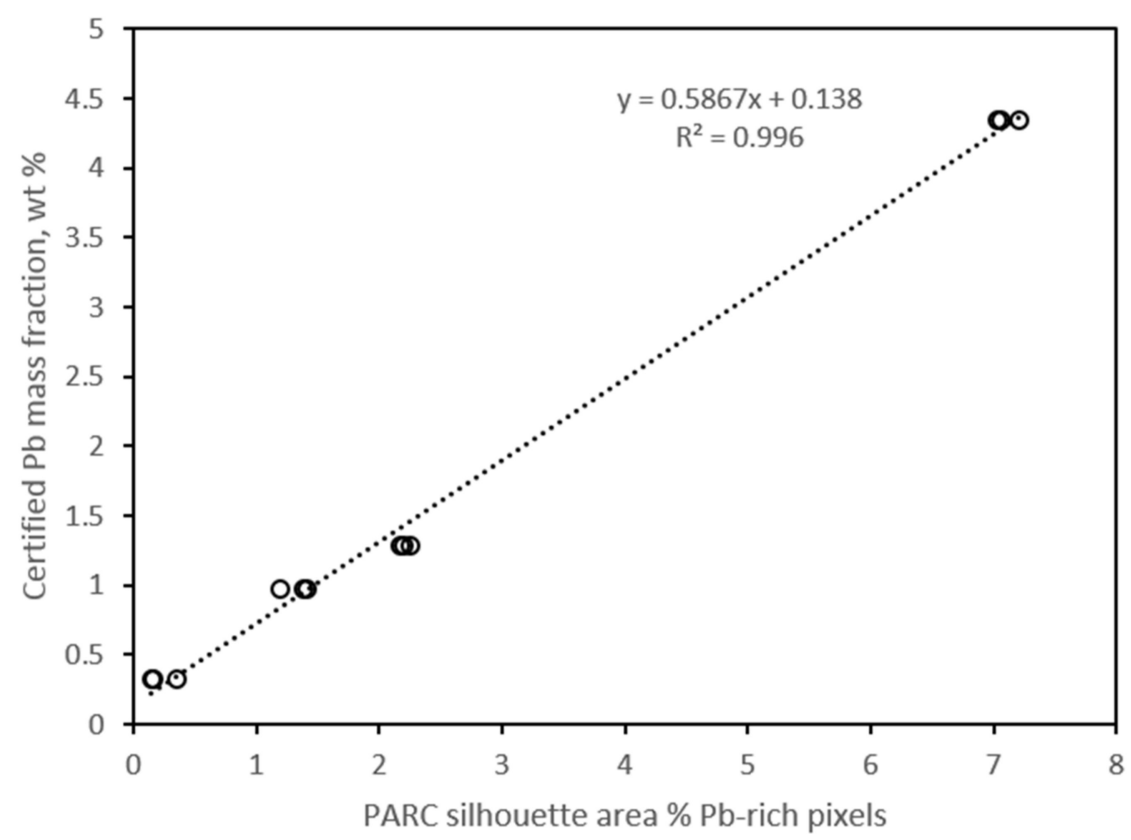

Figure 6. Certified $\mathrm{Pb}$ mass fraction (mass \%) against silhouette area \% of $\mathrm{Pb}$-rich pixels in PARC analyses. Showing all individual analyses per sample to show internal variability per triplicate set (linear regression is also based on complete data). Uncertainties in $\mathrm{Pb}$ mass fraction reported by NIST are negligible compared to the size of the symbols in the plot.

\section{Results and Discussion}

Section 3 presents the results of applying the dust characterisation methodology to the 31 dust deposit samples collected in the IJmond region, with emphasis on the distribution of detectable $\mathrm{Pb}$-rich phases in terms of host particles (grains). Section 3.1 reports the overall mineralogy of the samples, as analysed independently with both QXRD and the PARC approach. Section 3.2 discusses the quantitative makeup of the samples in terms of their constituent grain populations and the dust sources contributing them, with specific attention to those grain populations in which $\mathrm{Pb}$-rich phases were encountered. Section 3.3 discusses the occurrence of Pb-rich phases detected by PARC in the samples, where the results are presented first in more detail in Sections 3.3.1 and 3.3.2, then recapped and synthesised in an overall discussion in Section 3.3.3. Section 3.3.1 reports the total abundances of $\mathrm{Pb}$-rich phases per sample and how these are distributed with respect to numbers of host grains, irrespective of the grains' provenance. Section 3.3.2 reports the distribution of $\mathrm{Pb}$-rich phases over the different grain populations. Section 3.3.3 comprises an overall discussion of the main results regarding the distribution of Pb-rich phases in the samples, including discussion of the character and potential provenance of the $\mathrm{Pb}$-rich phase occurrences.

\subsection{General Mineralogy of Ijmond Dust Deposit Samples}

The overall mineralogy of the samples, as expressed in PARC group abundances, is summarised in Figure 7 and shown together with the results of the QXRD analyses for comparison. The full data for the respective QXRD and PARC results are given in Supplementary File S5-S8. The key observations from these results are discussed below.

\subsubsection{Crystalline Phase Proportions from QXRD}

The QXRD analyses of the dust deposit samples are summarised in Figure 7 as a stacked bar chart, showing all detected crystalline phases. The superimposed line brackets those phases whose occurrence is most strongly associated with steelworks related materials [13]. Except in samples 2-7 and 9-11, more than 50\% of the crystalline content of the samples comprises natural rock forming silicates quartz, kaolinite, muscovite, feldspar 
(represented by sodic anorthite), amphibole (hornblende), augite, together with halite. Samples 2-7 and 9-11, in contrast to the rest of the samples, have strikingly high contents of several phases associated with steelworks materials: the Fe-oxides hematite and magnetite; wustite; brownmillerite (C2(A,F)), silico ferrites of calcium and aluminium (SFCAs) and other Ca-ferrite types; calcic olivine (represented by kirschsteinite); the polymorphs of dicalcium silicate (C2S) larnite and $\alpha^{\prime}-\mathrm{C} 2 \mathrm{~S}$; Ca-aluminate phases (tricalcium aluminate (C3A) and mayenite (C12A7)); calcite, lime and portlandite; and finally, dolomite. Sample 1 has a moderately high content of hematite but is notably poorer in magnetite and lacking C2S polymorphs. Samples 15 and 30-36 have the lowest contents of the bracketed steelworks associated phases. Samples 8, 13, 14, 18-23 and 25-29 contain clearly detectable hematite \pm magnetite, together with small amounts of $\mathrm{C} 2 \mathrm{~S}$, kirschsteinite, calcite and in some cases also dolomite. The SFCAs and the Ca-ferrite phases $\mathrm{Ca}_{4} \mathrm{Fe}_{14} \mathrm{O}_{25}$ (CF2a), $\mathrm{Ca}_{2} \mathrm{Fe}_{16} \mathrm{O}_{25}$ (CF2b) and $\mathrm{Ca}_{2} \mathrm{Fe}_{22} \mathrm{O}_{33}(\mathrm{C} 2 \mathrm{~W} 4 \mathrm{~F} 9)$ are reported for all samples as quantified in the Rietveld refinement (coloured identically as a group in Figure 7). However, these characteristic iron-ore sinter phases are considered genuinely present only in cases where their combined abundance exceeds $8 \mathrm{vol} \%$, based on comparison with the PARC results and detailed inspection of the raw XRD patterns in samples lacking any (other) Ca-ferrites content. Lower abundances are considered a fitting artefact, and they are disregarded in the mineralogical interpretation of the results.

Regarding the carbon content of the samples as detectable in the QXRD analyses, graphite was specifically searched for in the raw patterns and included in the inventory of phases for which abundances have been quantified. However, the detection and quantification of graphite is adversely affected by several issues: (1) since graphite is composed of a light element, the overall reflection intensity is lower than almost all other, inorganic components; (2) the overall XRD pattern quality is sub-optimal due to the small amounts of material and variable crystallite sizes which strongly affect grain statistics and reflectionpeak shape; (3) due to its crystallographic structure, graphite develops a strong preferred orientation resulting in the strengthening of the strongest reflection showing a complete overlap with the main reflection of quartz a major constituent of the majority of dust samples. Therefore, it is reasonable to assume that anisotropic behaviour of the main quartz reflection (e.g., asymmetry) resulting from (1) and (2) will be compensated during fitting by modifying the graphite profile. Due to these issues, the uncertainty of graphite quantification is larger than for the other phases. Realistically, amounts of graphite $<10 \mathrm{wt}$ $\%$ cannot be positively identified or quantified by XRD with the measurement approach applied here. In the present set of samples, the quantified graphite abundance was invariably below this effective detection limit. All the QXRD results are discussed further in combination with the PARC results in following sections.

\subsubsection{PARC Group Abundances and Relationship with QXRD Analyses}

The samples contain between 13 and 53 area \% empty spectra pixels (Figure 7d), which overwhelmingly represent free carbon and organic material (as discussed in earlier Section Phase Model). These empty spectra therefore include all forms of carbon and organic material, which is suspected to be largely amorphous due to the lack of any detectable graphite in the samples with highest empty spectra content. For samples with a very high abundance of PARC empty spectra, the QXRD-analysed crystalline phase abundances are therefore expected to be out of proportion to the PARC group abundances. Further direct quantitative comparison of the PARC and QXRD results is necessarily restricted to the relative proportions of the non-carbon phases which can be cross identified between both analysis techniques. For this purpose, the PARC results shown in Figure $7 \mathrm{~b}$ are normalised to the total of all PARC groups excluding empty spectra, allowing an easier visual comparison of the PARC and QXRD analyses on a carbon-free basis. Figure 7c,d shows the PARC group abundances including empty spectra. To simplify the plots, chemically related PARC groups have been merged, and only those with abundance $>0.5$ area $\%$ are shown for each sample (based on the sum total of PARC groups including empty spectra). 
In Figure 7, a line annotation is drawn in both the QXRD and PARC results demarcating below it those phases and PARC groups interpreted as being strongly associated with steelworks materials, albeit not exclusively so. The phases and PARC groups above the line correspond with either natural silicates or phases of more ambiguous association, not excluding steelworks materials but also commonly other urban sources. The separately shown empty spectra are considered in this same ambiguous category. Samples 1-11 contain a structurally higher fraction of the likely steelworks-related PARC groups than the rest of the samples. The PARC group $\{\mathrm{Fe}\}$, confirmed by comparison with the QXRD to be chiefly a mixture of hematite and magnetite, is abundant in all these samples though most prominently in samples 1 and 7 . The PARC groups $\{\mathrm{Mg}, \pm \mathrm{Mn}, \mathrm{Fe}\},\{\mathrm{Ca}\},\{\mathrm{Mg}, \mathrm{Ca}\}$, $\{ \pm \mathrm{Al}, \mathrm{Ca}, \mathrm{Fe}\},\{\mathrm{Al}, \mathrm{Ca}\}$, and $\{\mathrm{Si}, \mathrm{Ca}\}$ are confirmed by the QXRD results to correspond with respectively magnesio-wustite; calcite/lime/portlandite; dolomite (or decarbonated residue thereof); brownmillerite, SFCA and other Ca-ferrite types; Ca-aluminates; and $\mathrm{C} 2 \mathrm{~S}$ polymorphs. These PARC groups clearly occur together and in higher abundance in samples 2-11 than elsewhere in the sample set. Sample 1 is notably lacking in $\{\mathrm{Mg}, \pm \mathrm{Mn}$, $\mathrm{Fe}\},\{ \pm \mathrm{Al}, \mathrm{Ca}, \mathrm{Fe}\}$ and $\{\mathrm{Al}, \mathrm{Ca}\}$ compared with samples 2-11, while the clear predominance of hematite over magnetite in the QXRD (noted above) is considered a related observation and discussed further in the following section. Samples 12-35 all contain significantly lower, but variable and non-trivial, total fraction of the demarcated steelworks-related PARC groups than samples 1-11, while sample 36 lacks them almost entirely. Samples 12-36 are dominated, in PARC terms, by a combination of empty spectra, $\{\mathrm{Si}\},\{\mathrm{Al}, \mathrm{Si}\}$, $\{ \pm \mathrm{Na}, \mathrm{Al}, \mathrm{Si}, \pm \mathrm{K}, \pm \mathrm{Ca}\},\{\mathrm{Mg}, \mathrm{Al}, \mathrm{Si}\},\{\mathrm{Na}, \mathrm{Cl}\}$, corresponding with carbon/organic material and the QXRD phases (respectively) quartz, kaolinite, feldspar (represented by sodic anorthite), mica (represented by muscovite) and $\mathrm{NaCl}$ (halite). Notably, sample 32 contains a significant abundance of the PARC groups $\{\mathrm{Ti}\},\{\mathrm{Si}, \mathrm{Ti}\}$ and $\{\mathrm{S}, \mathrm{Ba}(\mathrm{L} \alpha), \mathrm{Ba}(\mathrm{L} \beta)\}$. The former two are interpreted as Ti-rich oxides, while the latter group corresponds with a measurable abundance of $\mathrm{BaSO}_{4}$ (barite) in the same sample's QXRD analysis. Though not displayed in Figure 7, due to its overall abundance below the cut-off threshold of 0.5 area $\%$, sample 7 and other samples also contain clearly detectable abundances of $\{S$, $\mathrm{Ba}(\mathrm{L} \alpha), \mathrm{Ba}(\mathrm{L} \beta)\}$ group pixels, interpreted similarly as being $\mathrm{BaSO}_{4}$. A final important observation concerns the almost ubiquitous presence of $\{\mathrm{S}, \mathrm{Ca}\}$ and $\{ \pm, \mathrm{S}, \pm\}$ group pixels in the analysed samples, interpreted to correspond with the XRD detected phases gypsum and anhydrite as well as potentially other sulphate (and sulphite) phases. Samples 3, 5, 9 and 10, belonging to the above-described subset of samples (1-11) with structurally high abundance of likely steelworks-related phases, have particularly high abundance of these PARC groups, ranging from ca. 6-15 area \%. Notably, samples 13, 17, 23, 24, 27, and 32 contain between $3-5$ area $\%$ of these groups as well. 


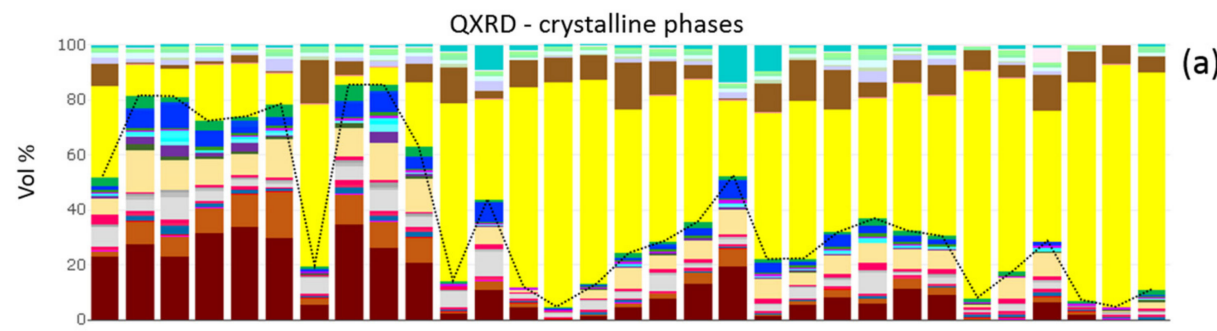

PARC - normalised excl. empty spectra

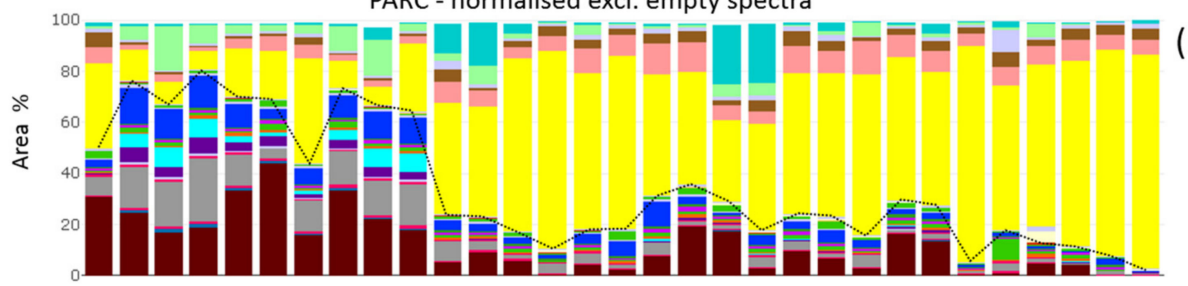

(b)

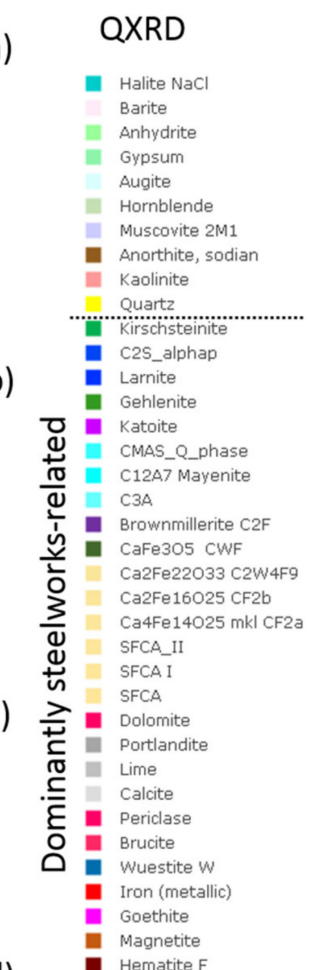

PARC

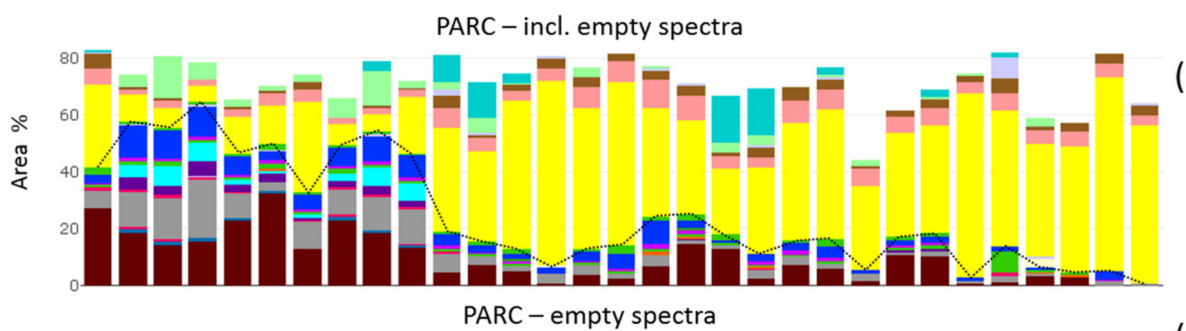

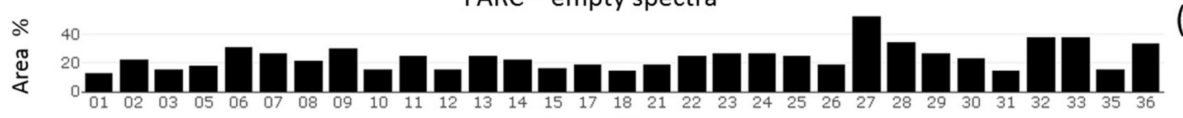

(d)

Hematite F

Sample ID

Figure 7. Overall sample mineralogy as analysed independently by QXRD (a) and PARC (b-d). QXRD crystalline phase proportions are reported as volume \% and normalised to 100. PARC group abundances are reported as silhouette area \% (of total analysed grains area), are filtered to show only those PARC groups exceeding a minimum threshold of 0.5 area $\%$ (per sample, including empty spectra). (b) shows the PARC group abundances normalised to total phases excluding empty spectra for comparison with QXRD results (see text for explanation). (c) shows group abundances including empty spectra, which are plotted separately in (d). The difference from 100 in (c) is dominantly made up of empty spectra, the rest comprising other groups with abundance $<0.5$ area $\%$ (the latter also accounts for the difference from 100 in (b)). The line trace annotations bracket those XRD phases and PARC groups strongly associated with steelworks materials. PARC results are aggregates of triplicate areas analysed per sample.

\subsection{Grain Population Abundances per Sample}

Figure 8 summarises, per sample, the relative abundances of the grain populations defined in Section 2.4.1, Table 1. Abundances are reported as area \% of the total analysed grains area per sample and represent the combination of triplicate sets of analysed areas per sample (summed population areas normalised to grand total grain area of the triplicate set). The full tabulated population abundances and PARC group abundances per population, per sample, are provided in Supplementary Files S9 and S10. As with the general mineralogy described in the previous section, the relative abundances of grain populations shown in Figure 8 vary widely between the samples, reflecting varying contributions from different steelworks-related, urban, natural and ambiguous sources. The main variations are discussed below, making explicit reference to the source categories shown in the legend of Figure 8 and listed in Table 1, as well as specific grain populations falling under these categories (described in more detail where applicable). 

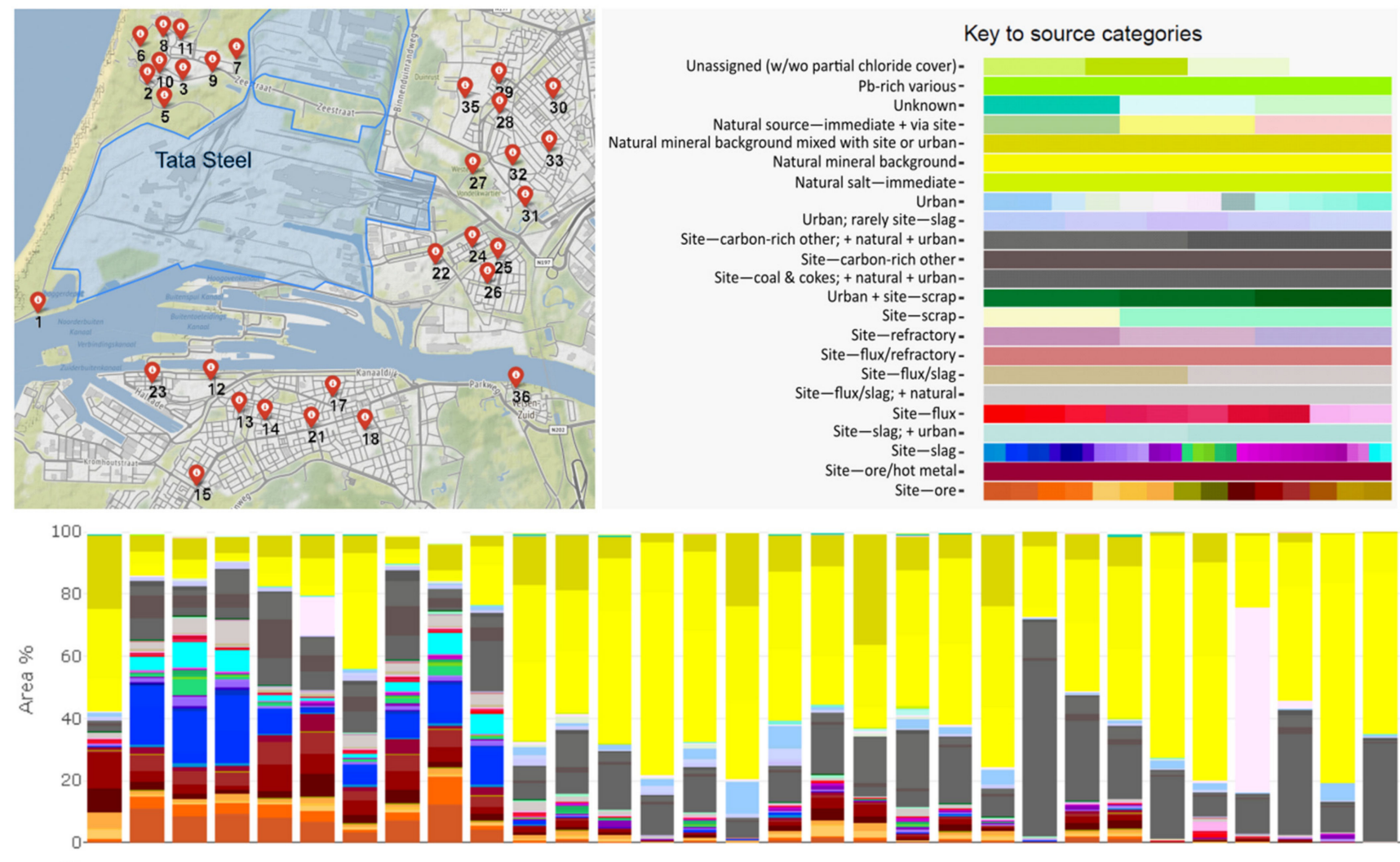

(a)

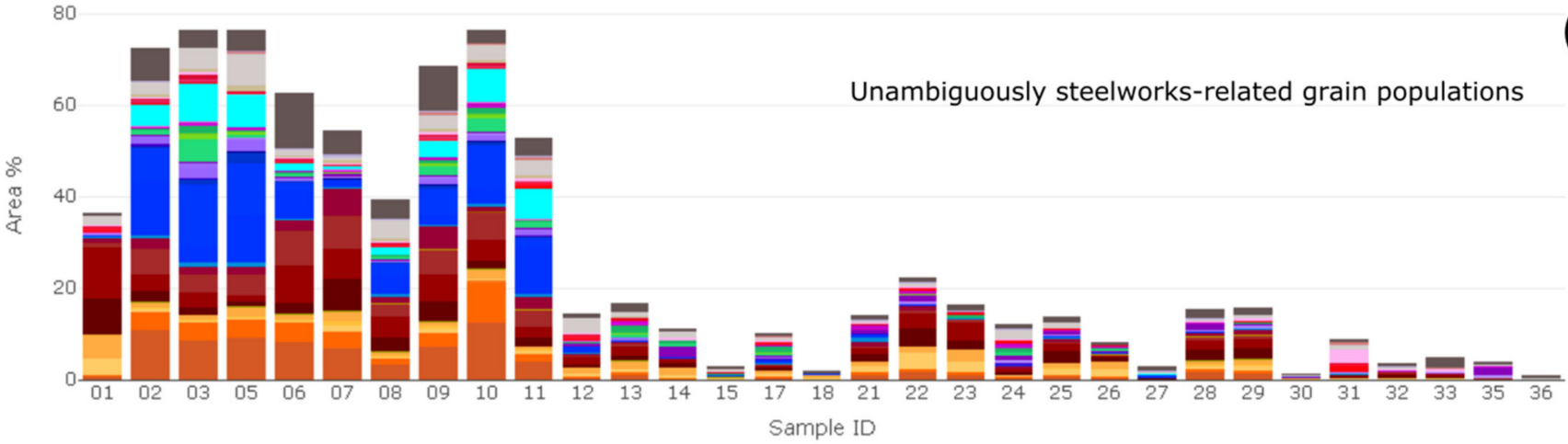

(b)

Figure 8. Overview stacked bar chart summarising abundances (silhouette area \%) of all grain populations for all samples. Colour-scheme used for grain populations is shown in full in Supplementary File S3B. Population groupings into interpretive categories are shown in the key in the figure (explanations provided in Table 1). (a) shows all grain populations; (b) shows only unambiguously steelworks-related grain populations.

\subsubsection{Unambiguous Steelworks-Related Populations}

In line with their overall mineralogy, samples 1-11 contain a structurally higher contribution of unambiguously identifiable steelworks-related sources, with 36-77 area \%, than samples 12-26, with 0.7-22 area \%. The most widespread of these grain populations (populations 1-16, "site-ore" in Figure 8) are those associated with iron ore and ore-agglomeration processes (sintering and pelletising), with $18-42$ area \% abundance in samples $1-11$, a range of 3-16 area \% in samples 12-14, 17, 21-26, 28 and 29, and much lower/insignificant abundance in the remaining samples. Sample 1 stands out from the others in having a large total amount of ore-related grains but notably lacking sintered ore material (populations 1-4). For this sample, the profile of the ore-related grain populations is consistent with a dominant contribution from raw ore material and possibly pelletised material. Grain populations associated with steelmaking slags and fluxes (source categories "site—slag", "site—flux", "site—flux/slag" in Figure 8), and most specifically those 
unequivocally related with the BOF-converter- and steel-ladle/casting floor processes, are most prominent in samples 2-6 and 8-11. Taken as a whole, these slag- and flux-related populations comprise 34-47 area \% of samples 2-6, and 25-30 area \% of samples 9-11. The nominally slag- and flux-related populations detected in samples 12-35 are present in much lower total abundance and with a different detailed breakdown of populations within this broader category. Specifically, the share of clearly identifiable converter slag material (populations 17-26) is much lower compared to (1) grains interpreted as generic steelmaking slag material, with $>50 \%$ surface coverage of sulphate phases (populations 35-39) and (2) a population (32) with a higher rate of confusion (misclassification) with granulated blast furnace slag and building materials of broadly similar mineralogy. Hence, the high abundance occurrence of steelmaking slag material is restricted to samples 2-6 and 8-11, while aside from these samples, the other notionally slag- and flux-related materials are markedly different in profile, have a higher internal share of sulphate-encrusted particles and are less easily distinguished from building materials (see below) detected in relatively high abundance in the same samples.

\subsubsection{Carbon-Rich Populations}

Carbon-rich particles (defined by containing $>40$ area \% empty spectra) have widely varying abundances in the samples from ca. 4 area \%, in sample 1, to 70 area \%, in sample 27, with notably high abundance in samples 28, 33 and 36 (34-40 area \%). Sample 32 also contains a similarly high total fraction of empty spectra (Figure 7d), with an abundance of obviously carbon-rich grains, but these grains are classified under a separate population defined by the presence of Ba-sulphate (population 94), and this is discussed later in this section. Currently, carbon-rich particles are the most problematic to adequately segment from the background (stub) in imagery as being coherent grains, in the first instance, and then to subdivide effectively into populations with unambiguous provenance. Such particles may become split into multiple (PARC-)grains in the grain segmentation mask, and the fluctuating localised mineralogy of the different parts of the same particle leads to these being classified under divergent populations. Moreover, steelworks-related coal and coke particles have an overlapping range of mineral phase proportions as charcoal of urban origin and natural, organic-rich soil. Nevertheless, these grain populations, and the various carbon-rich source materials they capture, require more detailed explanation due to their general abundance in the samples and the fact that some of these grains host $\mathrm{Pb}$-rich phases. Where necessary and sufficient, extra observations from the primary SEM imagery are used to resolve ambiguities in material type and provenance in the following discussion.

Site-coal and cokes; + natural + urban: Population 79 comprises grains rich in carbon where their non-carbon portion is dominated by quartz, clay, feldspar and mica. This is a highly ambiguous population that captures both coal and coke particles from the steelworks, on the one hand, and organic-rich soil on the other, due to the overlapping noncarbon mineralogy of coal and cokes and regular soil. Manual inspection of the particles' microstructure in the primary imagery is required, on a sample for sample basis, to make an informed judgement on the dominant material type captured by this population. In the case of the samples containing strikingly high fraction of population 79 in the present sample set-samples 27, 33, and 36-the particles are more consistent with being organic-rich soil than coal or coke material, based on comparison of the imagery with that of reference coal and coke material from the steelworks site: the empty spectra pixel content (carbon) is generally lower than seen in typical coal and cokes particles, while the microstructure of the surface is also lacking sedimentary layering (as in coal), or vesicularity (as in cokes, from degassing), and is instead unstructured and granular.

Site-carbon-rich other: Population 80 is defined by the presence of steelworksrelated PARC groups and is structurally more abundant in samples $2-11$ than in the rest of the samples, corresponding also with the higher general abundance of clearly identifiable steelworks-related grain populations (ore, slag and flux). This population captures diverse grains including: (1) graphite flakes with a fine dusting of steelworks phases (observed 
in directly sampled steel de-sulphurisation process material but not encountered in the present sample set after manual checking of imagery); (2) irregularly shaped composite particles comprising a mixture of smaller sub-particles (generally $<10 \mu \mathrm{m}$ ) with diverse mineralogy, including natural rock forming minerals (quartz, clay, feldspar and mica), Fe-oxides, calcite/portlandite and C2S, tentatively interpreted as reworked finer dust agglomerated into larger particles (as in population 104, described below, but at the higher end of a sliding scale of organic content); and 3) spuriously defined grain outlines, resulting in the juxtaposition of steelworks-related particles with adjacent background (sample stub) or carbon-rich particles and hence a high empty spectra pixel fraction. These grains thus represent, in all cases described, a mixing of different sub-particles, whether by genuine physical agglomeration or by an artefact of spurious grain segmentation.

Site-carbon-rich other; + natural + urban: Population 82 comprises grains with > $90 \%$ empty spectra, which are hence overwhelmingly dominated by carbon. Such grains are of ambiguous origin and may capture carbon-dominated particles from the steelworks site (including, but not restricted to, graphite) as well as diverse carbon-dominated particles of urban or natural origin. The abundances of this population are low in the current sample set, ranging from barely detected to 3.5 area \%. Population 81 comprises the remainder of grains with $>40 \%$ empty spectra not falling under any of the carbon-rich populations and is hence a broad category. This, as population 82, represents an ambiguous population capturing diverse grains. Generally, carbon-rich particles originating from the steelworks would be expected to be captured by the previous categories, and the majority of the grains in this population are, where manually inspected, considered to be of urban and natural origin. The abundances of this population range widely, from barely detected to 17 area \% in the samples, with no clear pattern of distribution except notably high abundances in samples 22 and 23.

\subsubsection{Urban Dust Sources}

Several grain populations interpreted as being derived from diverse urban sources occur with substantial abundance in some of the samples. The most consistently prominent of these in the present sample set are populations 83-91, which are interpreted as building materials, including cement and concrete. Samples 18 and 21 both contain a relatively high fraction (12-13 area \%) of populations belonging to this wider category, though the specific predominant populations differ in each case.

Grain population 94, defined as grains containing $>1$ area \% Ba-sulphate (PARC group $\{\mathrm{S}, \mathrm{Ba}(\mathrm{L} \alpha), \mathrm{Ba}(\mathrm{L} \beta)\})$, is the dominant population in sample 32, where it comprises almost 60 area $\%$ of the sample. In this sample, and in a handful of other samples $(1,22,27,31$, and 33) where this grain population is encountered in smaller quantities, the Ba-sulphate pixels are accompanied by Ti-oxide ( $\{\mathrm{Ti}\})$ and other Ti-rich PARC groups ( $\{\mathrm{Si}, \mathrm{Ti}\})$ and occur in grains variably rich in empty spectra (i.e., carbon / organic material). In these cases, the grain population has similar visual appearance and is tentatively interpreted as derived from paint or pigment. Sample 7 contains a high fraction of the same nominal grain population, but in this sample, the population clearly lacks Ti-oxide or other Ti-rich PARC groups, and the visual appearance of the grains is much more variable. In fact, the grains classified under this population in sample 7 do not appear to be a separate and coherent grain population compared to the other grains present in the sample. Rather, for this sample, our interpretation is that Ba-sulphate pixels are present in some limited quantity on the surfaces of many more particles in the image, which are of diverse origin, and that population 94 merely captures disparate grains passing the minimum threshold of $1 \%$ Ba-sulphate abundance. This is confirmed by inspecting the Ba-sulphate pixel content of the other detected grain populations present in the image. The natural silicate grain population 101 , which is ubiquitously present at some level in all samples, shows a clearly elevated fraction of Ba-sulphate pixels in samples 7 and 32 (Figure 9), suggesting strongly that the Ba-sulphate pixels themselves represent and independent source of fine material adhering to the surface of coarser particles of disparate origin. As discussed in later sections, in 
sample 7, the elevated Ba-sulphate pixel abundances are accompanied by clearly elevated $\mathrm{Pb}$-rich pixel abundances (as exemplified by population 101 in Figure 9), while this is not the case in all samples where Ba-sulphate pixels are abundant, most strikingly sample 32.

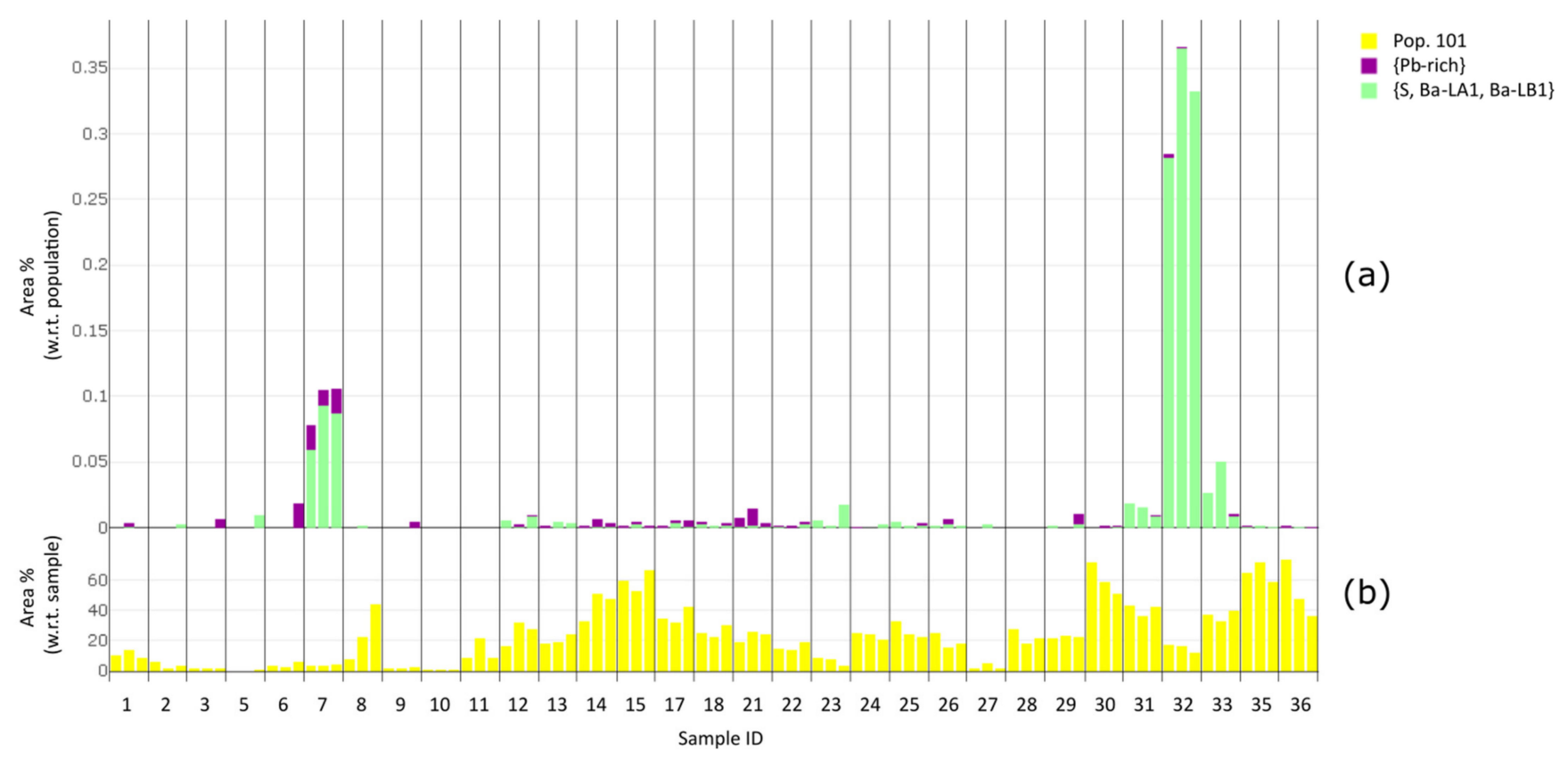

Figure 9. (a) Ba-sulphate (green) and Pb-rich (purple) abundances for the ubiquitous "quartz-rich" grain population 101 (Pop.101), reported as area \% with respect to the population. (b) Abundance of the grain population per sample. All individual triplicate analyses are shown.

\subsubsection{Natural and Mixed Material}

The remainder of the material in the samples is dominantly composed of grains rich in quartz, feldspar, clay and mica. These are subdivided into populations (101-103, natural mineral background, Figure 8) with grains containing $>60$ area \% of the PARC groups corresponding with these phases, which are interpreted as natural sand and mineral-rich soil and make up between 2 and 80 area \% of the samples, and a separate population (104, source category "natural mineral background mixed with site or urban" in Figure 8) with > 30 area $\%$ of these phases and higher content of other phases. The latter population is dominated by grains containing both natural silicates and phases associated with the steelworks, chiefly Fe-oxides, Ca-silicates (suspected C2S), Ca-Mg-silicates, calcite/portlandite and in some cases alumina. Population 104 is nearly ubiquitous in the samples, with only samples 35 and 36 containing negligible abundance. In most samples, a large part of the population represents an artefact of spurious grain segmentation whereby discrete steelworks-derived and natural silicate grains are defined as a single grain. In some samples, most strikingly sample 23, the abundance of genuinely mixed, composite particles is unmistakable, and volumetrically significant. These are interpreted as a physical agglomeration of smaller $(<10 \mu \mathrm{m})$ particles into composite particles in the $>100 \mu \mathrm{m}$ size-range. The precise mechanism by which this occurs, and over which timescale, is not clear. Road dust is known to contain similar composite particles formed by abrasion and aggregation [21]. In any case, such particles clearly represent a mixing of relatively fine $(<10 \mu \mathrm{m})$ material of natural, industrial (steelworks) and urban origin.

\subsection{Occurrence of Pb-Rich Phases in Samples}

\subsubsection{Total Pb-Rich Phase Abundances per Sample}

Figure 10a,b shows the distribution of $\mathrm{Pb}$-rich pixels over the host grains containing them for the IJmond dust deposit samples (tabulated data are provided in Supplementary 
File S11). Figure 10c shows the total Pb-rich pixel abundances on a logarithmic scale. The results are shown separately for each of the triplicate analyses per sample to provide a direct indication of the variation in results per triplicate set. $\mathrm{Pb}$-rich pixel abundances in this section are normalised to the total analysed area of grains per triplicate (or per sample). Separately from their grain population assignment, grains containing $\mathrm{Pb}$-rich pixels are categorised as follows:

- $\quad$ Pb-rich dominated: grains containing $>50$ area $\% \mathrm{~Pb}$-rich pixels and $>70$ area $\%$ when excluding empty spectra pixels. This is a subset of the grain population 111 (Table 1), which captures extremely scarce, discrete grains which in the PARC imagery of the current dataset (specifically) are dominated by Pb-rich pixels with little or no other PARC group present, except for superficial sub-particles or artefacts of grain segmentation.

- The remaining grains (in all populations) containing $\mathrm{Pb}$-rich pixels are subdivided according to the number of $\mathrm{Pb}$-rich pixels they contain, using a geometric binning sequence: $1-4,5-9,10-19,20-39,40-79,80-160$ and $\geq 160 \mathrm{~Pb}$-rich pixels.

Figure 11 shows the same data as Figure 10 but split into specific subsets of the above $\mathrm{Pb}$-occurrence categories to more clearly show their contributions. Figure 12 shows the aggregated triplicate results per sample. The overall distribution of $\mathrm{Pb}$-rich pixels over the above categories, across all samples combined, is summarised in Table 4.

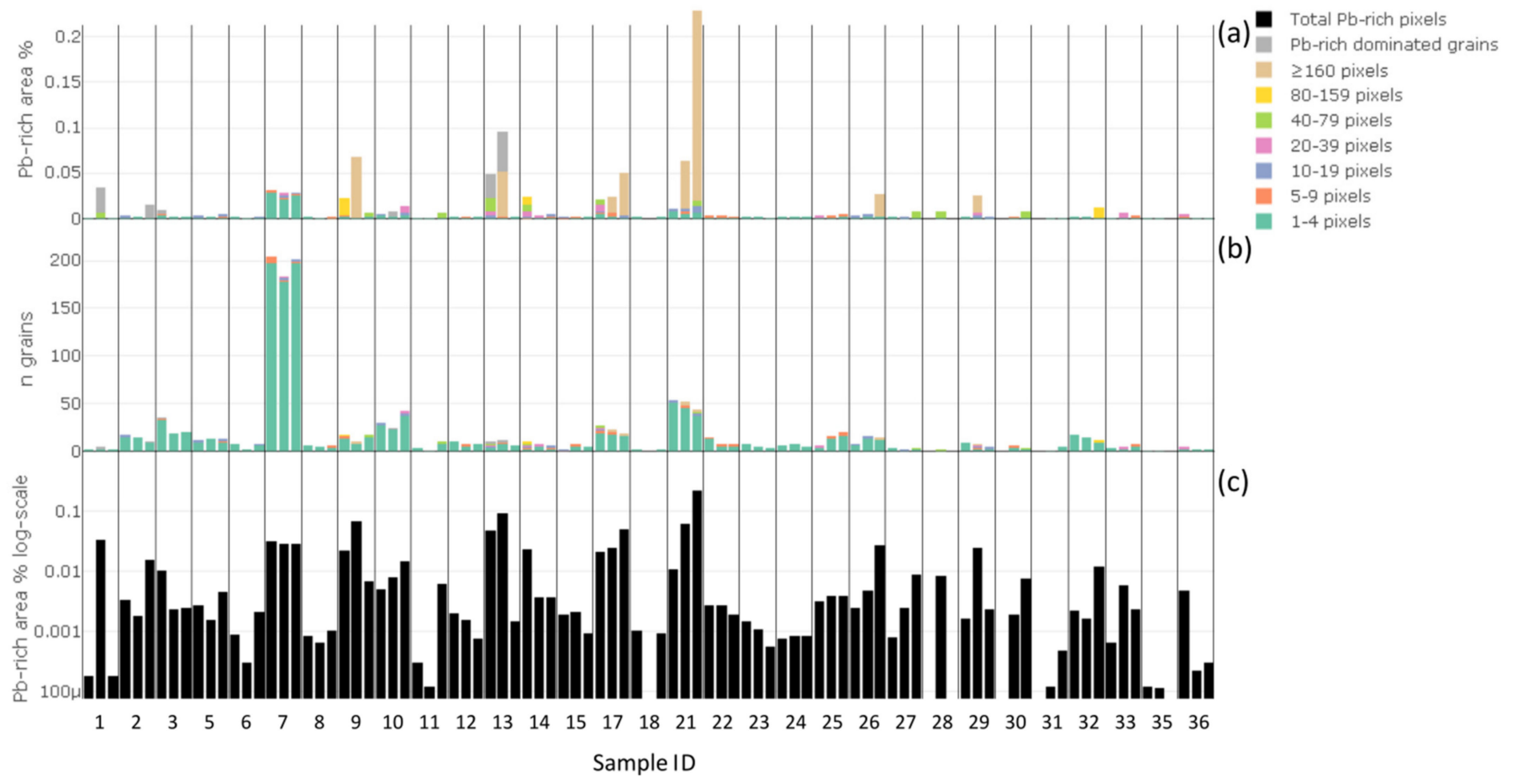

Figure 10. Abundance of $\mathrm{Pb}$-rich PARC group and number of host grains for all analysed regions (three regions per sample). (a) Detected Pb-rich abundance, reported as (silhouette) area \%, split by category for number of Pb-rich pixels per host grain; (b) number of host grains split by category as in (a); (c) total Pb-rich abundance with logarithmic y-axis scale (blank columns represent no detected $\mathrm{Pb}$-rich pixels).

The $\mathrm{Pb}$-rich pixel abundances in the samples generally fall well below the range detected in the NIST SRMs (Table 3). There, the minimum detected Pb-rich abundances (per individual triplicate analysis) were for NIST SRM 2587 (nominal 3000 ppm Pb by mass) and were in the range 1.4-7.0 $\times 10^{-1}$ area $\%$. Only the highest as-detected area percentage of $\mathrm{Pb}$-rich pixels, ca. $2.3 \times 10^{-1}$ area \% for a single analysis in sample 21 (Figure 10), overlaps the range detected in SRM 2587. The rest of the individual measurements show a range from no detected $\mathrm{Pb}$-rich pixels to $9.6 \times 10^{-2}$ area $\%$. The spread in triplicate analyses within samples is in some cases very large, most strikingly for sample 21 (when viewed 
with a linear scale) and for sample 1 (when viewed with a logarithmic scale). Aggregating the triplicate analyses per sample narrows the overall range of Pb-rich abundance across samples to $7.6 \times 10^{-5}$ (one pixel)-9.4 $\times 10^{-2}$ area \% (Figure 12). Samples 7, 9, 13, 17 and 21 stand out as having relatively high abundance of $\mathrm{Pb}$-rich pixels and contain 2.9-9.4 $\times$ $10^{-2}$ area $\%$. Moreover, in each of these samples, two of the three triplicate analyses yield an abundance of $>2.0 \times 10^{-2}$ area \%, though the spread within each triplicate set remains very high. The rest of the samples contain $\leq 1.2 \times 10^{-2}$ area $\%$ Pb-rich pixels, with at most one of their triplicate analyses showing a relatively elevated $\mathrm{Pb}$-rich pixel abundance.

Table 4. Pb-occurrence categories and contributions to total $\mathrm{Pb}$-rich pixels detected across all samples. See text in Section 3.3.1 for explanation of categories.

\begin{tabular}{ccccc}
\hline $\begin{array}{c}\text { Pb-Rich Occurrence } \\
\text { Category }\end{array}$ & $\begin{array}{c}\text { Number } \\
\text { of Grains }\end{array}$ & $\begin{array}{c}\text { \% of All } \\
\text { Pb-Hosting } \\
\text { Grains }\end{array}$ & $\begin{array}{c}\text { \% of All } \\
\text { Pb-Hosting } \\
\text { Grains by Area }\end{array}$ & $\begin{array}{c}\text { \% of Total } \\
\text { Pb-Rich Pixels }\end{array}$ \\
\hline $\begin{array}{c}\text { Pb-rich dominated } \\
\text { grains }\end{array}$ & 6 & 0.40 & 0.07 & 12.32 \\
\hline$\geq 160$ pixels & 10 & 0.66 & 1.34 & 45.05 \\
\hline $80-159$ pixels & 3 & 0.20 & 0.17 & 3.71 \\
\hline $40-79$ pixels & 11 & 0.72 & 0.78 & 6.68 \\
\hline $20-39$ pixels & 14 & 0.92 & 0.94 & 4.35 \\
\hline $10-19$ pixels & 27 & 1.78 & 4.40 & 3.81 \\
\hline $5-9$ pixels & 51 & 3.36 & 4.37 & 3.57 \\
\hline $1-4$ pixels & 1398 & 91.91 & 87.93 & 20.51 \\
\hline
\end{tabular}

Figure 10a reveals that most of the visible 'peaks', with elevated abundance of $\mathrm{Pb}$ rich pixels, correspond with contributions from either $\mathrm{Pb}$-rich dominated grains or grains containing $\geq 160 \mathrm{~Pb}$-rich pixels. For four of the top five samples by $\mathrm{Pb}$-rich phase abundance (samples 9, 13,17, and 20), the majority of the total $\mathrm{Pb}$-rich pixels are contributed by only 1-4 such grains per sample (Figure 12a,c). These large individual occurrences (Figure 11b) heavily influence the results of the individual triplicate analyses, producing the large internal spread per triplicate set observed for these samples. Nevertheless, including smaller individual contributions, these samples still show a higher overall $\mathrm{Pb}$-rich pixel abundance $\left(>2.0 \times 10^{-2}\right.$ area $\left.\%\right)$ in at least two of their three triplicate analyses. In more detail, when focusing on the contributions of grains containing $<160 \mathrm{~Pb}$-rich pixels (Figure 11c), sample 21 clearly contains an elevated total contribution from these in all three triplicates. Samples 9, 13, and 17 all show one triplicate analysis with a highly elevated contribution from such grains, but the internal spread per triplicate set clearly remains high and is caused by the uneven distribution and proportionally large contribution (with respect to the total $\mathrm{Pb}$-rich pixels) from few grains containing $\geq 30 \mathrm{~Pb}$-rich pixels.

The above described scarce individual grains bearing a larger number of $\mathrm{Pb}$-rich pixels contribute to large spread in the results of triplicate analyses in some samples and demonstrate the difficulty of accounting for the contribution of very scarce grains with an encountered occurrence of only ca. 1-4 in ca. 1000-6000 grains analysed per sample (when combining triplicates, with number of grains depending on particle size distribution of the material). However, such grains are unequivocally detected where present within an analysed area and flagged for further detailed examination of such occurrences. Moreover, the combination of $\mathrm{Pb}$-rich dominated grains with grains bearing $\geq 160 \mathrm{~Pb}$-rich pixels contribute $57 \%$ of the total Pb-rich pixels detected in all samples combined, though they represent only $1.1 \%$ of the host grains and only $0.018 \%$ of the total analysed grains. At the spatial scale of the analyses in this study, the detection in two or more of the triplicate analyses of even a small number of grains $(<10)$ with substantial $(\geq 40$ pixels $)$ amount of $\mathrm{Pb}$ rich pixels is considered a meaningful observation, albeit not a very precise quantification 
of abundance. For the purposes of discussing the results here, the detection of one or two such grains, isolated to one of the triplicates of analysed areas, is considered a clear positive identification-enabling qualitative description of such occurrences-but not a statistically meaningful difference in abundance with a sample in which no such grains are detected.
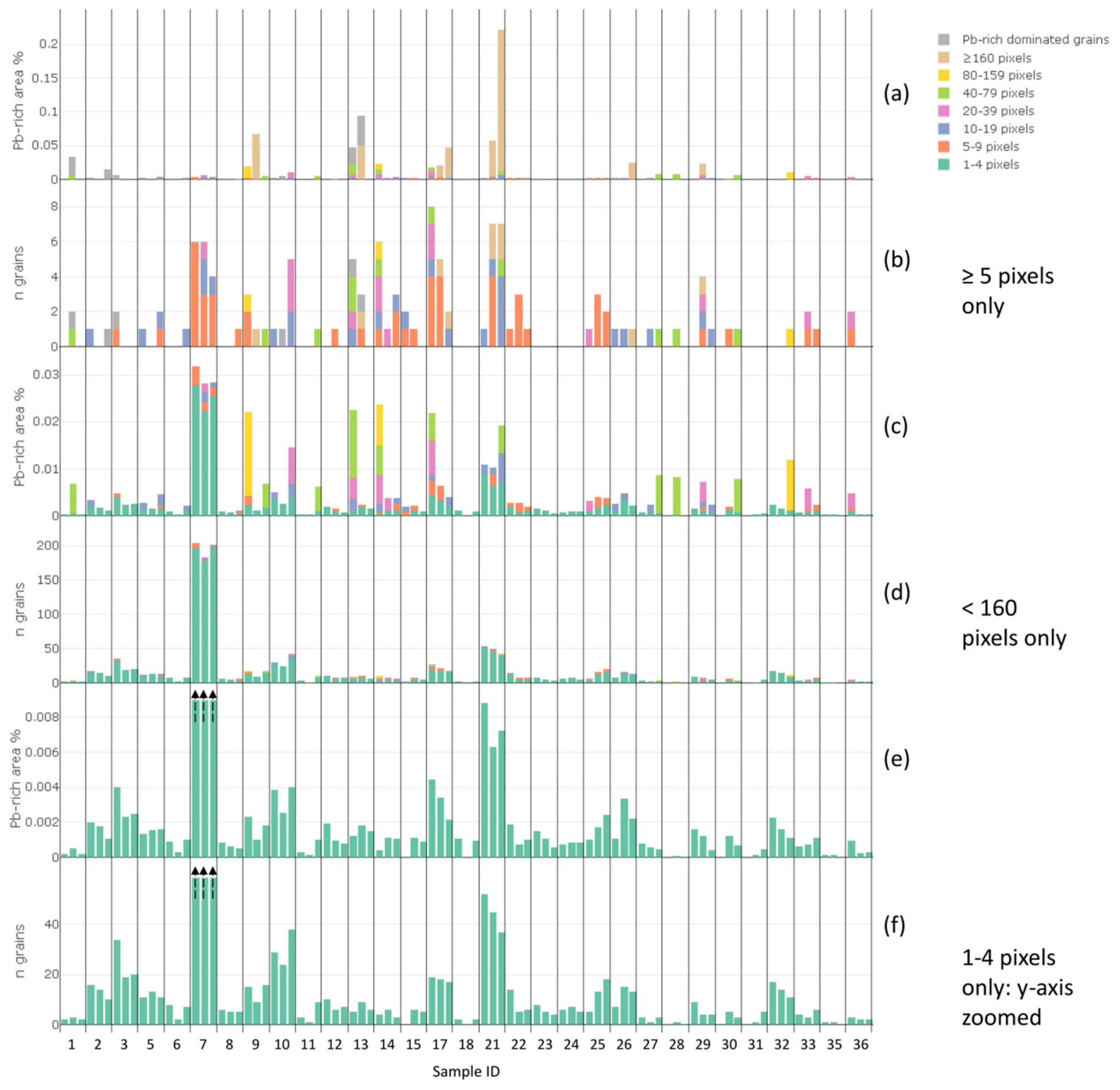

Figure 11. Filtered versions of results shown in Figure 10, showing here Pb-rich contributions from: $(\mathbf{a}, \mathbf{b})$, grains bearing $\geq 5$ Pb-rich pixels; $(\mathbf{c}, \mathbf{d})$, grains bearing < 160 pixels; $(\mathbf{e}, \mathbf{f})$, grains bearing 1-4 pixels $\mathrm{Pb}$-rich, with y-axis zoomed to the range of the dataset excluding sample 7 (where the relevant values can be read directly from (c,d)). Black dashed arrows in (e,f) indicate the bars that are truncated due to the zoomed $y$-axis range.

Grains containing 1-4 Pb-rich pixels represent ca. $92 \%$ of the host grains for $\mathrm{Pb}$-rich pixels across all samples in this study, and their numerical dominance over larger individual occurrences is clearly visible in Figure 10b. However, in general they contribute only a small total abundance of $\mathrm{Pb}$-rich pixels per sample and combining all samples only $21 \%$ of the total $\mathrm{Pb}$-rich pixels. When considering the contributions of only those grains bearing $1-4 \mathrm{~Pb}$ - 
rich pixels the spread in results per triplicate set decreases substantially for most samples along with total abundance of Pb-rich pixels (Figure 11f). Sample 7 differs markedly from the other four samples with highest $\mathrm{Pb}$-rich pixel content in showing a highly disperse distribution of Pb-rich pixels over almost 600 grains (Figure 12), representing ca. 15\% of the total grains in the sample, with a remarkably low spread in its triplicate analyses (Figures 10a and 11c). The overwhelming majority of the total Pb-rich pixels in this sample are contributed by small individual occurrences of only 1-4 pixels per grain, while no grains were found containing $\geq 40 \mathrm{~Pb}$-rich pixels. Hence, sample 7 is clearly unique among the samples due to its relatively high total abundance of $\mathrm{Pb}$-rich pixels and the distribution of these over a much larger fraction of its constituent grains.

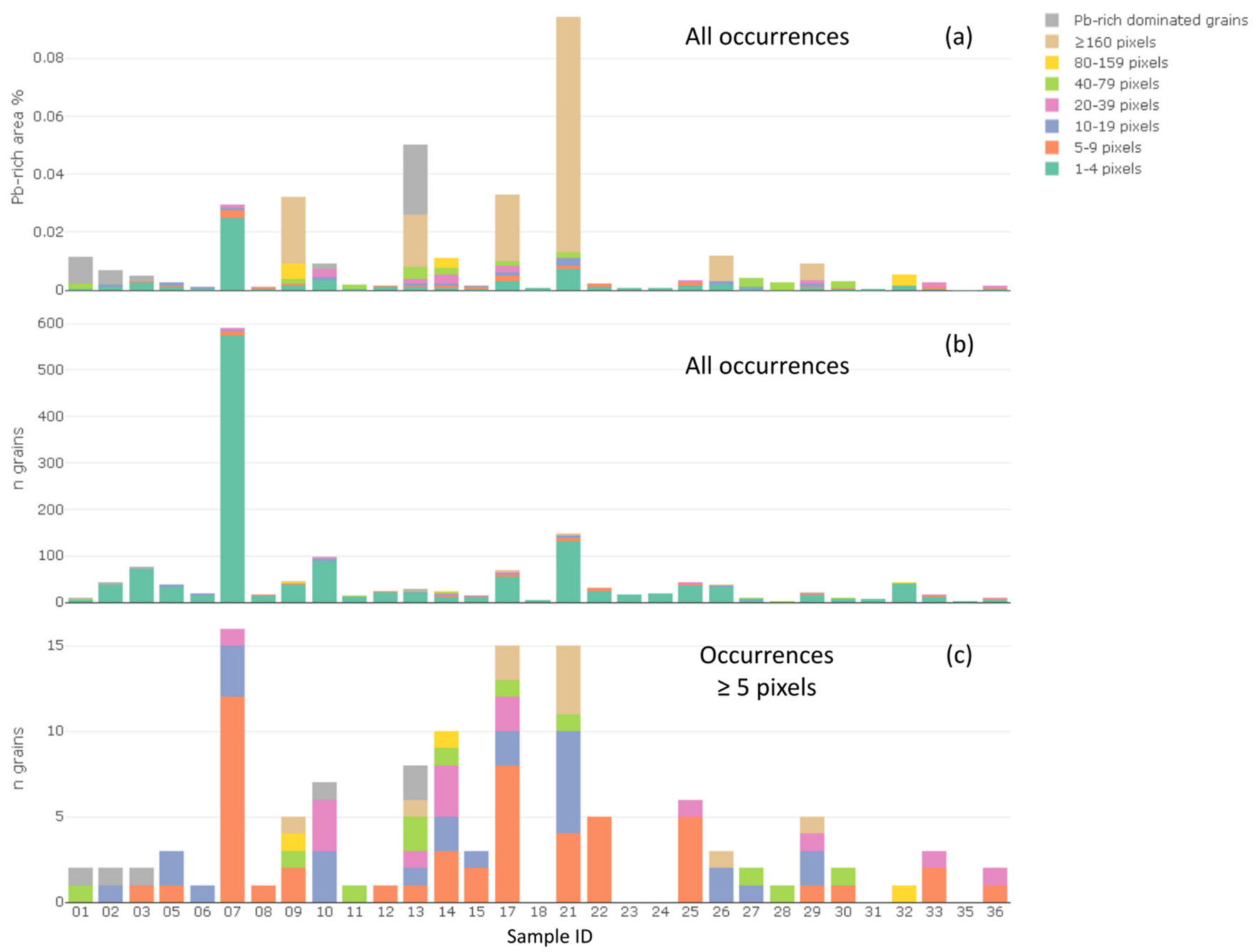

Figure 12. (a,b) as Figure 10 except showing aggregated results of triplicate analyses per sample. (c) showing number of host grains bearing $\geq 5 \mathrm{~Pb}$-rich pixels.

\subsubsection{Distribution of Pb-Rich Pixels over Grain Populations}

A central feature of the presented methodology is the quantitative characterisation of dust particle mineralogy and the classification of particles under populations to support inferences regarding their provenance. The detection of $\mathrm{Pb}$-rich phases is therefore always accompanied by this information regarding the host particles (grains). Figure 13 shows, for all the samples, the individual grains hosting $\mathrm{Pb}$-rich pixels and their grain population assignment, plotted as markers whose size represents the number of $\mathrm{Pb}$-rich pixels in each grain (see Supplementary File S12 for tabulated data). Grains containing $\geq 5$ pixels are shown separately, since (1) these grains are far less numerous per sample than those 
containing 1-4 pixels and (2) the relatively low number of occurrences warrants some specific discussion of where they occur, i.e., in which samples and grain populations. Figure 14 shows, per sample: a recap of the grain population abundances ( $a$ and $b$ ); the grain populations' contributions of Pb-rich pixels to the sample ((c) and (d), as area \%); and the percentage abundance of the host grains (relative to total analysed grains), by area (e) and by grain count (f).

The discussion of the primary results in these figures starts with an overview of the dominant contributing grain populations to the $\mathrm{Pb}$-rich pixel budget per sample, and then focusses on the nature of, and overall patterns observed in, the Pb-rich occurrences: first, the extremely scarce grains dominated by $\mathrm{Pb}$-phases, followed by other more substantial superficial occurrences of $\mathrm{Pb}$-rich pixels on grains ( $\geq 5$ pixels per grain) and then the far more numerous grains bearing only $1-4 \mathrm{~Pb}$-rich pixels.

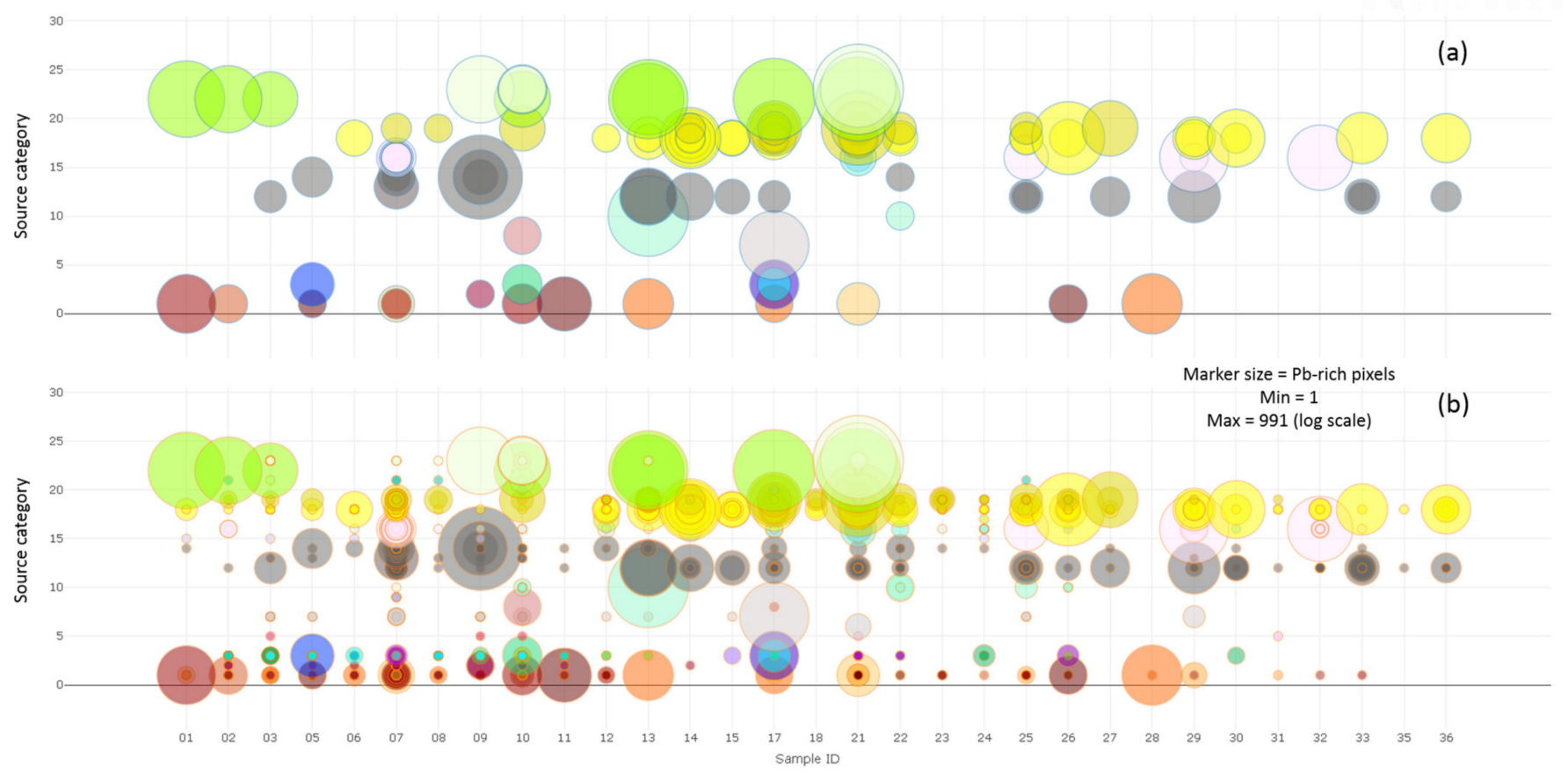

Figure 13. All individual occurrences of Pb-rich phase per grain, represented by markers plotted by sample and interpretive source category, with marker size representing absolute area of Pb-rich phase (pixels) per grain (logarithmic scale). Colourscheme as Figure 8, indicating grain population. (a) shows all occurrences of $\geq 5$ pixels, (b) shows all occurrences. Tabulated data provided in Supplementary File S12.

\section{Overview of Grain Populations' Pb-Rich Contributions Per Sample}

No systematic relationship is observed between the total $\mathrm{Pb}$-rich pixel abundances of the samples and their overall makeup in terms of grain populations (Figure 14). While the large spread in results per triplicate analysis set implies a large uncertainty in the quantification of the total $\mathrm{Pb}$-rich pixels per sample, this observation is rather categorical. The five samples with highest total $\mathrm{Pb}$-rich pixel abundance $(7,9,13,17,21)$, for which clearly elevated $\mathrm{Pb}$-rich pixel abundances are seen in two or more of the triplicate analyses per sample, have widely divergent profiles of grain population abundances: more than $50 \%$ of the material in samples 7 and 9 comprises grains belonging to unambiguous steelworksrelated populations (Figure 14b), while samples 13, 17, and 21 are, in contrast, dominated by natural silicate (populations 101-103), natural silicate mixed with diverse urban and industrial material (population 104), urban building materials (specifically population 89) and a lesser contribution of carbon-rich material (specifically population 79).

As discussed in the previous Section 3.3.1, more than $50 \%$ of the total Pb-rich pixels detected in samples $9,13,17$ and 21 are contributed by only 1-4 grains in each case, yet 
these samples also contain a substantial number of other grains bearing variable amounts of $\mathrm{Pb}$-rich pixels. This is visible when comparing the grain populations' total contributed $\mathrm{Pb}$-rich pixels (Figure 14c) and abundance of the host grains (Figure 14e,f) in Figure 14, where the grain populations contributing the dominant share of $\mathrm{Pb}$-rich pixels barely register in the latter plot. The total Pb-rich pixel abundance in sample 9 is dominated by a single occurrence of $584 \mathrm{~Pb}$-rich pixels in one carbon-rich grain and an otherwise unclassified grain containing 139 pixels (Figure 13). Sample 13's total Pb-rich pixel budget is dominated by the contributions of two grains with $>40$ area $\% \mathrm{~Pb}$-rich pixels (population 111) which, moreover, are visibly discrete grains comprising almost exclusively $\mathrm{Pb}$-rich pixels (the occurrence category Pb-rich dominated grains, with $>70 \%$ Pb-rich pixels, as defined in the previous Section 3.3.1), and a single Zn-rich grain (population 75). The dominant contributions of $\mathrm{Pb}$-rich pixels in samples 17 and 21 are from 1-4 grains each with either $>40$ area \% Pb-rich pixels (population 111) or just under this threshold. None of these grains in samples 17 and 21 falls into the category of Pb-rich dominated grains and, instead, they all apparently represent occurrences of superficial, fine $\mathrm{Pb}$-rich sub-grains or layers on an underlying substrate grain.

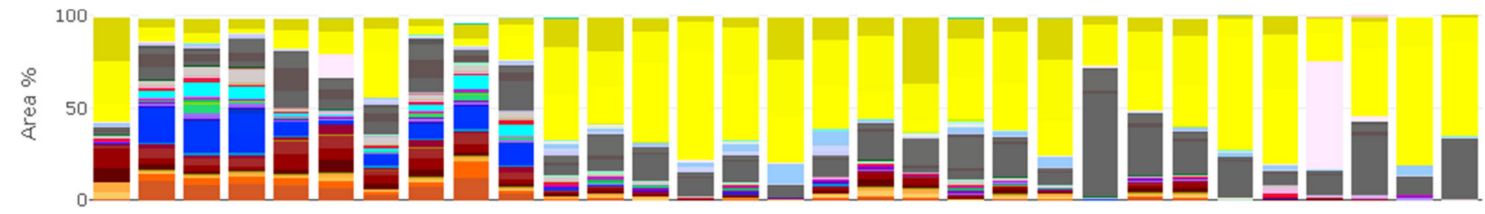

(a)

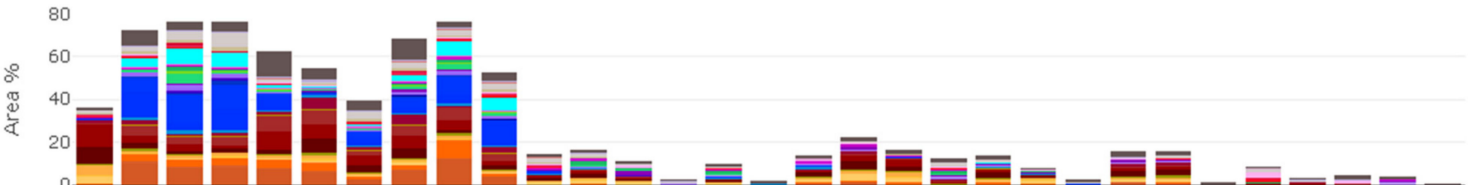

(b)

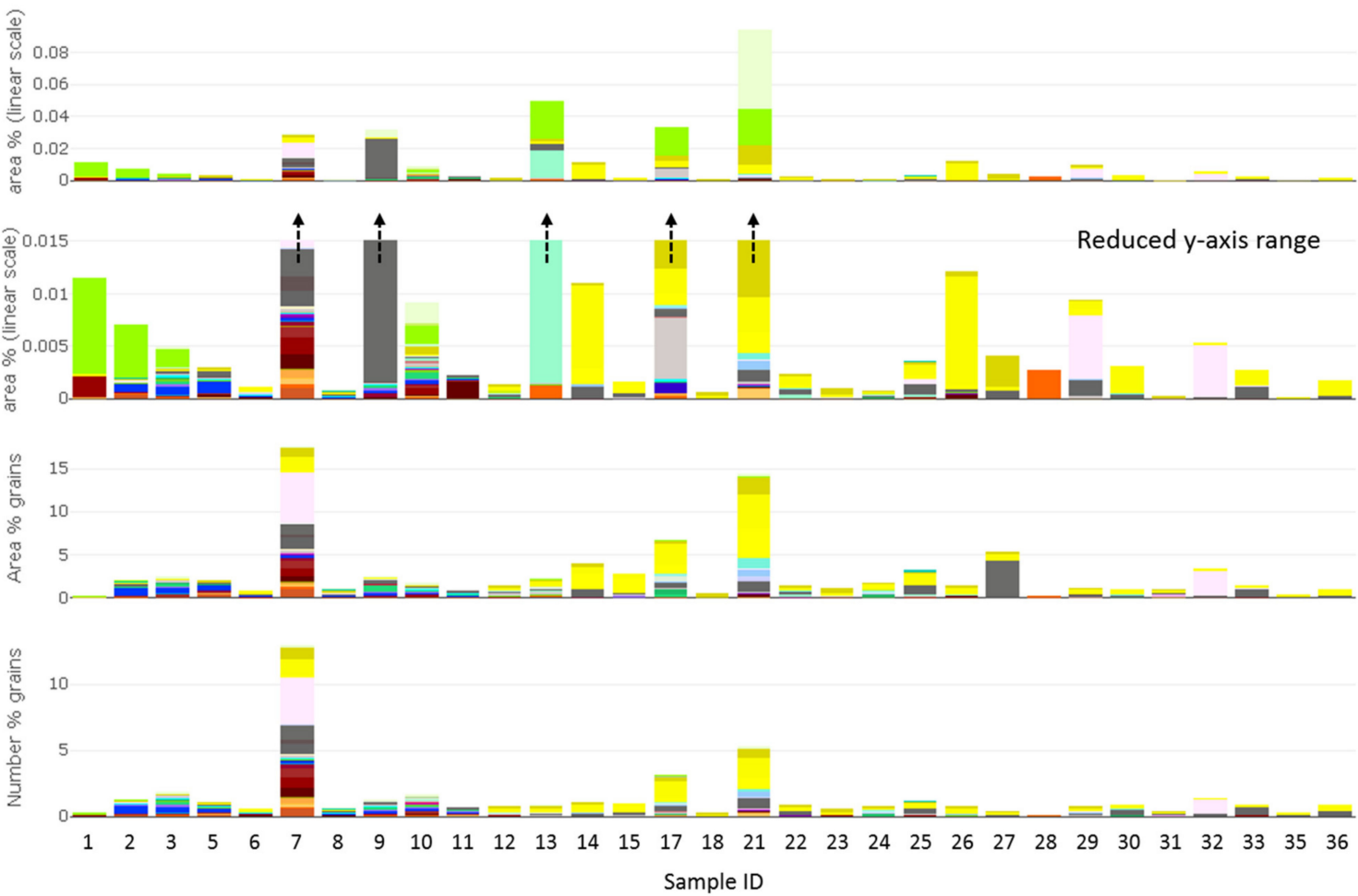

(c)

(d)

(e)

(f)

Figure 14. (a) Grain population abundances (all); (b) showing only unambiguously steelworks-related grain populations; (c) contributions of Pb-rich pixels from grain populations (as area \% with respect to sample); (d) as (c) but with reduced $y$-axis range; (e) host grains as percentage of total grains in sample, by grain area; (f) as (e) but by number of grains. Colour scheme for grain populations as Figure 8. 
Sample 7, as discussed in the previous section, is notable because its $\mathrm{Pb}$-rich pixels are dispersed over a much higher percentage of its grains than in the other samples with highest $\mathrm{Pb}$-rich pixel content. Figure 14 shows that, moreover, all the constituent grain populations contribute significantly to the total $\mathrm{Pb}$-rich pixel budget of the sample, while there is a somewhat disproportionate contribution of the Ba-sulphate bearing grain population (population 94) when comparing its $\mathrm{Pb}$-rich pixel contribution with its overall abundance in the sample.

Regarding the samples with lower Pb-rich pixel abundances, $<0.015$ area \% (150 ppm area), inspecting Figure $14 \mathrm{~d}$ reveals that the majority of $\mathrm{Pb}$-rich pixels in samples $1-3$ and sample 10 are contributed by grains from the (by-definition) Pb-bearing populations 111 ( $>40$ area \%) and 114 (otherwise unclassified grains containing any amount of Pb-rich pixels $<40$ area \%). In samples 1-3 these contributions represent a single Pb-rich dominated grain in each case; in sample 10 , one $\mathrm{Pb}$-rich dominated grain and one grain with a large superficial concentration of $\mathrm{Pb}$-rich pixels over a visibly different substrate. The $\mathrm{Pb}$-rich pixels in samples 14 and 26 are contributed overwhelmingly by grains belonging to the natural silicate populations (populations 101-103), of which 2-3 such grains dominate the total $\mathrm{Pb}$-rich contribution in each case. In samples 29 and 32 the large majority of their detected $\mathrm{Pb}$-rich pixels are contributed by grains belonging to the Ba-sulphate bearing population (population 94), where this is heavily skewed by the contributions of 1-2 grains in each case.

Taken as a whole, the results in Figure 14 reflect the dominant contribution of scarce particles with a high concentration of $\mathrm{Pb}$-rich pixels-variously, $\mathrm{Pb}$-rich dominated grains or diverse grains with a large covering of $\mathrm{Pb}$-rich pixels on a distinct substrate-in seven out of the 31 samples $(1-3,10,13,17$, and 21). In samples 14, 17, 21, and 26 there is (also) a substantial contribution of grains comprising natural silicate and natural silicate mixed with urban and industrial material (populations 101-104; visible in Figures 13 and 14d). These latter grain populations contribute consistently to the $\mathrm{Pb}$-rich budget of samples 12-36, and they represent host grains even in the samples with barely any detected $\mathrm{Pb}$-rich pixels (e.g., sample 35). Grains containing $>1 \%$ Ba-sulphate pixels (population 94) contribute Pb-rich pixels in samples 7, 29, and 32, while as noted in previous Section 3.2, Ba-sulphate pixels are encountered in elevated concentrations in other grain populations within the same samples as well (Figure 9). Grains belonging to populations (79-82) defined by their high carbon/organic content are widespread in the samples as $\mathrm{Pb}$-rich pixel bearing grains, but they are generally not a major contributor to the total Pb-rich pixels in the samples (sample 9 is heavily skewed by a single grain). Finally, the unambiguous steelworks-related grain populations contribute only small total abundances of $\mathrm{Pb}$-rich pixels to the current samples. Sample 7 stands out as having a relatively large contribution of $\mathrm{Pb}$-rich pixels from these populations, but in this sample, the Pb-rich pixels are distributed over all the present grain populations broadly in proportion with their overall area fraction in the sample except for the disproportional contribution of the Ba-sulphate bearing grain population. Hence, except in sample 7, the general load of $\mathrm{Pb}$-rich pixels on unambiguous steelworks-related grain populations is low in relation to the total range of $\mathrm{Pb}$-rich contents in the samples.

\section{Grains with $\geq 5 \mathrm{~Pb}$-Rich Pixels \\ $P b$-phase dominated grains}

In the current sample set, only six clearly discrete, $\mathrm{Pb}$-phase dominated particles larger than $10 \mu \mathrm{m}$ in diameter (Figure 15a) have been detected out of 91,591 analysed grains in total. These are counted as a separate category of Pb-rich phase occurrence in Figures 10-12, but fall under grain population 111 in Figure 13, which comprises all grains containing $>40$ area $\% \mathrm{~Pb}$-rich pixels. Of the six grains, four are encountered as solitary occurrences per sample $(1,2,3,10)$, while sample 13 contains two such grains (one each in two of the triplicate analyses). Hence, these grains represent extremely scarce occurrences, though their contribution to the total detected $\mathrm{Pb}$-rich pixel abundance per sample where they are 
encountered in the analyses is large or even dominant (Figure 12a). Quantitative analyses of the EDS sum-spectra from these grains' Pb-rich pixels (Supplementary File S13A) shows a general lack of associated $\mathrm{S}, \mathrm{Cl}$, and $\mathrm{Cr}$, which rules out sulphide, sulphate, chloride, chlorate, and chromate forms for these specific grains. Pb-oxide or carbonate is tentatively considered a likely candidate (where the latter may be indicative of substantial weathering [22]), though specifying more precisely the compound form is beyond the scope of the study at present. The analyses suggest that these grains comprise Pb-phases throughout their bulk instead of representing a superficial occurrence atop a distinct (Pb-poor) substrate grain.

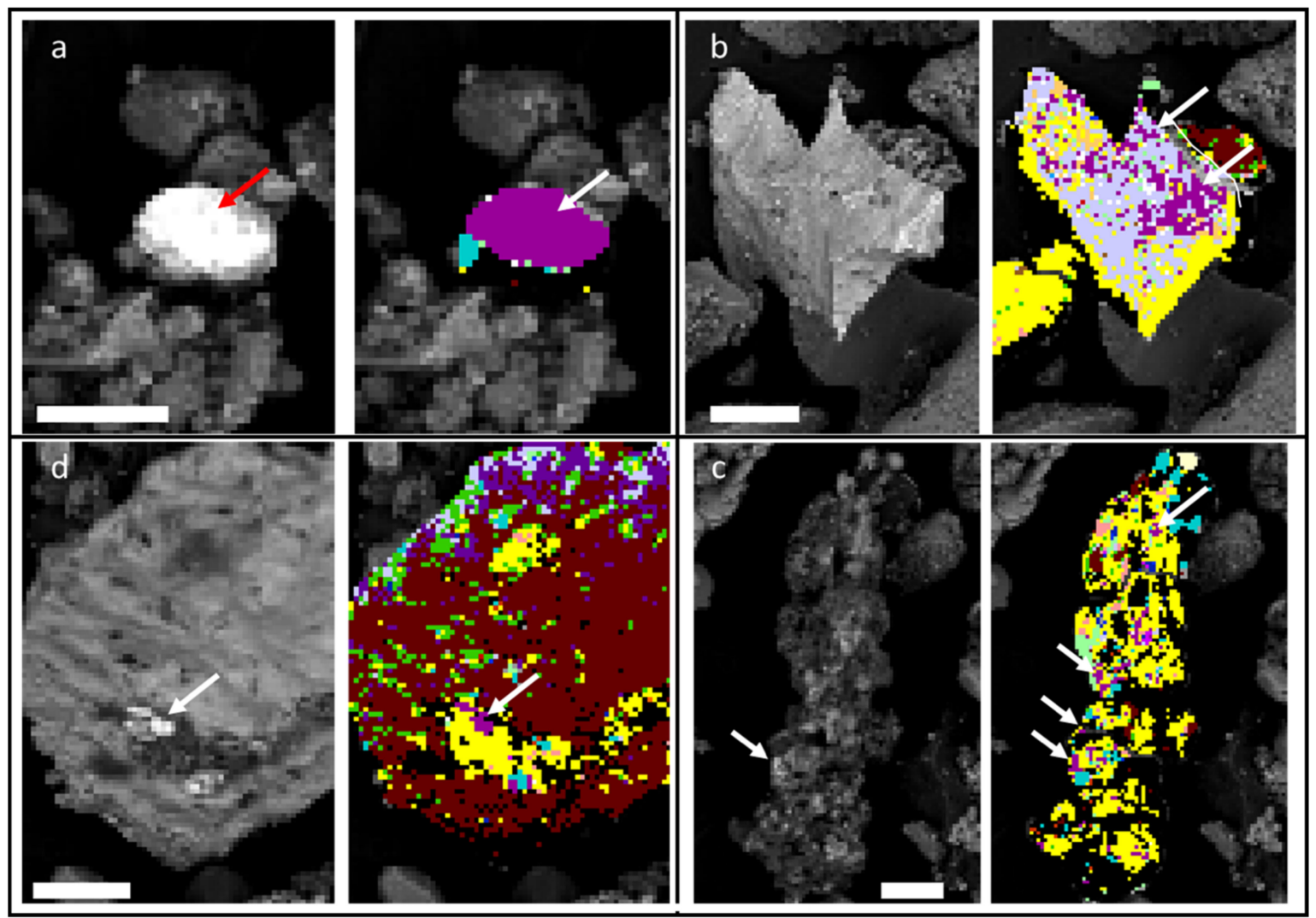

Figure 15. Illustrative imagery of Pb-pixel occurrences in the dust samples, showing for each example (left) BSE and (right) PARC phase map (identical pixel resolution for both images). Arrows indicate $\mathrm{Pb}$-rich pixels in at least the PARC imagery (Pb-rich pixels are coloured dark magenta) and where visible as bright pixels in the BSE images. (a) Pb-phase dominated grain belonging to population 111, with superficial adhering $\mathrm{NaCl}$ (turquoise). (b) Silica-rich grain (from population 114) with large concentration of $\mathrm{Pb}$-rich pixels and $\mathrm{Zn}$-Si rich pixels (lilac) occupying much of its surface, with additional P-Si rich pixels (orange). Yellow $\{\mathrm{Si}\}$ group pixels reflect a silica-dominated substrate. Note conchoidally fractured appearance. (c) Composite grain (population 104), comprising numerous smaller sub-grains of natural silicate (primarily quartz (yellow)) and $\mathrm{FeOx}$ (dark brown), with superficial $\mathrm{NaCl}$ (bright blue), sulphate (light green) covering, and several clear, distinct $\mathrm{Pb}$-rich sub-grains. The dark regions within the grain shown in (c) are empty spectra pixels and represent a combination of topography and detector-shadow artefacts and potentially organic material between the other detected phases. (d) Iron-ore sinter grain with discrete $\mathrm{Pb}$-rich sub-grains, also clearly visible in BSE image as bright regions. The scale bars in all images denote 20 pixels $=32 \mu \mathrm{m}$.

Other Pb-rich phase occurrences comprising $\geq 5$ pixels per grain

Aside from the handful of clearly discrete, $\mathrm{Pb}$-phase dominated particles described above, most of the largest magnitude occurrences ( $\geq 80$ pixels) of $\mathrm{Pb}$-rich phases in the samples are in the form of fine material (sub-particle diameter $<10 \mu \mathrm{m}$ ), or patchy layers, adhering to the surface of larger particles. Specifically, in sample 21, four grains were observed with large abundances (244-991) of $\mathrm{Pb}$-rich pixels, where these pixels appear to 
form part of a layer rich in $\mathrm{Zn}, \mathrm{Pb}, \mathrm{P}$ (and in one case also $\mathrm{Cu}$ ) on an underlying silica-rich or aluminosilicate substrate (Supplementary File S13B). These grains were classified under the populations 111 ( $>40 \% \mathrm{~Pb}$-rich pixels), 114 (otherwise unclassified, with $\mathrm{Pb}$-rich pixels) and 104 (natural silicate mixed with urban / industrial material). We interpret these grains to represent a distinct population in sample 21, which will be discussed in later sections. One such example is shown in Figure 15b. Across all samples, occurrences of 5-79 Pb-rich pixels per grain are also generally limited in number, with only $0-16$ such grains per sample. Such occurrences also dominantly comprise superficial sub-particles adhering to coarser $(>10 \mu \mathrm{m})$ particles or are present as part of $>10 \mu \mathrm{m}$-sized composite particles comprised of many similarly sized sub-particles $(<10 \mu \mathrm{m})$ (Figure 15c). The most common and widespread host particles for these occurrences belong to grain populations comprising natural silicate material and mixtures of natural silicate with industrial (steelworks) and other urban dust sources (populations 101-104). The only other grain populations for which there are $\mathrm{Pb}$-rich occurrences of this magnitude in more than three samples are those defined by their nominally high carbon/organic content (of ambiguous provenance) and populations related to iron ore preparation. The numbers of grains involved for these latter two categories are very limited: 20 grains in total for the carbon-rich populations 79-82, and 10 for the ore-related populations 1-15 (excluding grains in sample 7, where the type of $\mathrm{Pb}$-rich phase occurrence differs markedly from those in the other samples as discussed separately below). Closer inspection of the individual cases detected reveals that several of the grains classified as populations 79-82 with larger $\mathrm{Pb}$-rich occurrences have high content of empty spectra pixels due to artefacts of grain segmentation, detector shadow effects or composite particles comprising smaller sub-particles (as in the example in Figure 15c). No distinctive $\mathrm{Pb}$-rich occurrence type is associated with the carbon rich particles. No systematic association is seen between any specific type of carbon-rich particles and any particular type of $\mathrm{Pb}$-rich occurrence within the 20 grains examined. In all cases (including the misclassified artefact grains) the $\mathrm{Pb}$-rich phase is present as an apparently superficial layer on larger particles or as fine sub-particles within composite particles. Inspection of the imagery of the individual ore-related grains bearing $\geq 5 \mathrm{~Pb}$-rich pixels shows occurrences of both comparatively large sub-particles/concentrated domains of Pb-rich pixels (several $\mu \mathrm{m}$ dimension, e.g., (Figure 15d)) and scattered individual pixels, implying ca. $1 \mu \mathrm{m}$-sized sub-particles. In both cases, the interpretation is that these represent superficial occurrences. In summary, of all the individual occurrences of $\geq 5 \mathrm{~Pb}$-rich pixels, the overwhelming majority are apparently superficial material on diverse host grains. These occurrences take the form of variously, (1) scattered individual pixels representing ca. $1 \mu \mathrm{m}$-sized subparticles through to 2) larger individual sub-particles of a few $\mu \mathrm{m}$ diameter and 3 ) wider domains of $\mathrm{Pb}$-rich pixels which may be a layer of generally elevated $\mathrm{Pb}$ concentration lacking clearly defined sub-particles.

\section{Grains with 1-4 Pb-Rich Pixels}

As discussed in Section 3.3.1, grains with 1-4 Pb-rich pixels make up the vast majority $(92 \%)$ of the total host grains found across all samples. They represent, therefore, the most widely distributed occurrence of detectable $\mathrm{Pb}$ in the samples, and warrant special attention for this reason, albeit that their total contribution of $\mathrm{Pb}$-rich pixels in most samples is low (Figure 11). Figure 16 shows the same information as Figure 14, i.e., the distribution of $\mathrm{Pb}$-rich pixels over grain populations but filtered to show only the contributions of grains with 1-4 Pb-rich pixels. Sample 7 stands out clearly with a relatively large total contribution of $\mathrm{Pb}$-rich pixels ( 0.025 area \% or $250 \mathrm{ppm}$ area) from grains in this $1-4 \mathrm{~Pb}$-rich pixel occurrence category shared over all its constituent grain populations. For this sample, the picture changes little when compared with the unfiltered data shown in Figure 14 in either total $\mathrm{Pb}$-rich abundance or the relative contributions of the grain populations, since the large majority of its $\mathrm{Pb}$-rich pixels belong to this occurrence category. In the remainder of the samples, the much lower range of total $\mathrm{Pb}$-rich pixel abundances $(<0.008$ area $\%$ or $80 \mathrm{ppm}$ area) requires a separate plot (Figure 16b) to adequately see the variations among 
them. Within this range, sample 21 has by far the highest content of Pb-rich pixels $(0.0075$ area $\%$ or $75 \mathrm{ppm}$ ), which is distributed over around $5 \%$ of the sample's analysed grains (due to the host grains' relative coarseness, this represents around $12 \%$ of the total grains by area). The main contributing grain populations in this case comprise natural silicates and natural silicates mixed with urban and industrial material (populations 101-104), with smaller contributions from building material (primarily population 89 ) and carbon-rich populations (primarily population 79), and an almost negligible contribution from other populations related to steelworks processes (ore and slag related).

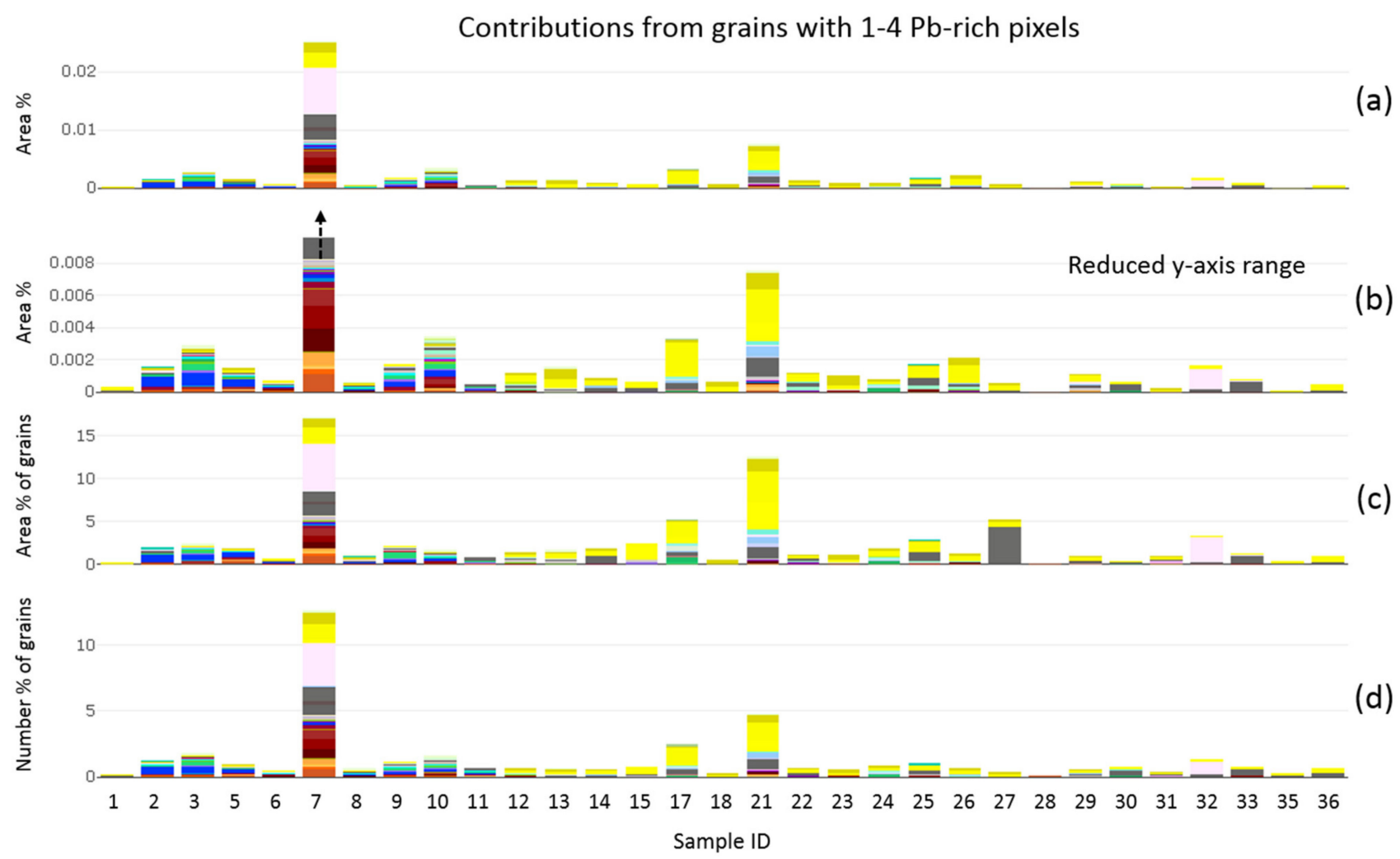

Figure 16. As Figure 14 after filtering data by excluding those grains with $\geq 5 \mathrm{~Pb}$-rich pixels. (a) contributions of Pb-rich pixels from grain populations (as area \% with respect to sample); (b) as (a) but with reduced y-axis range; (c) host grains as percentage of total grains in sample, by grain area; (d) as (c) but by number of grains. Colour scheme for grain populations as Figure 8.

The rest of the samples show fluctuating abundances (in the occurrence category of 1-4 $\mathrm{Pb}$-rich pixels) between almost zero (a single pixel in sample 35) and 0.0035 area \% (35 ppm area). For samples 12-36, most of these Pb-rich pixels are located on grains comprising natural silicates and natural silicates mixed with urban and industrial material (populations 101-104), while smaller amounts are located on carbon-rich grains (populations 79-82), and in sample 32 on grains with $>1 \%$ Ba-sulphate pixels (population 94). In all these samples, these grain populations are volumetrically the most prominent. Taken as a whole, in samples 2-6 and 8-11 an apparent preferential association is observed between $\mathrm{Pb}$ rich pixels and grain populations related to steelmaking BOF converter slag. These grain populations have broadly similar abundances in the relevant samples as those related to iron ore preparation but clearly contribute more $\mathrm{Pb}$-rich pixels than the latter in this occurrence category of 1-4 pixels per grain. Specifically, grains from these BOF slag populations with a high coverage of superficial sulphate (weathering product) stand out as disproportionate contributors of $\mathrm{Pb}$-rich pixels within this category. More broadly, for the current sample set, an apparent relationship was observed between the total abundance of $\mathrm{Pb}$-rich pixels and that of S-rich pixels (the sum of all PARC pixel groups defined by the 
presence of a S peak) in the samples when considering only those grains with $<5 \mathrm{~Pb}$-rich pixels, i.e., also including the S-rich pixels of those grains with no detected $\mathrm{Pb}$-rich pixels. When plotted as raw pixels in Figure 17 and zooming the $y$-axis range to those samples with fewer Pb-rich pixels, a positive envelope trend is apparent, with increasing minimum $\mathrm{Pb}$-rich pixels as the number of S-rich pixels increase. A straight line passing from the origin to the point with highest S-rich pixel count, and closely hugging the main body of data points with $<100 \mathrm{k}$ S-rich pixels, defines an empty region in the plot. This apparent relationship could be interpreted as either entirely coincidental or as lying somewhere on a spectrum between the two following extreme scenarios:

(1) A genuine geochemical association in these samples between S-rich (Pb-poor) and $\mathrm{Pb}$-rich phases, resulting in a certain minimum ratio of $\mathrm{Pb}$-rich pixels to S-rich pixels;

(2) A false classification artefact, where a certain fraction of actual S-rich pixels are misclassified as $\mathrm{Pb}$-rich with the density plot discrimination method described in previous sections (Figures 4 and 5).

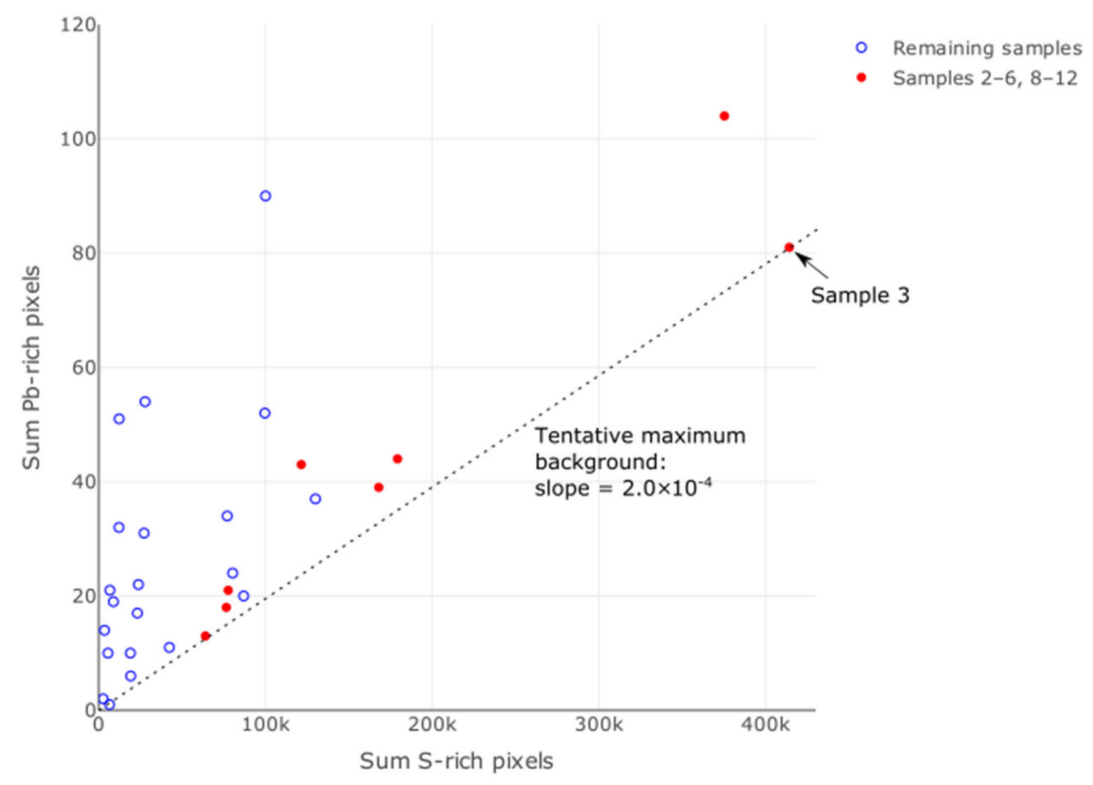

Figure 17. Pixel counts per sample (combined triplicates): Pb-rich vs sum of all S-rich pixels, for all grains containing 0-4 $\mathrm{Pb}$-rich pixels (excluding those with $\geq 5 \mathrm{~Pb}$-rich pixels). Sum S-rich pixels includes all PARC groups defined by presence of S peak. Samples 2-6 and 8-11 are highlighted (larger red symbols; see Section 3.3.2 ("Grains with 1-4 Pb-Rich Pixels") for further discussion).

Regarding (1), much of the S-rich pixel occurrence in the samples-especially in those plotting close to the line drawn in Figure 17-is interpreted as superficial sulphate-rich weathering products on the grains. A potential association between (atmospheric) chemical weathering products and the occurrence of $\mathrm{Pb}$-rich phases precipitated on the surface of the same grains is not an unreasonable hypothesis. Regarding (2), such a sharply defined empty region in the plot is somewhat suggestive of a background artefact, given that the rejected pixels screened in the density plot (plotting outside of the polygon defined in Figure 4) are overwhelmingly classified as S-rich thereafter, i.e., the potential confusion in classification is dominantly between the $\mathrm{Pb}$-rich and $\mathrm{S}$-rich (Pb-poor) pixels whose abundances are plotted in Figure 17. To address this uncertainty, a secondary check was performed on sample 3, which has the highest S-rich pixel content of the samples plotted in Figure 17, and individual pixel spectra were manually inspected in those grains containing 1-4 $\mathrm{Pb}$-rich pixels. The $(\mathrm{Pb})$ peak position and shape were scrutinised per spectrum and, in almost all cases, the detected $\mathrm{Pb}$-rich pixels were confirmed to contain plausible $\mathrm{Pb}$ signal in their spectra. Nevertheless, the apparent $\mathrm{Pb}$-rich pixel spectra associated with the sulphate-encrusted grains show generally low signal intensity, barely above the minimum 
threshold for classification, at the $\mathrm{Pb}-\mathrm{M}$ position. Moreover, many of the S-rich pixels in the same grains have similarly low signal at the $\mathrm{Pb} / \mathrm{S}$ position since they represent thin layers of likely multi-phase intergrowth over a distinct (S-poor) substrate, resulting in dilution of the $\mathrm{S}$ signal. As discussed in Section 2.4.2, the discrimination between $\mathrm{Pb}$ and $\mathrm{S}$ signal is less clear at lower intensity. We conclude that the apparent relationship between scarce, isolated $\mathrm{Pb}$-rich pixels and sulphate-encrusted converter slag grains cannot be entirely disregarded as an artefact of false detection. However, the context of occurrence of these $\mathrm{Pb}$-rich pixels is such that they are close to the limit of detectability of the current method. Finally, any background false detection of Pb-rich pixels as function of total S-rich pixels implied by the above observations would have negligible impact on the total Pb-rich pixel contents of the samples, including those grains containing $\geq 5 \mathrm{~Pb}$-rich pixels.

\subsubsection{Synthesis and Interpretation of Results}

The aim of this article is primarily to demonstrate the practical application of a novel dust characterisation technique, incorporating $\mathrm{Pb}$-rich phase detection. The set of 31 samples are geographically distributed around the heavily industrialised IJmond region, including locations in very close proximity to the integrated steelworks of Tata Steel in IJmuiden. Because the samples were collected on a single day, they represent an approximate snapshot in time, allowing for the fact there will inevitably have been accumulation of dust over some unspecified period prior to sampling at these localities. Pending a wider study of more samples, taken at different times from the same precise sampling locations, and including bulk chemical analyses, we draw only some general implications from the presented analyses regarding the distribution of $\mathrm{Pb}$-rich phases detectable by the PARC method. These are discussed briefly below as part of a recap of the main results described in depth in the previous sections.

\section{Overall Abundances of Detectable Pb-Rich Phases}

The total range of $\mathrm{Pb}$-rich pixel contents in the samples (combining triplicate analyses per sample) is from almost zero (1 pixel) up to $9.4 \times 10^{-2}$ area \% (0-940 ppm area) (Figure 12). The maximum abundance measured in a single analysis (one of the triplicates) within a sample is in sample 21, $2.3 \times 10^{-1}$ area $\%$ (2300 ppm area) (Figure 10). This is the only single analysis result that overlaps with the range of individual triplicate analyses within NIST SRM 2587 (nominal 3000 ppm Pb, Table 3). The range of Pb-rich pixel abundances in the current set of IJmond dust samples is generally substantially lower than in the set of four NIST SRM samples which have nominal 3000-40,000 ppm elemental mass fraction of $\mathrm{Pb}$. A clear distinction needs to be drawn between bulk chemical elemental mass fraction of $\mathrm{Pb}$ versus the (silhouette area) abundance and distribution of detectable $\mathrm{Pb}$-rich phases with the presented method. Pending further bulk chemical analyses of the same samples, we simply conclude that the range of abundance of detectable, surface-exposed $\mathrm{Pb}$-rich phases in the samples is substantially lower than in these standard reference materials. The internal spread on triplicate analyses per sample is high in numerous cases (Figure 10), due to a nugget effect on the spatial scale of the analyses, i.e., the dominant influence of presence/absence of scarce grains with large concentration of $\mathrm{Pb}$-rich pixels in the individual analyses. Taking into account both the aggregated results and internal variation for triplicate analyses, per sample, there are five samples with notably elevated $\mathrm{Pb}$ rich pixel abundance compared to the rest: samples 7, 9, 13, 17 and 21, whose (aggregated triplicate) abundances range from ca. 2.9-9.4 $\times 10^{-2}$ area \% (290-940 ppm area). The rest of the samples variously contain consistently low total abundances across all their triplicate analyses or show a single 'spike' abundance of Pb-rich pixels (one analysis of the triplicate set). The range of these samples' total Pb-rich pixel abundances is $\leq 1.2 \times 10^{-2}$ area \% (120 ppm area). 


\section{Distribution of Pb-Rich Phases with Respect to Grains and Grain Populations}

No systematic relationship is observed between the overall grain population makeup of the samples and the total Pb-rich pixel abundances in them (Figure 14). For most samples with any elevated $\mathrm{Pb}$-rich pixel abundance in one or more of their triplicate analyses (with respect to the general range observed across all analyses), this is dominated by the contribution of only 1-4 grains (particles) (Figures 11 and 12). Overall, considering the grand total of $\mathrm{Pb}$-rich pixels detected in all samples, the majority of $\mathrm{Pb}$-rich pixels are concentrated in or on very scarce grains: ca. $57 \%$ of the total $\mathrm{Pb}$-rich pixels are contained in only $1.1 \%$ of the total (Pb-rich pixel-)host grains and $0.018 \%$ of the total analysed grains (by grain count), where these grains comprise (1) discrete particles dominated (in their bulk) by $\mathrm{Pb}$-phases, and (2) particles with a large amount of superficial $\mathrm{Pb}$-rich material atop them ( $\geq 160$ pixel threshold) (Figure $15 a, b$, respectively). Conversely, $92 \%$ of the host grains containing any detected $\mathrm{Pb}$-rich pixels contain only 1-4 pixels and contribute only $21 \%$ of the total $\mathrm{Pb}$-rich pixels. This most abundant category of host grains comprises only $1.5 \%$ of the total number (ca. 92,000) of analysed grains across all the samples. Sample 7 deviates markedly from this overall trend. This sample contains ca. $2.9 \times 10^{-2}$ area \% (290 ppm) total Pb-rich pixels (Figure 12), with remarkably low spread in its triplicate analyses (Figure 10), compared to the other top-five samples in terms of total Pb-rich abundance, and a very disperse distribution of the total $\mathrm{Pb}$-rich pixels over ca. $15 \%$ of the analysed grains (Figure 14f). Moreover, in sample 7, the large majority of the total Pb-rich pixels are contained in grains with only 1-4 detected pixels (Figure 12). The remaining four of the top-five $\mathrm{Pb}$-rich samples contain both 1) a scarce handful of grains which are either $\mathrm{Pb}$-phase dominated or have $>160 \mathrm{~Pb}$-rich pixels, and 2) somewhat elevated contributions from the more numerous grains with lower concentration of $\mathrm{Pb}$-rich pixels (across the range from 1-160 pixels per grain) (Figure 12). In these samples, qualitative examination of the imagery confirms that the $\mathrm{Pb}$-rich pixels are all in the form of superficial sub-particles with size $<<10 \mu \mathrm{m}$ (barring one "dense" Pb-phase dominated particle in sample 13). Moreover, similarities are observed in the spectra of pixels comprising both larger and smaller magnitude occurrences in some samples (e.g., sample 21, discussed in the following section). This suggests that the larger-magnitude individual occurrences (of $\mathrm{Pb}$ rich pixels on a grain) in some of these samples may simply represent the tip of a pyramid of occurrences-ranging from more numerous, but smaller magnitude, occurrences to larger, less numerous ones-of superficial $\mathrm{Pb}$-rich sub-particles with overlapping characteristics and sources (per sample).

$\mathrm{Pb}$-rich pixel occurrences of $\geq 5$ pixels per grain have been encountered in at least one grain from each of the major source categories, though some categories show more occurrences than others (Figure 13). Natural silicate grains and composite grains comprising natural silicate mixed with urban/industrial material (populations 101-104) are the most numerous and widespread host grains of $\mathrm{Pb}$-rich occurrences of $\geq 5$ pixels across the sample set as a whole. Moreover, these grains figure most prominently as the grain populations carrying the greatest load of $\mathrm{Pb}$-rich pixels per sample, outside of the handful of extremely scarce "nugget" grains with exceptionally high $\mathrm{Pb}$-rich pixels per grain (Figure 14). Aside from these grains, only carbon-rich (populations 79-82) and iron-ore related grains (populations 1-15) figure as host grains of more substantial $\mathrm{Pb}$-rich pixel occurrences in several samples. However, the contribution of these grains to the overall $\mathrm{Pb}$-rich pixel budget of the samples in which they are contained is generally only small (Figure 14). The most common occurrence-magnitude category, $1-4 \mathrm{~Pb}$-rich pixels per grain, sees contributions from all major categories of grain population (Figure 16): in samples 12-36, chiefly natural silicate grains and mixed natural silicate with urban/industrial material which are generally the dominant grain populations in those samples; in samples 1-11 chiefly steelworks-related grains, which are dominant in those samples. A possible association between scarce ( $<30 \mathrm{ppm}$ area per sample), isolated $\mathrm{Pb}$-rich pixels and sulphate-rich weathering crusts on BOF converter slag grains is seen in samples 2-6 and 8-11, though these $\mathrm{Pb}$-rich pixels' spectral characteristics place them at the limits of detectability of the 
method (due to low signal intensity at the position of $\mathrm{Pb}-\mathrm{M} / \mathrm{S}-\mathrm{K} \alpha$ and correspondingly poorer discrimination between the two elements' signals).

\section{Character and Potential Provenance of the Detected Pb-Rich Phase Occurrences}

The primary EDS-SI analyses, on which the PARC method is based, impose clear limitations on the ability to precisely identify the actual compounds (phases) represented by the $\mathrm{Pb}$-rich pixels. The $\mathrm{Pb}$-rich pixels are physically interpretable as occurrences $\mathrm{of} \mathrm{Pb}$ at the major element concentration level at the length-scale of $\sim 1 \mu \mathrm{m}$ (order of magnitude only). These pixels may therefore represent, variously, coherent single-phase analyses containing $\mathrm{Pb}$ as a major element (i.e., true $\mathrm{Pb}$-phases), or signal from dispersed but discrete nano-particles/nano-inclusions atop/within a $\mathrm{Pb}$-free matrix. Due to the inferred superficial nature of much, if not most, of the detected $\mathrm{Pb}$-rich pixels, the chemical signal invariably reflects the chemistry of the substrate material as well as the overlying Pb-rich material. Ruling out the occurrence of some phases, such as Pb-chlorides/chlorates due to the absence of $\mathrm{Cl}$ signal, can be possible in some cases. However, the common spatial association of $\mathrm{Pb}$-rich and S-rich pixels_-generally superficial sulphate material-leads to mixed signal from sulphate phases in such cases, regardless of whether the phases represented by the $\mathrm{Pb}$-rich pixels are also rich in $\mathrm{S}$ (i.e., $\mathrm{Pb}$-sulphides and sulphates). The discrete $\mathrm{Pb}$-rich dominated grains (e.g., in Figure 15a), categorised separately in the above results, show spectra dominated by $\mathrm{Pb}$ - and $\mathrm{O}$-signal, with little $\mathrm{S}, \mathrm{Cl}$ or meaningful other element concentration the quantitative analyses on their sum-spectra (see Supplementary File S13A). Hence, for these grains, chloride/chlorate, sulphite/sulphate and chromate forms of $\mathrm{Pb}$ are excluded. We tentatively infer that they may represent $\mathrm{Pb}$-oxide or carbonate.

In sample 7, the sum-spectra derived from grouping the $\mathrm{Pb}$-rich pixels per grain population show an unmistakable $\mathrm{Cr}$ signal in addition to $\mathrm{Pb}$. When quantified (Figure 18), these sum-spectra analyses lie close to, or on the line joining the origin with the theoretical composition of $\mathrm{PbCrO}_{4}$. Moreover, some $\mathrm{Pb}$-rich pixel sum-spectra from samples 26 and 29 (not plotted in Figure 18) also show elevated $\mathrm{Cr}$ signal and plot close to the line. For these $\mathrm{Pb}$-rich pixels, the inferred corresponding phase identity is $\mathrm{PbCrO}_{4}$. The likely implications of this are discussed further below.

$\mathrm{PbCrO}_{4}$ is a known component of some (historic) yellow paints and pigment $[23,24]$, and it is also used in fireworks/pyrotechnics as a delay composition [24,25]. In sample 7, the $\mathrm{Pb}$-rich pixels, interpreted as dominantly $\mathrm{PbCrO}_{4}$, generally occur as scattered individual pixels representing sub-particles of at most ca. $1 \mu \mathrm{m}$ in diameter. These Pb-rich pixels are associated spatially with Ba-sulphate pixels and occur on the surfaces of all the constituent grain populations present in the sample with an apparently random distribution over these. Ba-sulphate has diverse uses and, just as $\mathrm{PbCrO}_{4}$, is used in both paints and pigments as well as pyrotechnic compositions [25-27]. The association of $\mathrm{PbCrO}_{4}$ and Ba-sulphate could reflect a source as either paint/pigment or fireworks. The association of $\mathrm{PbCrO}_{4}$ and Ba-sulphate, with a lack of accompanying Ti-oxide pixels, marks out sample 7 compared with sample 32 and other samples that contain a consistent association of Ba-sulphate pixels with Ti-oxide but no accompanying $\mathrm{PbCrO}_{4}$. In those samples we consider the Ba-sulphate and Ti-oxide to derive from a different source, potentially white pigment or paint, where the combination of Ba-sulphate and Ti-oxide may be used (e.g., [28]). In the case of sample 7 , we tentatively suggest the co-occurrence of ultra-fine $\mathrm{PbCrO}_{4}$ with Ba-sulphate is more likely associated with deposition of fine particulate material from fireworks, where both components are known ingredients of pyrotechnic delay compositions [25].

For the remainder of the samples except 7, 26 and 29, the $\mathrm{Pb}$-rich pixels are not rich in $\mathrm{Cr}$ and are also not clearly identifiable with any specific $\mathrm{Pb}$ phase. Aside from in those samples, the $\mathrm{Pb}$-rich pixels associated with iron-ore related grains show spectra dominated by $\mathrm{Pb}( \pm \mathrm{S}), \mathrm{O}$ and elements obviously reflecting the adjacent or underlying material (Supplementary File S13C). With the exception of one occurrence (11 pixels) in a grain in sample 17, any $\mathrm{Cl}$ signal observed in these spectra is invariably accompanied by $\mathrm{Na}$ and reflects mixed signal with adjacent $\mathrm{NaCl}$ on the surface of the same grains (visible as 
$\{ \pm, \mathrm{Na}, \mathrm{Cl}, \pm\}$ group pixels). Therefore, for these $\mathrm{Pb}$-rich pixels, a chloride form of $\mathrm{Pb}$ is excluded, while oxide/sulphate/(hydrous-)carbonate forms remain plausible, where the latter two are known as potential speciation forms of $\mathrm{Pb}$ emissions from sintering plants [7]. However, none of these phases are uniquely associated with such emissions, and the source of the Pb-rich phases may be unrelated to the particles they now occur on.

In sample 21, four grains were encountered (as described briefly in Section 3.3.2, "Grains with $\geq 5 \mathrm{~Pb}$-Rich Pixels") with an intimate spatial association of $\mathrm{Pb}$ - and $\mathrm{Zn}$-rich material and silica/aluminosilicate (Figure 15b and Supplementary File S13B examples $\mathrm{i}-\mathrm{iv})$. In three of these (S13B examples i-iii), the grains have a conchoidally fractured appearance, while in one case (iii) the grain is fortuitously oriented such that it clearly reveals a distinct $\mathrm{Pb}-\mathrm{Zn}$-rich layer (also with elevated $\mathrm{P}$ ) on the surface of an otherwise aluminosilicate dominated substrate. The fourth grain (iv) sees a large abundance of $\mathrm{Pb}$-rich pixels in combination with $\mathrm{Zn}$-Cu-rich pixels, the latter in apparently oxide form, on an apparently silica-rich substrate. It is not possible to directly discern the phase identities corresponding with the $\mathrm{Pb}$ - and $\mathrm{Zn}$-rich pixels in these grains, but together they appear to form part of a distinct surface layer atop conchoidally fractured aluminosilicate shards. We suggest that these most likely represent shards of glazed pottery or roof tiling, where both are known Pb-contamination sources in the Netherlands [29]. In other samples $(9,10$, $13,17,22,25$, and 36), Zn signal is also present in the spectra of some of the encountered $\mathrm{Pb}$-rich pixels, some of which are also associated with silica-rich grains, though this is not universally the case. In sample 13, one grain was observed with a substantial occurrence of Pb-rich pixels, while otherwise dominated by Zn-rich, Fe-poor pixels (Supplementary File S13D). The apparent association of $\mathrm{Pb}$ and $\mathrm{Zn}$ in several samples, with diverse other mineralogical associations, would require further investigation to interpret confidently. Possible sources of material with association of $\mathrm{Pb}$ and $\mathrm{Zn}$ include historic $\mathrm{Zn}-\mathrm{Pb}$ galvanising material [30] (no longer produced locally), pyrotechnic compositions for fireworks (which may also contain additionally $\mathrm{Cu}$ ) [25,31-33] and potentially stack emissions from integrated steelmaking which are known to contain concentrations of both elements [34,35]. Beyond the specific examples in sample 21, we do not speculate further on which, if any, of these sources contribute to the $\mathrm{Zn}$ associated $\mathrm{Pb}$-rich pixels in the current samples.

The combined results of the analyses suggest three fundamental types of $\mathrm{Pb}$-phase occurrence in the samples: (1) discrete, dense $\mathrm{Pb}$-oxide or $\mathrm{Pb}$-carbonate particles $>10 \mu \mathrm{m}$ in diameter; (2) Pb-phases occurring on the surface of particles where there is an intrinsic association with specific materials, such as glazed pottery and ceramics; and (3) coincidental occurrence of (ultra-)fine superficial $\mathrm{Pb}$-rich phases on unrelated coarser particles. We cannot currently interpret the sources of most of the Pb-rich occurrences with any confidence. Tentatively, there may be a systematic association between superficial $\mathrm{Pb}$-rich phase occurrence and a very low percentage $(<<1 \%)$ of iron-ore (agglomerate) grains, based on solitary occurrences in 10 samples (excluding sample 7), though the extremely low frequency of occurrence makes any statistical argument weak. The $\mathrm{Pb}$-rich pixels observed on these grains would be consistent with the speciation expected for sintering plant emissions (as discussed above), though not uniquely so. A possible association of scarce, isolated $\mathrm{Pb}$-rich pixels with sulphate-rich weathering crusts on BOF converter slag particles is observed, though this represents $<30 \mathrm{ppm}$ area $\mathrm{Pb}$-rich pixels per sample at most, and these pixels are at the limits of detectability for the method (as discussed in previous sections). Nothing can be inferred of any true Pb-rich phase association from these pixels due to their low spectral signal of $\mathrm{Pb}$ and / or $\mathrm{S}$ and inferred dominant signal of adjacent and underlying material. Beyond this, no relationship is observed between any of the unambiguously steelworks-related grain populations and the occurrence of $\mathrm{Pb}$-rich phases - either in terms of the total $\mathrm{Pb}$-rich abundance in the samples, or in terms of consistent association of $\mathrm{Pb}$-rich pixels with specific grain populations. Indeed, in samples $12-36$, which contain structurally lower contribution of steelworks-related grain populations, the total $\mathrm{Pb}$-rich pixel contents fluctuate over a wider range (higher maximum) than samples 1-11, and the Pb-rich pixels are most commonly associated with natural/urban/mixed (composite) grains. One of the 
primary conclusions of this study is that in most separate occurrences (i.e., host grains) of $\mathrm{Pb}$-rich pixels, these represent superficial adhering fine material $(<10 \mu \mathrm{m})$ on the surface of coarser particles $(>>10 \mu \mathrm{m})$. As such, the lack of clear relationships between host-grains and $\mathrm{Pb}$-occurrence is not unexpected, since any such association need only reflect the process by which the coarser materials acquire their superficial covering from a potentially unrelated source of finer $\mathrm{Pb}$-rich material.
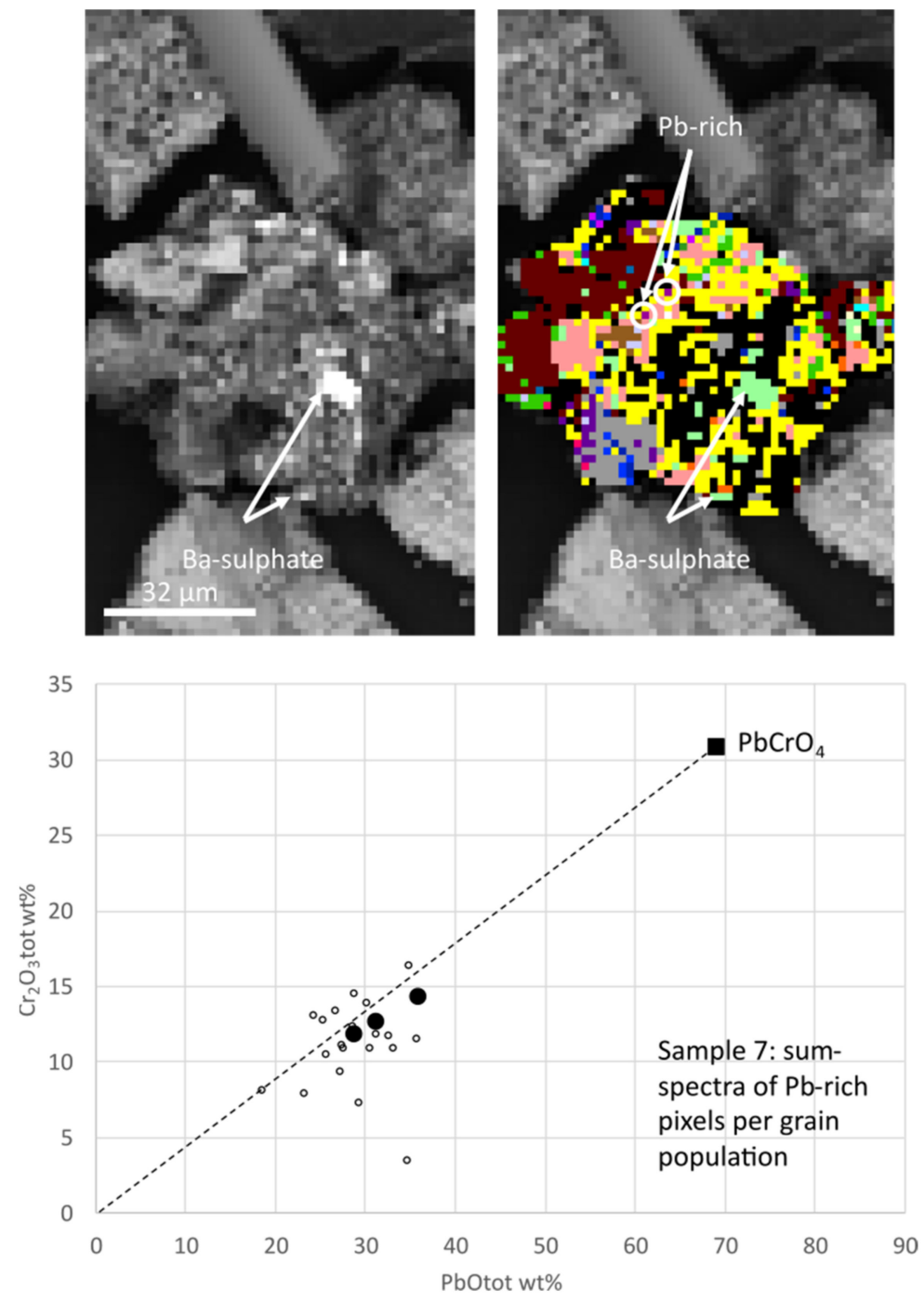

Figure 18. (Image) Typical $\mathrm{Pb}$-rich occurrence in sample 7 grains—two isolated $\mathrm{Pb}$-rich pixels on the surface of a grain with additionally Ba-sulphate pixels (left, BSE; right, PARC phase map). Such occurrences dominate the contribution to total $\mathrm{Pb}$-rich pixels in sample 7. (Plot) Quantitative EDS analyses of sum-spectra for $\mathrm{Pb}$-rich pixels from sample 7, grouped by grain population. Sum-spectra based on 10-50 pixels (total) are shown as smaller unfilled circles. Three spectra based on $>50$ pixels are shown with larger filled circles. The line represents a mixing line between the composition of $\mathrm{PbCrO}_{4}$ and generic $\mathrm{Pb}$ - and $\mathrm{Cr}$-free material, expected in case of mixed chemical signal in the pixels. Note the clustering of most of the data points close to the line. Full EDS quantitative analyses of PARC sum-spectra are given in Supplementary File S14.

Given the public health concern regarding $\mathrm{Pb}$ in the environment in the IJmond, and the wider province of North Holland, it would be of interest to relate the $\mathrm{Pb}$-occurrences reported here to past or current industrial and urban sources (bearing in mind also a background abundance of ca. $17 \mathrm{ppm} \mathrm{Pb}$ in the upper continental crust [36]). The broader area of North- and South-Holland is known to be contaminated with $\mathrm{Pb}$ [37], presumably 
from historical economic activity over the last four centuries. The banks of the old waterways, and the old historical centres in the larger region of Holland, show soil Pb contents between $400-800$ ppm and above 800 ppm, respectively. In the survey of European soils by Reimann et al. [38], exceptionally high Pb-levels were also reported for the agricultural soils of the Netherlands. Whether this soil related $\mathrm{Pb}$ becomes remobilised and dispersed as airborne dust is unknown. The ongoing application of $\mathrm{Pb}$ is also widespread, mainly in car batteries and as $\mathrm{Pb}$-sheet in buildings, and $\mathrm{Pb}$-usage, including recycle streams, in the Dutch economy is estimated at 70 thousand tons annually. The Dutch accumulated stock of $\mathrm{Pb}$ is estimated at 1.5 million tons [39]. Elshkaki et al. [40] reported on the non-intentional flow of $\mathrm{Pb}$ into the Netherlands' environment associated with many activities. According to this study, metal processing accounts for the largest non-intended $\mathrm{Pb}$ air-emissions on par with air-emissions from intended usage (car batteries, $\mathrm{Pb}$-sheet in buildings). Fine particulate material from fireworks displays may account for some incidental, localised contaminations with $\mathrm{Pb}$ and other heavy metals ( $\mathrm{Ba}, \mathrm{Zn}, \mathrm{Cu}, \mathrm{Sr}$ and more [31-33]). Finally, a known source of lead in the IJmond region is the local Tata Steel plant, which reports [41] current emission levels of around $1000 \mathrm{~kg} / \mathrm{y}$, though this is a substantially reduced level compared to previously. The evidently varied occurrences of discrete $\mathrm{Pb}$ phases found in the coarse airborne dust deposit samples studied here likely reflect contributions from several of these ongoing economic activities, as well as historical build-up, and we do not speculate further based on the current analyses.

\section{Conclusions}

A method has been presented for screening coarse airborne dust for Pb-rich phase occurrence during quantitative characterisation of particle mineralogy, chemistry and provenance. This is based on SEM-EDS-SI analysis and processing of raw SI data using the custom software PARC. SI pixels are assigned to (1) a grain ID (discrete particle), (2) group (phase), (3) grain population, and quantitative information per grain regarding size, mineralogy, chemistry and provenance is hence derived and aggregated in different groupings (sample, sample-population, pooling of grains from different samples, etc.).

Specifically, in this study, a solution has been developed for discriminating SI pixels with high $\mathrm{Pb}$ signal from those with high $\mathrm{S}$ but lacking in $\mathrm{Pb}$, at the measurement conditions, using $15 \mathrm{kV}$ accelerating voltage, required for the wider analytical objectives. Using a consistent difference in the precise location and shape of $\mathrm{Pb}-\mathrm{M} \alpha$ vs. S-K $\alpha$ at the level of individual SI pixel spectra, near-perfect discrimination is obtained in analyses of $\mathrm{Pb}$-rich reference phases $\left(\mathrm{PbCrO}_{4}\right.$ and $\left.\mathrm{PbS}\right)$ versus $\mathrm{S}$-rich, $\mathrm{Pb}$-poor phases $\left(\mathrm{BaSO}_{4}, \mathrm{CaSO}_{4}, \mathrm{FeS}_{2}\right.$, $\mathrm{HgS}, \mathrm{MoS}_{2}$ ) in polished section. The developed method serves as a screening procedure to detect the presence of $\mathrm{Pb}$ where concentrated as a major element $(\sim 10 \%)$ at the length-scale of $1 \mu \mathrm{m}$ or greater. The approach is not able to detect less concentrated Pb-occurrence in the form of solid solution, ultra-thin surface layers or low-density dispersal of discrete nanoparticles. By applying this screening to thousands of grains $\left(\right.$ ca. $\left.10^{3}-10^{4}\right)$ per sample, and (where appropriate) pooling samples, inferences can be made regarding the distribution of the detectable $\mathrm{Pb}$-rich phases across grain populations and samples in combination with quantitative characterisation of their broader mineralogy, chemistry and provenance.

The $\mathrm{Pb}$-detection method has been applied to a set of four standard reference materials from NIST comprising urban dust, powdered paint and soil material with elemental concentrations (mass fraction) of $\mathrm{Pb}$ ranging from $3000 \mathrm{ppm}$ to $4 \mathrm{wt} \%$. For this set of somewhat disparate materials a strong linear correlation is observed between the PARC-detected Pb-rich phase fraction (by silhouette area) and the certified elemental $\mathrm{Pb}$ mass fraction.

The method has been applied to a set of 31 dust deposit samples collected in close proximity to the integrated steelworks of Tata Steel in IJmuiden, the Netherlands. The results show generally low abundance of detectable $\mathrm{Pb}$-rich phases $(<120 \mathrm{ppm}$ by silhouette area), with the exception of five samples with total abundance of $290-940 \mathrm{ppm}$ by area. Of these five samples, four see the majority of their elevated content of $\mathrm{Pb}$-rich pixels 
concentrated in a few scarce grains ( $<0.1 \%$ of the total analysed grains in each case), with a larger number (ca. 1-5\%) of grains bearing lower concentrations of $\mathrm{Pb}$-rich pixels.

Out of the 31 samples and $92 \mathrm{k}$ analysed grains, six discrete Pb-phase dominated particles $(>10 \mu \mathrm{m})$ were found. The rest of the occurrences of $\mathrm{Pb}$-rich pixels represent superficial fine sub-grains $(<10 \mu \mathrm{m})$ or layers atop coarser particles of diverse mineralogy and provenance. The most common and widespread host grains for the more substantial of these superficial $\mathrm{Pb}$-rich phase occurrences comprise natural silicates or composite particles with a mixture of natural silicate and industrial/urban sub-particles. Regarding unambiguously steelworks-related grain populations, 10 individual grains (spread over 10 different samples) associated with iron-ore preparation were encountered with substantial $\mathrm{Pb}$-rich pixel occurrences on their surfaces, though their overall contribution to the $\mathrm{Pb}$-rich pixel load per sample is low in all cases. Substantial occurrences of Pb-rich pixels in the other steelworks-related populations were even scarcer.

One of the samples analysed deviated markedly from all the others, and contained highly dispersed, fine (sub-micron) $\mathrm{PbCrO}_{4}$ sub-particles randomly distributed over the surface of all its constituent grain populations, associated with superficial $\mathrm{BaSO}_{4}$ contamination of the same particles. This sample is interpreted, tentatively, as reflecting contamination from fireworks-related precipitated material. The sources of the $\mathrm{Pb}$-rich pixels in the other samples with clearly elevated $\mathrm{Pb}$-rich pixel abundance may reflect diverse contamination sources from historic and ongoing economic activity. No correlation is observed between the abundance of steelworks-related coarse airborne dust particles and elevated $\mathrm{Pb}$-rich phase occurrence in the samples detectable with the method.

Supplementary Materials: The following Supplementary Files (S1-S14) are available online at https:/ / www.mdpi.com/article/10.3390/min11090929/s1. S1: details of QXRD phases; S2: details of PARC groups; S3: documentation of grain population model; S4: PARC analysis results for NIST SRMs; S5: tabulated QXRD data; S6: raw XRD patterns; S7: repository of complete PARC imagery per sample (hosted at https:/ / doi.org/10.5281/zenodo.5119167); S8: PARC group abundances per sample; S9: PARC grain population abundances per sample; S10: PARC group abundances per grain population per sample; $\mathrm{S} 11$ : $\mathrm{Pb}$ occurrence category contributions per sample; $\mathrm{S} 12$ : individual $\mathrm{Pb}$ occurrences; S13: example Pb host grain imagery and EDS analysis; S14: tabulated quantitative EDS analyses of PARC group sum-spectra.

Author Contributions: Conceptualisation, J.S., S.v.d.L., C.v.H.; methodology, J.S., C.v.H., A.-B.S., F.v.d.D., S.M.; investigation, J.S., C.v.H., F.v.d.D., S.v.d.L.; data curation, C.v.H., J.S.; writing-original draft preparation, J.S.; writing—review and editing, S.v.d.L., C.v.H., A.-B.S., S.M., P.T.; sampling, P.T. All authors have read and agreed to the published version of the manuscript.

Funding: This research received no external funding.

Data Availability Statement: Data is contained within the article or Supplementary Materials S1-14, of which S7 is openly available at https:/ / doi.org/10.5281/zenodo.5119167.

Acknowledgments: We wish to acknowledge and thank Tata Steel for supporting this long-term development project and allowing us to publish the work. We thank TNO for collaborating in the conceptualisation and sampling campaign for this study. Michiel de Roo is thanked for ongoing collaboration and software development of PARC.

Conflicts of Interest: Authors J.S., C.v.H., F. v.d.D., A.-B.S., S.M. and S.v,d.L. are employees of Tata Steel in IJmuiden, the Netherlands.

\section{References}

1. Geraets, L.; Schulpen, S. RIVM Report: Health Risk Assessment Graphite Rains Wijk Aan Zee (in Dutch: Inschatting Gezondheidsrisico's Grafietregen Wijk Aan Zee); RIVM: Bilthoven, The Netherlands, 2019; Available online: https:/ / rivm.openrepository.com/handle/ $10029 / 623106$ (accessed on 9 July 2021). [CrossRef]

2. Aguilera, A.; Bautista, F.; Gutiérrez-Ruiz, M.; Ceniceros-Gómez, A.E.; Cejudo, R.; Goguitchaichvili, A. Heavy Metal Pollution of Street Dust in the Largest City of Mexico, Sources and Health Risk Assessment. Environ. Monit. Assess. 2021, 193, 1-16. [CrossRef]

3. Tessier, A.; Campbell, P.G.C.; Bisson, M. Sequential Extraction Procedure for the Speciation of Particulate Trace Metals. Anal. Chem. 1979, 51, 844-851. [CrossRef] 
4. Lee, P.-K.; Choi, B.-Y.; Kang, M.-J. Assessment of Mobility and Bio-Availability of Heavy Metals in Dry Depositions of Asian Dust and Implications for Environmental Risk. Chemosphere 2015, 119, 1411-1421. [CrossRef]

5. Han, Z.; Bi, X.; Li, Z.; Yang, W.; Wang, L.; Yang, H.; Li, F.; Ma, Z. Occurrence, Speciation and Bioaccessibility of Lead in Chinese Rural Household Dust and the Associated Health Risk to Children. Atmos. Environ. 2012, 46, 65-70. [CrossRef]

6. Bardelli, F.; Cattaruzza, E.; Gonella, F.; Rampazzo, G.; Valotto, G. Characterization of Road Dust Collected in Traforo Del San Bernardo Highway Tunnel: Fe and Mn Speciation. Atmos. Environ. 2011, 45, 6459-6468. [CrossRef]

7. Sammut, M.L.; Noack, Y.; Rose, J.; Hazemann, J.L.; Proux, O.; Depoux, M.; Ziebel, A.; Fiani, E. Speciation of Cd and Pb in Dust Emitted from Sinter Plant. Chemosphere 2010, 78, 445-450. [CrossRef]

8. Jiang, M.; Nakamatsu, Y.; Jensen, K.A.; Utsunomiya, S. Multi-Scale Analysis of the Occurrence of Pb, Cr and Mn in the NIST Standards: Urban Dust (SRM 1649a) and Indoor Dust (SRM 2584). Atmos. Environ. 2014, 82, 364-374. [CrossRef]

9. Xing, W.; Yang, H.; Ippolito, J.A.; Zhang, Y.; Scheckel, K.G.; Li, L. Lead Source and Bioaccessibility in Windowsill Dusts within a $\mathrm{Pb}$ Smelting-Affected Area. Environ. Pollut. 2020, 266, 115110. [CrossRef]

10. Lee, P.K.; Yu, S.; Chang, H.J.; Cho, H.Y.; Kang, M.J.; Chae, B.G. Lead Chromate Detected as a Source of Atmospheric Pb and Cr (VI) Pollution. Sci. Rep. 2016, 6, 1-10. [CrossRef]

11. Choël, M.; Deboudt, K.; Flament, P.; Lecornet, G.; Perdrix, E.; Sobanska, S. Fast Evolution of Tropospheric Pb- and Zn-Rich Particles in the Vicinity of a Lead Smelter. Atmos. Environ. 2006, 40, 4439-4449. [CrossRef]

12. Brown, R.S.; Millette, J.R.; Mount, M.D. Application of Scanning Electron Microscopy for Pollution Particle Source Determination in Residential Dust and Soil. Scanning 1995, 17, 302-305. [CrossRef]

13. Small, J.A.; van Hoek, C.J.G.; Schollbach, K.; Moosavi-Khoonsari, E.; van der Does, F.J.L.; Melzer, S.; de Jong, T.P.R.; de Bie, T.; Versfeld, R.A.; de Roo, M.; et al. A Method for Analysis of Nuisance Dust from Integrated Steel Works: Chemical and Mineralogical Characteristics of Contributing Sources. Environ. Sci. Eur. 2020, 32, 1-30. [CrossRef]

14. Van Hoek, C.; Small, J.; van der Laan, S. Large-Area Phase Mapping Using PhAse Recognition and Characterization (PARC) Software. Micros. Today 2016, 24, 12-21. [CrossRef]

15. Newbury, D.E. Mistakes Encountered during Automatic Peak Identification of Minor and Trace Constituents in Electron-Excited Energy Dispersive X-Ray Microanalysis. Scanning 2009, 31, 91-101. [CrossRef] [PubMed]

16. Stanley, C.R. On the Special Application of Thompson-Howarth Error Analysis to Geochemical Variables Exhibiting a Nugget Effect. Geochem. Explor. Environ. Anal. 2006, 6, 357-368. [CrossRef]

17. National Institute of Standards and Technology. NIST Certificate of Analysis; SRM 1649b; Urban Dust; U.S. Department of Commerce: Gaithersburg, MD, USA, 2016.

18. National Institute of Standards and Technology. NIST Certificate of Analysis; SRM 2580; Powdered Paint (Nominal Mass Fraction of 4\% Lead); U.S. Department of Commerce: Gaithersburg, MD, USA, 2020.

19. National Institute of Standards and Technology. NIST Certificate of Analysis; SRM 2584; Trace Elements in Indoor Dust (Nominal Mass Fraction of 1\% Lead); U.S. Department of Commerce: Gaithersburg, MD, USA, 2016.

20. National Institute of Standards and Technology. NIST Certificate of Analysis; SRM 2587; Trace Elements in Soil Containing Lead from Paint (Nominal $3000 \mathrm{mg} / \mathrm{kg}$ Lead); U.S. Department of Commerce: Gaithersburg, MD, USA, 2003.

21. Wijesiri, B.; Egodawatta, P.; McGree, J.; Goonetilleke, A. Understanding the Uncertainty Associated with Particle-Bound Pollutant Build-up and Wash-off: A Critical Review. Water Res. 2016, 101, 582-596. [CrossRef] [PubMed]

22. Ruby, M.V.; Schoof, R.; Brattin, W.; Goldade, M.; Post, G.; Harnois, M.; Mosby, E.; Casteel, S.W.; Berti, W.; Carpenter, M.; et al. Advances in Evaluating the Oral Bioavailability of Inorganics in Soil for Use in Human Health Risk Assessment. Environ. Sci. Technol. 1999, 33, 3697-3705. [CrossRef]

23. Abel, A.G. 3-Pigments for Paint. In Paint and Surface Coatings; Lambourne, R., Strivens, T.A., Eds.; Woodhead Publishing: Sawston, UK, 1999; pp. 91-165. [CrossRef]

24. Zarogiannis, P.; Marquart, H. Framework Contract No ECHA/2008/2-Reference Number ECHA/2008/2/SR25: Service Request on Providing Actual Data on the European Market, Uses and Releases/Exposures for Lead Chromate; European Chemicals Agency: Helsinki, Finland, 2010; Available online: https: / / echa.europa.eu/documents/10162/d5d34d4d-bf57-4fd8-af61-87742f0ff5d8 (accessed on 9 July 2021).

25. Pyrotechnic Chemistry. Available online: https://web.archive.org/web/20140508095954/http://www.islandgroup.com/ military/pyrotechnic_chemistry.php (accessed on 9 July 2021).

26. Kresse, R.; Baudis, U.; Jäger, P.; Riechers, H.; Wagner, H.; Winkler, J.; Wolf, H. Barium and Barium Compounds. In Ullmann's Encyclopedia of Industrial Chemistry; Wiley-VCH: Weinheim, Germany, 2007. [CrossRef]

27. National Center for Biotechnology Information; PubChem Compound Summary for CID 24414, Barium Sulfate. Available online: https: / / pubchem.ncbi.nlm.nih.gov/compound/Barium-sulfate (accessed on 9 July 2021).

28. Phenix, A.; Soldano, A.; Van Den Berg, K.J.; Van Driel, B. “The Might of White”: Formulations of Titanium Dioxide-Based Oil Paints as Evidenced in Archives of Two Artists' Colourmen, Mid-20th Century. Proceedings of ICOM-CC Triennial Conference 2017, Copenhagen, Denmark, 1-8 January 2017.

29. Walraven, N.; Bakker, M.; Vanos, B.; Klaver, G.; Middelburg, J.J.; Davies, G. Pollution and Oral Bioaccessibility of Pb in Soils of Villages and Cities with a Long Habitation History. Int. J. Environ. Res. Public Health 2016, 13, 221. [CrossRef]

30. Fasoyinu, F.A.; Weinberg, F. Spangle Formation in Galvanized Sheet Steel Coatings. Metall. Trans. B 1990, 21, 549-558. [CrossRef] 
31. Hickey, C.; Gordon, C.; Galdanes, K.; Blaustein, M.; Horton, L.; Chillrud, S.; Ross, J.; Yinon, L.; Chen, L.C.; Gordon, T. Toxicity of Particles Emitted by Fireworks. Part. Fibre Toxicol. 2020, 17, 1-11. [CrossRef]

32. Baranyai, E.; Simon, E.; Braun, M.; Tóthmérész, B.; Posta, J.; Fábián, I. The Effect of a Fireworks Event on the Amount and Elemental Concentration of Deposited Dust Collected in the City of Debrecen, Hungary. Air Qual. Atmos. Health 2015, 8, 359-365. [CrossRef]

33. Mennen, M.G.; Kliest, J.J.G.; van Bruggen, M. RIVM Report 609022 002-Vuurwerkramp Enschede: Metingen van Concentraties, Verspreiding En Depositie van Schadelijke Stoffen: Rapportage van Het Milieuonderzoek. 2001. Available online: https: / / rivm.openrepository.com/handle/10029/9589 (accessed on 19 April 2001).

34. Mustafa, S.; Luo, L.; Zheng, B.T.; Wei, C.X.; Christophe, N. Effect of Lead and Zinc Impurities in Ironmaking and the Corresponding Removal Methods: A Review. Metals 2021, 11, 407. [CrossRef]

35. Berdowski, J.; van der Most, P.; Slager, J.M.; Mulder, W.; Hlawiczka, S.; Fudala, J.; Bloos, J.P.; Verhoeve, P.; Quass, U.; Pierce, M.; et al. EMEP/EEA Air Pollutant Emission Inventory Guidebook 2016: 2.C.1. Iron and Steel Production; European Environment Agency: Copenhagen, Denmark, 2016; Volume 147.

36. Rudnick, R.L.; Gao, S. Composition of the Continental Crust, 2nd ed.; Elsevier Ltd: Amsterdam, The Netherlands, 2013 ; Volume 4. [CrossRef]

37. Provincie Noord-Holland. Handelingskader Provincie Noord-Holland Voor Diffuus Lood in de Bodem. Inhoudsopgave. 2019. Available online: https:/ /www.google.com.hk/url?sa=t\&rct=j\&q=\&esrc=s\&source=web\&cd=\&ved=2ahUKEwj20o7 r7NDyAhWknGoFHVvtCVsQFnoECAMQAQ\&url=https\%3A\%2F\%2Fwww.noord-holland.nl\%2FOnderwerpen\%2FWater_ Bodem\%2FBodem\%2FBeleidsdocumenten\%2FHandelingskader_provincie_Noord_Holland_voor_diffuus_lood_in_de_bodem. pdf\&usg=AOvVaw0DyigIATvnefmh0eypMCvn (accessed on 24 September 2019).

38. Reimann, C.; Fabian, K.; Birke, M.; Filzmoser, P.; Demetriades, A.; Négrel, P.; Oorts, K.; Matschullat, J.; de Caritat, P.; Albanese, S.; et al. GEMAS: Establishing Geochemical Background and Threshold for 53 Chemical Elements in European Agricultural Soil. Appl. Geochem. 2018, 88, 302-318. [CrossRef]

39. Elshkaki, A.; Van Der Voet, E.; Van Holderbeke, M.; Timmermans, V. The Environmental and Economic Consequences of the Developments of Lead Stocks in the Dutch Economic System. Resour. Conserv. Recycl. 2004, 42, 133-154. [CrossRef]

40. Elshkaki, A.; van der Voet, E.; Van Holderbeke, M.; Timmermans, V. Long-Term Consequences of Non-Intentional Flows of Substances: Modelling Non-Intentional Flows of Lead in the Dutch Economic System and Evaluating Their Environmental Consequences. Waste Manag. 2009, 29, 1916-1928. [CrossRef]

41. Factsheet on Lead. Available online: https://omgeving.tatasteel.nl/assets/user/Factsheets/Factsheet_Lood.pdf (accessed on 15 July 2021). (in Dutch). 